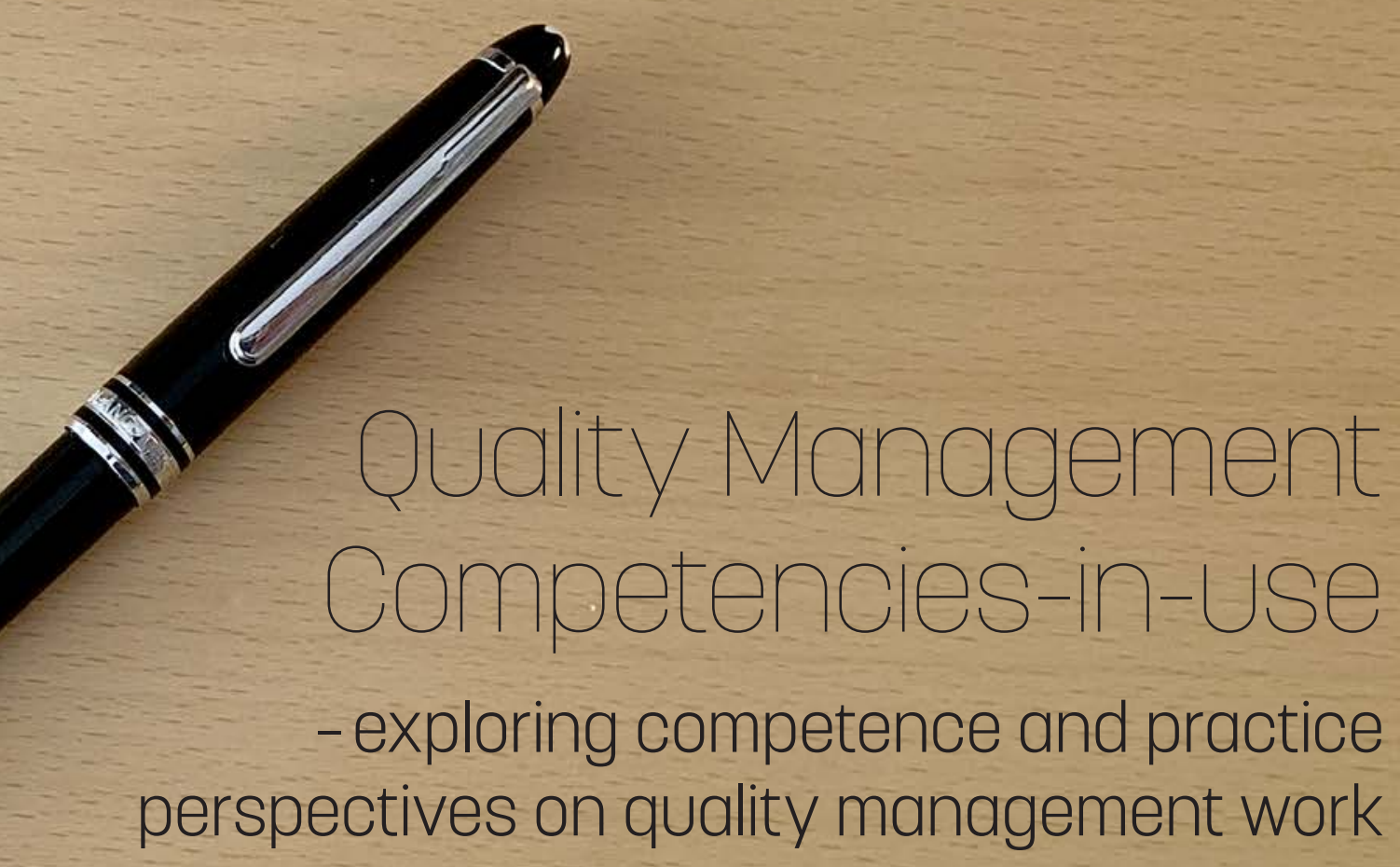

Jason Martin 


\title{
Quality Management Competencies-in-use - exploring competence and practice perspectives on quality management work
}

\author{
Jason Martin
}

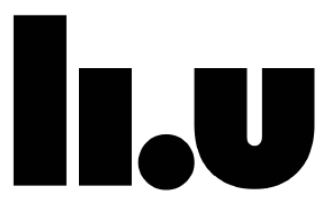

LINKÖPING UNIVERSITY

\section{9}

Department of Management and Engineering Linköping University, SE-581 83 Linköping, Sweden 
(C) Jason Martin, 2019, unless otherwise noted

Quality Management Competencies-in-use

-exploring competence and practice perspectives on quality management work

Linköping Studies in Science and Technology, Dissertation No. 2020

ISBN: 978-91-7929-987-3

ISSN: 0345-7524

Printed by LiU-Tryck, Linköping, 2019

Distributed by:

Linköping University

Department of Management and Engineering

SE-581 83 Linköping, Sweden

Tel.:+4613281000 
'Sometimes doing your best is not good enough.

Sometimes you must do what is required'.

-Winston S. Churchill 



\begin{abstract}
Quality management is an established, widespread and well-researched management concept. Yet, surprisingly little research can be found on understanding the potential for action that is required in order to perform quality management work. The field of quality management has a strong emphasis not only on a customer and supplier focus (external), but also on a process focus (internal). This creates a constant challenge in the way in which quality management is conceived and realised. Another challenge is reflected in current research that describes the need for conceptual change in quality management due to extensive ongoing changes in society and the business environment. The nature and pace of technological development, coupled with changes in social behaviour, continuously bring out new customer needs and new ways for customers to interact with the producers of goods and services. This requires adaptive and innovative approaches for organisations, in order to stay competitive and relevant.
\end{abstract}

This thesis uses competence-based and practice-based perspectives to better understand the requirements placed on quality management in meeting these challenges. It investigates what quality management work is and what properties must exist, in terms of competence and practice, in order to make quality management work possible. The purpose of this thesis is, therefore, to explore how the theoretical perspectives of competence and practice can contribute to an increased understanding of what is required to perform quality management work. Three research questions are posed and answered. The first research question concerns the nature of quality management work and how its key factors may be characterised; the second research question deals with competencies of quality management and how these are interrelated with quality management work; the third research question concerns how the interplay between quality management competencies can be understood. The research questions are answered by interpreting the findings of five papers included in the thesis, using a conceptual framework.

The results of the thesis suggest two main directions of quality management work: expansive and adaptive quality management work. Expansive work is characterised by explorative practice, radical change to existing processes or the development of new processes, a logic of development, an orientation towards development and innovation, a striving to increase external efficiency and a striving to increase process variation. Adaptive work is characterised by exploitative practice, incremental change to existing processes, a logic of performance, an orientation towards goals and productivity, a striving towards internal efficiency and a striving to decrease process variation. Quality management competencies relate to quality management work in combining role dependency and discretion. Role dependency signifies the potential and capability to assume multiple role-responsibilities. Discretion is the 'freedom of movement' for quality practitioners to engage in practices and choose quality management work directions according to task and situation. The interplay between quality management competencies is understood as the combined effects of two competence antecedents: individual and/or collective dispositions to change and learning. This thesis extends research on quality management by increasing our knowledge and understanding of the requirements needed, not only to select and perform existing quality management practices, but also to adopt and engage in practices where emergence is accommodated by ambidexterity. 



\section{Sammanfattning}

Kvalitetsutveckling är ett etablerat, utbrett och välbeforskat managementkoncept. Trots detta går det att hitta förvånansvärt lite forskning vilken fokuserar på en ökad förståelse för de handlingsförmågor som faktiskt krävs för att utföra kvalitetsutveckling. Som koncept särskiljer sig kvalitetsutveckling i sitt dubbla fokus på både ett internt, processrelaterat innehåll och ett externt, kundfokuserat innehåll. Detta skapar en konstant utmaning för hur kvalitetsutveckling kan förstås och omsättas i praktiker. En annan utmaning som beskrivs i forskningen är behovet av konceptuell förändring som krävs i kvalitetsutveckling för att möta kunna samhälleliga och marknadsmässiga förändringar. Hastigheten och innehållet i den tekniska utvecklingen samt förändringar i sociala beteenden utvecklar hela tiden nya kundbehov och nya sätt att interagera med leverantörer av varor och tjänster. Detta kräver anpassningsinriktade och innovativa förhållningssätt för organisationer att vara relevanta samt att kunna bibehålla och öka konkurrenskraften.

Kompetensteoretiska och praktikteoretiska perspektiv används i avhandlingen för att bättre förstå de krav som kan ställas på modern kvalitetsutveckling i att möta dessa utmaningar. Avhandlingen undersöker vad modern kvalitetsutveckling är och vilka egenskaper som måste finnas, i termer av kompetens och praktik, för att möjliggöra att modern kvalitetsutveckling utförs. Syftet med denna avhandling är således att utforska hur kompetensteoretiska och praktikteoretiska perspektiv kan bidra till en ökad förståelse för vad som krävs för att utföra kvalitetsutvecklingsarbete. Tre olika forskningsfrågor behandlas. Den första forskningsfrågan handlar om vad kvalitetsutvecklingsarbete är och hur det kan karaktäriseras i termer av nyckelfaktorer. Den andra forskningsfrågan berör kompetenser för kvalitetsutveckling och hur dessa kan kopplas till arbete med kvalitetsutveckling. Den tredje forskningsfrågan handlar om hur samspelet mellan kompetenser för kvalitetsutvecklingsarbete kan förstås. Forskningsfrågorna besvaras genom att tolka de empiriska resultaten i fem bilagda artiklar utifrån ett konceptuellt ramverk.

Avhandlingens resultat visar på två huvudsakliga inriktningar på innehållet i kvalitetsutvecklingsarbete: expansivt och adaptivt kvalitetsutvecklingsarbete. Nyckelfaktorer i expansivt arbete är "explorative" praktik, radikal förändring av existerande processer eller utveckling av nya processer, utvecklingslogik, utvecklings- och innovationsorientering, extern effektivitet samt ökning av processvariation. Nyckelfaktorer i adaptivt arbete är "exploitative" praktik, inkrementell förändring $i$ existerande processer, prestationslogik, mål och produktivitets-orientering, intern effektivitet samt att minska och styra processvariation. Kopplingen mellan kompetenser för och arbetet med praktiker i kvalitetsutveckling utgörs av en potential för rollberoende och handlingsfrihet. Rollberoende beskriver en individuell och/eller kollektiv kapacitet att kunna tillägna sig samt byta mellan olika definierade rollansvar. Handlingsfrihet beskriver kapaciteten att kunna välja inriktning på innehållet $\mathrm{i}$ arbetet beroende på uppgift och situation. Samspelet mellan kompetenser för kvalitetsutvecklingsarbete kan beskrivas som den samlade effekten av två förutsättningar (eng. antecedent) för kompetens: individuell och/eller kollektiv benägenhet för förändring och lärande. Avhandlingens resultat bidrar till forskningen om kvalitetsutveckling på två huvudsakliga sätt. Dels genom att öka kunskap och förståelse för de krav som ställs på att välja och prestera existerande kvalitetsutvecklingspraktiker. Dels genom att öka förståelsen om hur anpassning och utövande av dessa praktiker går till där framväxandet av praktiker stimuleras genom att möjliggöra organisatorisk ambidextri. 



\section{Acknowledgements}

The moment has finally come to place the final full stop in my doctoral thesis, thereby ending a journey that started nearly four years ago. During my time as a doctoral student I have learned to search for the underlying properties that must be in place in order for something observable to exist and to be what that something is. As a researcher, the critical question to always ask oneself is what really makes something possible? Equally important is, of course, to ask oneself who really makes something possible? Without the support and contribution from many people, my journey would never have been possible. All the people around me, far and near, deserve my sincerest gratitude for supporting me. However, there are a few I wish to mention to whom I am especially grateful.

First of all, in order to become an academic, I kind of started off in a completely wrong way. I spent my young working life commanding in the field, later on moving on to office and board room command. Though I have always loved research and have always had a vibrant academic disposition, I did not enter university at young age and I did not complete my postgraduate studies until later on in life. However, I was lucky enough to be able to explore a new path in life that I had thought was closing. Therefore, when the very real opportunity to someday, perhaps, be called 'Dr. Martin' was offered to me by my future main supervisor, Professor Mattias Elg, I jumped at it without any hesitation whatsoever. Not only did I get a chance to pursue a dream, I was able to do it within the research area that topped my extensive list of academic interests and with full funding (which is no small deal!). It was my pie in the sky come true and for this I will be forever grateful to Mattias, who has been my unwavering supporter and confidant from the start to the end. Thank you, Mattias, for your engagement, encouragement and invaluable advice whenever I needed it. Also, thank you for all fun, creative and often mind-boggling discussions we have had. But most of all, thank you for showing the confidence in allowing me the academic freedom to explore and pursue my very own way towards treading the Parnassus.

In my 'dream team' of supervisors I have also had the immense privilege to include Professor Ida Gremyr and Associate Professor Andreas Wallo as my co-supervisors. I am ever thankful to have had such an energetic, competent and fun supervisor team giving me unlimited support in my work. It has been a pleasure and a greatly rewarding learning experience to do research and co-author articles with you. I humbly thank you for inspiring, challenging and motivating me to reach my ultimate goal.

It has been my great honour to also stand on the shoulders on other intellectual giants. Thank you, Professor Emeritus Per-Erik Ellström and Associate Professor Henrik Kock, for sharing your enormous wealth of knowledge and experience with me. I would also like to thank Professor Maria Huge-Brodin, Associate Professor Peter E. Johansson and Senior Lecturer Daniel Lundqvist for spending their precious time giving me invaluable input in order to improve my thesis draft. I owe a special thanks to both Professor Emeritus Göran Collste and Professor Elin Wihlborg for help and encouragement in different ways. I must also mention my colleagues in the Division of Education and Sociology at Linköping University and the Department of Behavioural Sciences and Learning for support and excellent collaboration. Funding and financial support is important, and I would like to acknowledge the Swedish Quality Management Academy through the Swedish Institute for Quality and also the HELIX Competence Centre at Linköping University for kindly allowing me to do the research necessary for my dissertation (and get paid for it!). 
I have been very fortunate to be a part of a fantastic team of colleagues, headed by Professor Mats Abrahamsson, in the Division of Logistics and Quality Management at Linköping University and the Department of Industrial Engineering and Management. The professionalism and positive spirit you all display every single day is truly awe-inspiring, and that's not even mentioning all the fun and laughs that come with such a warm, inviting and creative work environment. In particular, I would like to mention Maria H-B, Fredrik and Elisabeth for being such well-spirited companions, never far from the zone of joy and laughter. However, I must make it clear, once and for all, that Elisabeth will never, ever, be as 'supergeil' as I am. A special thanks goes to Kristina for all your kind help and supreme service. Also, the group of fellow doctoral students during my time, both in the division and from far away have all, in different ways, inspired and helped me along my journey. I therefore owe my sincere thanks to Magdalena, Promporn, Priscilla, Henrik, Linnea, Malin, Niklas, David, Björn, Olle, Andrea and Jan.

Last but not least, I am forever indebted for the tireless support from my loving family and friends. Endless have the times been when 'I just have to do a little bit more writing' or 'I just have to do a little bit more reading'. I am unable to truly express the gratitude I feel towards the most important people in my life, Camilla and Lovisa. Without your limitless patience, encouraging words and endless love I would never have succeeded. You are the ones who truly made it all possible, so thank you for putting up with me and believing in my dream.

The final words are for my daughter Lovisa to whom I would like to say: you can become whatever you want. All it takes is some imagination, a lot of determination and about 10,000 hours. Of that I am living proof.

Dixit.

Linköping, October, 2019

Jason Martin 


\section{CONTENTS}

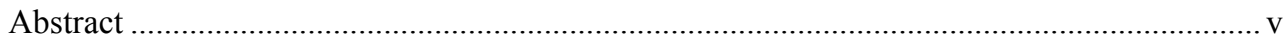

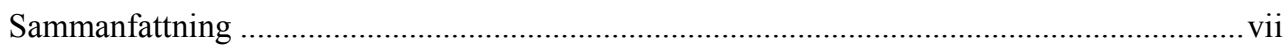

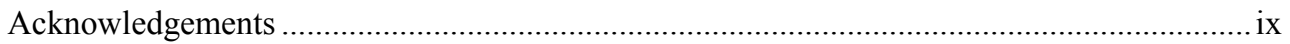

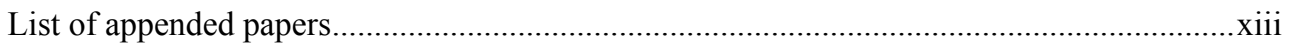

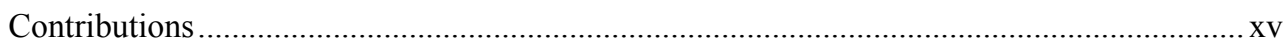

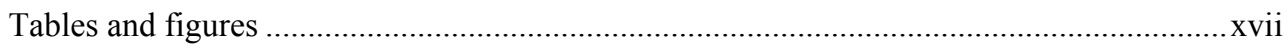

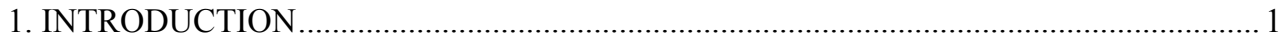

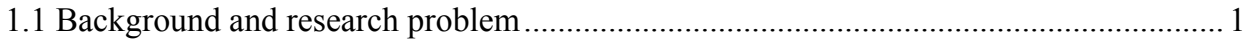

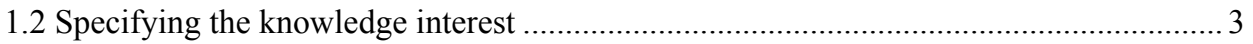

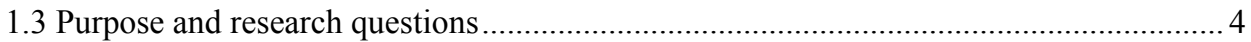

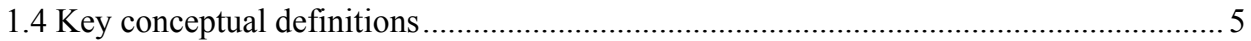

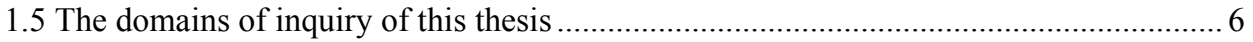

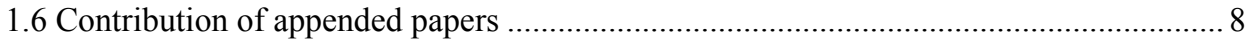

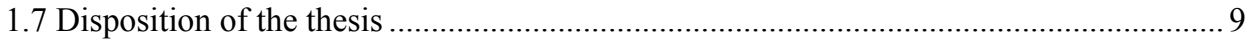

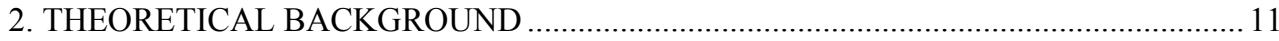

2.1 Previous literature on quality management and quality management work ................. 11

2.2 Theoretical perspectives on quality management work ............................................ 19

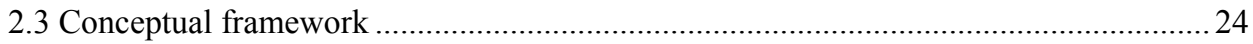

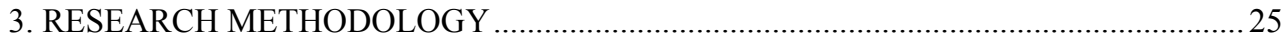

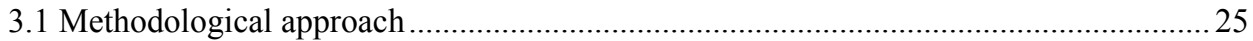

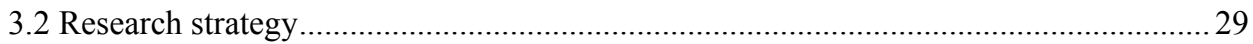

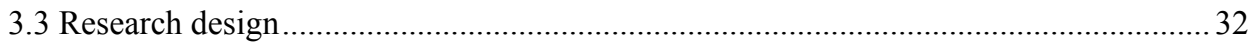

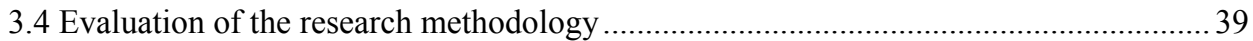

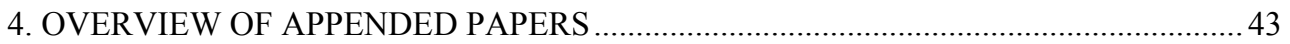

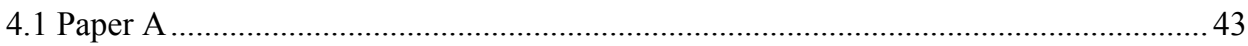

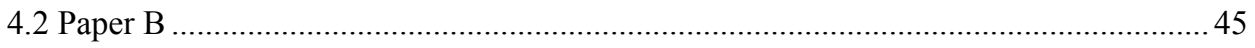

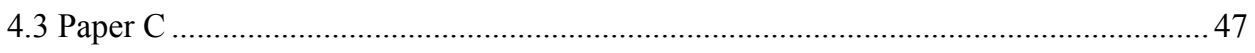

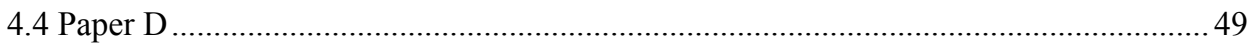

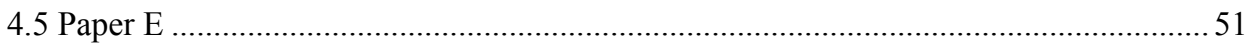

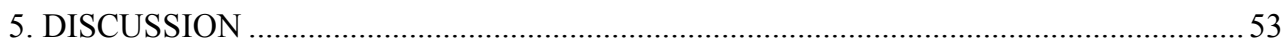

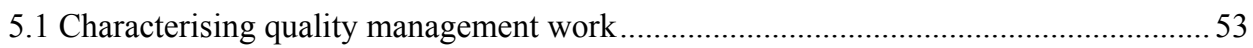


5.2 Relationships between quality management competencies and quality management work

5.3 Understanding the interplay between quality management competencies.................... 62

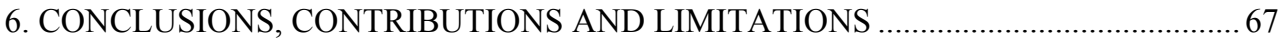

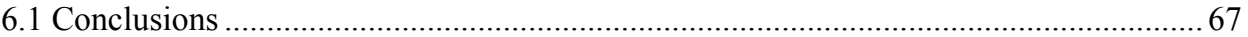

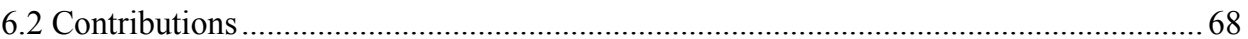

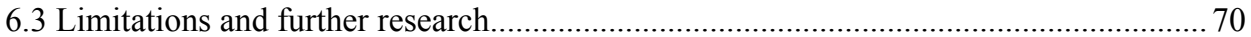

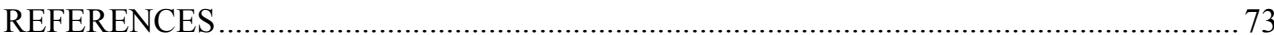




\section{List of appended papers}

The papers are appended in their complete versions. In the extended summary, the papers will be referred to by their Latin letters as outlined below:

\section{Paper A}

Martin, J., Elg, M., Wallo, A., and Kock, H. (2018), 'Four facets of learning in performance measurement'.

Published online and in International Journal of Productivity and Performance Measurement, Vol. 67 No. 9, pp. 1608-1624.

DOI: $10.1108 / I J P P M-11-2017-0320$

\section{Paper B}

Martin, J., Elg, M., and Gremyr, I. (2019), 'Fit for purpose? Exploring competence in quality management'.

Published online and in International Journal of Quality and Service Sciences, Vol. 11 No. 3, pp. 317-333.

DOI:10.1108/IJQSS-06-2018-0054

\section{Paper C}

Martin, J., Elg, M., Gremyr, I., and Wallo, A. (2019), 'Towards a quality management competence framework: exploring needed competencies in quality management'.

Accepted for print publication and published online in Total Quality Management and Business Excellence.

DOI: $10.1080 / 14783363.2019 .1576516$

\section{Paper D}

Gremyr, I., Elg, M., Hellström, A., Martin, J., and Witell, L. (2019), 'The roles of quality departments and their influence on business results'.

Accepted for print publication and published online in Total Quality Management and Business Excellence.

DOI: $10.1080 / 14783363.2019 .1643713$

\section{Paper E}

Elg, M., Birch-Jensen, A., Gremyr, I., Martin, J., and Melin, U. (2019), 'The Role of Quality Management in an Era of Digitalisation'.

Revised version of paper presented at the $21^{\text {st }}$ QMOD-ICQSS conference, Cardiff, UK, 2018. Working paper.

Published articles have been reprinted with the permission of the copyright holders. 



\section{Contributions}

The principal contributions to the appended papers are outlined below. It should be noted that all work in the papers has been jointly conducted in close collaboration between the listed authors. I have been deeply committed and involved in all phases of the work in all of the papers except article D, where I came in at a later stage and took main responsibility for the re-analysis and rewriting of the paper.

Paper A: Jason Martin, Mattias Elg, Andreas Wallo and Henrik Kock.

Martin and Elg jointly initiated the paper. Elg designed the study and took main responsibility for the empirical work. Martin wrote the first draft with Elg, Wallo and Kock providing critical input. Martin conducted the main data analysis, jointly supported by Elg, Wallo and Kock. All authors jointly revised and rewrote the manuscript.

Paper B: Jason Martin, Mattias Elg and Ida Gremyr.

Martin initiated the paper. All authors jointly designed the study. Martin wrote the first draft with Elg and Gremyr providing critical input. Martin took main responsibility for the empirical work, Elg and Gremyr participated. Martin conducted the main data analysis, jointly supported by Elg and Gremyr. All authors jointly revised and rewrote the manuscript.

Paper C: Jason Martin, Mattias Elg, Ida Gremyr and Andreas Wallo.

Martin initiated the paper, designed the study and wrote the first draft with Elg, Gremyr and Wallo providing critical input. Martin took main responsibility for the empirical work, Elg and Gremyr participated. Martin conducted the main data analysis, jointly supported by Elg, Gremyr and Wallo. All authors jointly revised and rewrote the manuscript.

Paper D: Ida Gremyr, Mattias Elg, Andreas Hellström, Jason Martin and Lars Witell.

Gremyr initiated the paper and designed the study together with Elg, Witell and Hellström. Martin participated in the subsequent data analysis and writing. All authors jointly revised and rewrote the manuscript.

Paper E: Mattias Elg, Andrea Birch-Jensen, Ida Gremyr, Jason Martin and Ulf Melin.

Elg initiated the paper and designed the study together with Gremyr, Martin and Birch-Jensen. Martin took main responsibility for the empirical work, Elg, Birch-Jensen, Gremyr participated. Martin participated in the data analysis and writing. All authors jointly revised and rewrote the manuscript. 



\section{Tables and figures}

Tables

Table 1. The papers and their main connection to the thesis and research questions ..........8

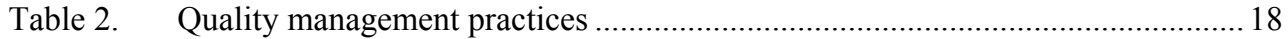

Table 3. Summary of the appended paper's research designs.............................................. 33

Table 4. Summary of quality criteria and evaluation for the qualitative study designs ..... 40

Table 5. Summary of quality criteria and evaluation for the quantitative study designs ... 40

Table 6. Distribution of learning facets within CIs, classified by personnel category....... 44

Table 7. Main competence dimensions with their respective quality management

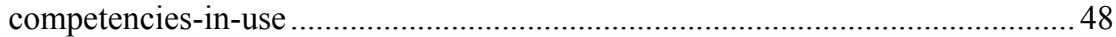

Table 8. Factor loadings for the items that describe quality practices .............................50

Table 9. Differences in business results by quality department role .................................50

Table 10. Key factors in adaptive and expansive quality management work ......................54

Table 11. Examples of adaptive and expansive quality management work in the performance of quality management practices.....................................................56

Table 12. Potential for exploitation and exploration depending on level of agent discretion..

\section{Figures}

Figure 1. Relationships between the domains of inquiry of the thesis .............................. 7

Figure 2. Functional scope of quality management and quality management orientations. 14

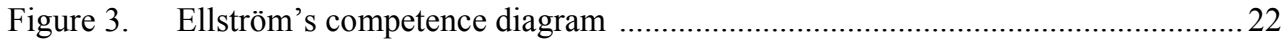

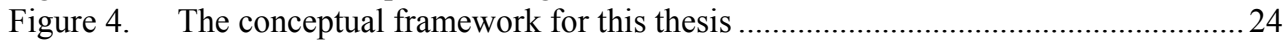

Figure 5. Relationships between the methodological premise, theoretical background and

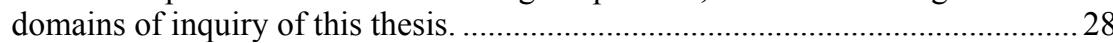

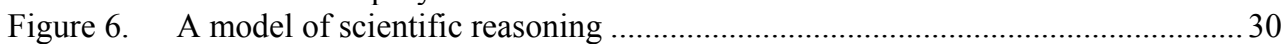

Figure 7. Overview of the research process for the thesis, 2016-2019 ............................. 32

Figure 8. The bi-directional interactive research process ............................................. 35

Figure 9. Interactive research activities for the SQMA research project ......................... 36

Figure 10. Relationships between performance measurement and learning, a tentative framework for analysis................................................................................ 44

Figure 11. Degree to which quality management practitioners feel that they perform tasks for which they would have needed more formal competence.

Figure 12. Degree to which quality management practitioners feel that they perform tasks for which they would have needed more actual competence

Figure 13. Generic role-responsibility characteristics of quality management .................... 48

Figure 14. Quality management orientations with directions of quality management work. 55

Figure 15. The relationship between quality management competencies and quality management work

Figure 16. Proposed interplay between quality management competencies due to competence antecedents .... 



\section{INTRODUCTION}

This chapter introduces the topic and context for this thesis, in seven sections. The first section provides the reader with the background and research problem for this thesis. In the second section, the knowledge interest guiding the purpose and research questions is specified. The third section covers the overall purpose of the work and the research questions. In the fourth section, the key concepts connected to the purpose and research questions are briefly described and related to each other. The fifth section features an outline of the domains of inquiry, specifying the domains of the research context, study object and main focus. In the sixth section, the contribution of each paper included in the thesis is described. The seventh and last section of the chapter outlines the disposition of the thesis.

\subsection{Background and research problem}

This thesis is about understanding the ways of working with quality management in terms of competence and practice. In this thesis, quality management is defined as a management approach that systematically facilitates the continuous quality improvement of products and services in organisations. Continuous quality improvement is achieved by employing a systematised set of quality management practices and techniques, in order to accomplish the quality management principles of customer focus, continuous improvement and teamwork (Dean \& Bowen, 1994; Evans \& Lindsay, 2011; Prajogo \& McDermott, 2005).

The field of quality management has a strong emphasis not only on a customer and supplier focus (external) but also on a process focus (internal), making it somewhat unique (Bergman \& Klefsjö, 2010). The dual perspectives in quality management also carry an inherent conflict of interest since it is necessary to constantly balance rigidity (i.e. improving processes by controlling for variation) and flexibility (i.e. developing processes by increasing variation). This prevailing conflict of interest in quality management is a main theme throughout this thesis and I propose that one of the ways to address this conflict is to identify and characterise the key factors that encapsulate the nature of quality management work. I propose also that infusing the concepts and theoretical perspectives of competence and practice offers a constructive approach to achieving this. In this thesis, quality management work is understood as the content and process of selecting, adopting and engaging in particular quality management practices in specific situations, in order to achieve the quality level as expected by the internal or external customer.

The concept of competence is important for both researchers of a management field and for practitioners in that management field. For researchers and practitioners alike, competence is paramount as a way to describe and understand what is required in order to perform the necessary practices in a particular task or job. This is particularly important for managerial levels and those working in human resources, who are responsible for recruiting, staffing and organising management work. Within the research field of quality management, research on competence is, however, scarce ${ }^{1}$. Certainly, research in the field of quality management has been immense regarding related phenomena during recent decades, and as a consequence, research on quality management practices and roles has evolved into a niche in quality management research (e.g. Ahire, Landeros \& Golhar, 1995; Dean \& Bowen, 1994; Flynn, Schroeder \& Sakakibara, 1994; Maguad, 2006; Sousa \& Voss, 2001; 2002).

\footnotetext{
${ }^{1}$ A notable recent exception is Ingason and Jónsdóttir (2017), which appears to be the first real attempt to gain further understanding of quality manager competencies.
} 
Stratton (1996), Chen, Paetsch and Paulraj (1997), and Larson (1998) emerged as fairly early examples of work to evaluate the roles in quality management and to add the concept of quality management practice, though this work did not provide any theory-based understanding of the specific nature of quality management practices. Another research avenue focussed on describing and defining quality management practices. For example, Saraph, Benson and Schroeder (1989) were early to construct measures of quality management practice. Dahlgaard et al. (1998) describe practices as regionally and culturally dependent, to some extent. More recently, Kim, Kumar and Kumar (2012) have described the relationship between quality management practices and innovation. Other studies have examined the link between quality management practices and performance. Samson and Terziovski (1999), for example, were early in showing that quality management practices, in particular practices related to leadership, people management and customer focus, can be used to predict performance. Prajogo and Sohal (2003) suggested that quality management practices support not only product quality performance but also product innovation performance. Furthermore, Zhang, Linderman and Schroeder $(2012 ; 2014)$ described the suitability of different quality management practices in stable and dynamic contexts. Taylor and Wright (2003) and Zu (2009) addressed infrastructure and practices in terms of successful quality management implementation. Sousa \& Voss (2001; 2008) investigated the importance of context for quality management practice. Kaynak (2003) addressed top management and quality management practices linked to performance. Several studies contribute to a further understanding how factors such as context (e.g. Sousa \& Voss, 2001), contingency (Sitkin, Sutcliffe \& Schroeder, 1994; Sousa \& Voss, 2008), infrastructure (Zu, 2009), firm size (Temtime, 2003), performance (Flynn, Schroeder \& Sakakibara, 1994) and management and leadership (Albacete-Sáez, Fuentes-Fuentes \& Bojica, 2011; Lakshman, 2006) link to quality management practice. Certainly, practices linked with specified roles in quality management have been addressed (e.g. Elg, Gremyr, Hellström \& Witell, 2011; Evans, 2013; Wadell \& Stewart, 2004; Zu, 2009). Thus, many aspects of quality management practice have been investigated, but research that specifically links practice and competence theory to the field of quality management is scarcer.

Perhaps as a consequence of this relative void in research, the concept of competence is also rather shallowly perceived in quality management research (e.g. Anttila \& Jussila, 2017; Sila \& Ebrahimpour, 2003; Antony, 2013; Dahlgaard-Park, 2011; van Kemenade, 2014; Sandholm, 2005; Sörqvist, 2014; Weckenmann, Akkasoglu \& Werner, 2015), and competence theory stands out as an under-utilised avenue towards understanding quality management work. In addition, bodies that certify standards in Quality Management Systems [QMS] afford little research-based guidance concerning the competencies that are required to perform quality management practices. With so relatively little researcher and practitioner attention being paid to understand the competencies of quality management and how they relate to actual work, it can be questioned whether contemporary organisations have sufficient knowledge and understanding to organise truly purposeful quality management work. It is, therefore, not surprising that interest for a competence perspective in quality management research is growing (e.g. Ingason \& Jonsdottír, 2017), and that calls for more research into the competencies in quality management are being made (e.g. Rogala, 2016). This is also indirectly accentuated by the research pointing out major challenges for quality management as a result of claims of rapid ongoing change in organisations (e.g. Antony, 2013; Maguad, 2006; Weckenmann, Akkasoglu $\&$ Werner, 2015). I therefore propose that a better understanding about what is required in order 
to perform ${ }^{2}$ quality management work must start by analysing and describing the relationships between the practices, competencies and actions in quality management work.

In this thesis, the capacity to successfully ${ }^{3}$ perform a defined practice in a defined situation, i.e. successful competence-in-use, is described as a function between the individual and the situation/social structure ${ }^{4}$ in which the particular practice is to be performed (Ellström, 1992;1997). The changes and evolving practices of quality management really exacerbate the need to find ways to increase our understanding of quality management competence-in-use. This calls for even more attention to be paid to the nature of quality management, and it is therefore proposed that efforts should also be made to further understand what mediates and conditions the potential and capacity to successfully engage in particular quality management work in a particular quality management situation. This study is an attempt to bridge the above-described knowledge gap concerning what is required to perform quality management work and to contribute to an increased understanding of quality management practices and competencies.

\subsection{Specifying the knowledge interest}

A thesis purpose and its research questions should emanate from a direction of inquiry or a specific knowledge interest (Alvesson, 2014; Habermas, 1972). Habermas claims that knowledge is not a free, 'stand-alone' concept, but is always related to the basic interests that justify and legitimise the desired knowledge (1972). He further categorises three knowledge interests for researchers: technical cognitive, practical cognitive, and critical, emancipatory knowledge interests. Within the research field of quality management, most studies are predominantly driven by technical cognitive interests that focus on aspects of rationality, utility and the need to further particular technical or managerial knowledge (e.g. Antony, 2015; Burcher, Lee \& Waddell, 2008; Chen, Paetsch \& Paulraj, 1997; Evans \& Lindsay, 2011; Flynn, Schroeder \& Sakakibara, 1994; Linderman, Schroeder, Zaheer, Liedtke \& Choo, 2004; Reed, Lemak \& Mero, 2000). Studies with a practical cognitive knowledge interest, aimed at a deeper understanding of quality management and focusing on interpretation, understanding and meaning, are less frequent. The purpose of the work described in this thesis is primarily guided by an ambition to contribute to an increased understanding of what it takes to engage and enact in the practices of quality management. Exploring theory in order to increase this understanding directs the knowledge interest to mainly comprise a practical rather than technical cognitive interest (Habermas, 1972) in this thesis. The character of the subject and approach to research are not about liberation or emancipation, hence a critical, emancipatory knowledge interest, focussed on liberation from repressive social and ideological conditions (Alvesson \& Willmott, 1992; Habermas, 1972), is not in focus in this thesis.

I argue that infusing and applying knowledge and insights from one field into the research of another field makes it possible to gain a deeper understanding of the nature and conditions that characterise that latter field. This is in line with what Gregor and Hevner (2013) label as

\footnotetext{
2 This thesis uses the term performing quality management work to describe the engagement in action and the enacting of behaviour in realising quality management practices within the boundaries of a specific task, role and/or situation.

${ }^{3}$ The term successful is used in this thesis to describe a goal-aligned output and/or performance as defined by the rules, shared implicit practical understandings and the norms governing the means and ends of practices within the context of a practice environment (Sandberg \& Tsoukas, 2011; Schatzki, 2001; 2005).

${ }^{4}$ Social structures are defined as the routinised relational structures constituting the organisational context (Archer, 1995; Danermark et al., 2002; Collier, 1994; Fleetwood, 2004; 2005; Sayer, 1992).
} 
exaptation, i.e. knowledge contribution seeking to adapt, or more accurately, exapt known knowledge, such as competence theory and practice theory, into a 'new' (or at least previously theoretically under-explored) field, such as quality management, thereby contributing with extended knowledge and further conceptual understanding to the field and particular context of quality management. Such extended knowledge is necessary not only in order to better design and organise quality management work. It may be vital also to utilise the full potential of quality management to increase organisational performance. The mode of contribution to quality management theory adopted in this thesis to achieve this can be described as adopting constitutive reasoning (Cornelissen \& Durand, 2014), in which the conceptual constructs ${ }^{5}$ forming competence and practice are aligned and integrated with established conceptual constructs forming quality management. The expanded theoretical understanding that this mode of contribution is expected to bring is one of the reasons that a strategy based on abductive scientific reasoning (Peirce, 1931-1958) is used in this thesis. Of course, it is also possible to derive technical cognitive knowledge (Habermas, 1972) from the results presented in this thesis. Such results may, to differing degrees, be transformed more directly into practice. For example, the specific competencies required to perform quality management can be adopted in recruitment processes or in the managerial responsibilities of organisational design. An additional intended contribution, therefore, is to provide managers and human resource practitioners with practical tools that are useful in handling management responsibilities and tasks such as organisational development, policy development, recruitment, talent mapping, and the development of training and education.

\subsection{Purpose and research questions}

Against the backdrop given in this introduction, it can be argued that the evolution of quality management entails a constant re-evaluation of the practices used to meet or preferably exceed customer expectations. It has been argued that such an endeavour benefits from being competence-based, in order to further our knowledge and understanding of quality management work in contexts and settings of constant change. Having introduced the thesis subject, the problem area and the specific knowledge interests, it is time to state the purpose and research questions of this thesis:

To explore how the theoretical perspectives of competence and practice can contribute to an increased understanding of what is required to perform quality management work.

This purpose can be achieved by answering the following three research questions:

RQ1. What key factors characterise the nature of quality management work?

The first research question addresses the need to understand, define and describe quality management work. Based on research literature, concepts and theoretical perspectives, past and present interpretations will be analysed in order to identify key factors that characterise quality management work.

\footnotetext{
5 The term constructs is used to describe the often unobservable, or latent, abstract variables that together characterise and form an attributional concept. Constructs can, in turn, be operationalised into manifest, or observable, and testable variables (e.g. Cronbach \& Meehl, 1955; Van de Ven, 2013). For example, in this thesis it is proposed that customer focus, continuous improvement and teamwork are not only the underpinning principles (Dean \& Bowen, 1994) but also the constructs that, together, form the concept of quality management.
} 
RQ2. How are competencies in quality management related to quality management work?

Answering the second research question will enable us to better understand the nature of the relationships between quality management competencies and quality management work, as characterised in RQ1. Based on the specific quality management competencies that Paper C describes, competence theory and practice theory are applied in order to further understand in what ways competencies in quality management link and support ways of working in quality management.

RQ3. How can the interplay between quality management competencies be understood?

The answer to the third research question is expected to enable us to understand aspects of the interaction between competencies in quality management in order to facilitate the desired actions and behaviour needed in quality management work. Answering this question will provide further understanding on what makes successful quality management work possible.

\subsection{Key conceptual definitions}

In this section, the key concepts used in this thesis are defined. The definitions are needed in order to fully grasp the extent and meaning of the purpose and research questions stated in Section 1.3. The definitions cover concepts related to the study object, and concepts rooted in the theoretical perspectives of this thesis. A more detailed outline of the concepts and perspectives can be found in Chapters 2 and 3.

\subsubsection{Quality and quality management}

Quality is defined as a measure of the ability of a service and/or product to meet or preferably exceed customer expectations (Bergman \& Klefsjö, 2010). The management of quality, or quality management, is defined as a management concept that systematically facilitates continuous quality improvement in organisations (Flynn, Schroeder \& Sakakibara, 1994). Quality management can be described in more detail as a principle-based system approach to organising and routinising the performance of quality management practices and techniques aimed at realising the principles (also labelled as constructs) of customer focus, continuous improvement and teamwork (Dean \& Bowen, 1994; Evans \& Lindsay, 2011; Prajogo \& McDermott, 2005), and also product and service quality (Sousa \& Voss, 2002; Parasuraman, Zeithaml \& Berry, 1985). In this thesis, quality management is viewed both as a theoretical concept but also as a term to describe a social structure constituting a practice environment. According to Schatzki $(2001 ; 2005)$, practice environments are conditioned environments with institutionalised practices that dictate performance.

\subsubsection{Quality management work and quality management practices}

Quality management work is defined as the way practices are selected, adopted and engaged in specific situations, in order to achieve and sustain high quality output aimed at providing customer satisfaction through continuous improvement, development and the maintenance of processes and defect prevention on all organisational levels (Flynn, Schroeder \& Sakakibara, 1994). In terms of quality management, practices are activities and actions needed to implement quality management principles with techniques selected from a range of techniques (or tools) 
that are available to make the practices effective (Dean \& Bowen, 1994). In this thesis, quality management work is thus viewed as context-dependent, and can also be described as quality management practice-in-use.

Many attempts have been made to frame the practices that represent the practice environment of quality management (e.g. Addey, 2004; Antony, 2013; Dahlgaard et al., 1998; Elg, Gremyr, Hellström \& Witell, 2011; Fundin, Bergman \& Elg, 2017; Ismail \& Maling, 2002; Kim, Kumar \& Kumar, 2012; Sousa \& Voss, 2001). In this thesis, the extensive literature review provided by $\mathrm{Zu}(2009)$ is used as a basis to outline the practices that characterise the practice environment of quality management. The quality management practices described by $\mathrm{Zu}$ (2009) include both core practices (i.e. 'hard' practices, which are oriented towards technology and methodology) and infrastructure practices (i.e. 'soft' practices, which are oriented towards people and culture). The quality management practices that constitute the practice environment of quality management in this thesis are: top management support, customer relationships, supplier relationships, workforce management, high-quality information, product/service design, and process management. In this thesis, the organisational function of quality management is also considered to be the organisational entity that is usually responsible for governing the adoption of quality management systems such as ISO 9001 (Lo \& Yeung, 2018).

\subsubsection{Competence and practice in quality management}

This thesis is primarily based on the concept of competence as a dynamic combination of individual, structural and context-dependent competence aspects that together define a capacity or potential for action in a specific situation (Ellström, 1992; 1997). The competence aspects of an individual are composed of the formal and actual competencies of the individual. The structural competence aspects are composed of competencies that are officially demanded and those that are actually required by the job. Competence is also understood to be a primarily interactive concept. It is neither solely individual nor task-focussed, but focusses on the interaction between individuals and the task or job at hand (Ellström \& Kock, 2008). Based on Ellström (1997), competence is thus defined in this thesis as the capacity for enacting successful behaviour in order to solve a task or job in a defined situation. A practice is the way in which a task is solved, and is defined as the combination of shared rules, pools of practical understanding and shared normative assumptions on the ends and means for the particular practices shared within a specific practice environment. (Lindberg \& Rantatalo, 2014; Sandberg \& Tsoukas, 2011; Schatzki, 2001; 2005). Any competence related to a particular practice is viewed as representing a kind of 'perceived contextual suitability' (Lindberg \& Rantatalo, 2014, p. 565) for how to successfully do things related to the particular practice environment. Since the research contexts in all studies compiled in this thesis were situated within a workplace context, the terms competence and professional competence are used interchangeably with occupational competence (e.g. Delamare Le Deist \& Winterton, 2005; Ellström, 1997).

\subsection{The domains of inquiry of this thesis}

Figure 1 shows the three domains of inquiry, each of which relates to the overall purpose and research questions of this thesis. The context domain concerns the social structure of quality management. The social structure of quality management contains both common, interorganisational understandings and specific intra-organisational understandings of the concept of quality management. The empirical material in the five appended papers all relates to the context of quality management in general (albeit in different organisational settings) and its 
related principles, practices and techniques. The context domain denotes the boundaries of inquiry as outlined by the purpose. Nested within the context scope is the study object of the thesis. The study object guides and delimits the focus of the thesis which pertains to research related to quality management work and quality management practices. Research Question 1 is positioned within this domain. The topic of competencies in quality management practices forms the main focus, and is nested within the study object of quality management. This is shown by the positioning of Research Questions 2 and 3.

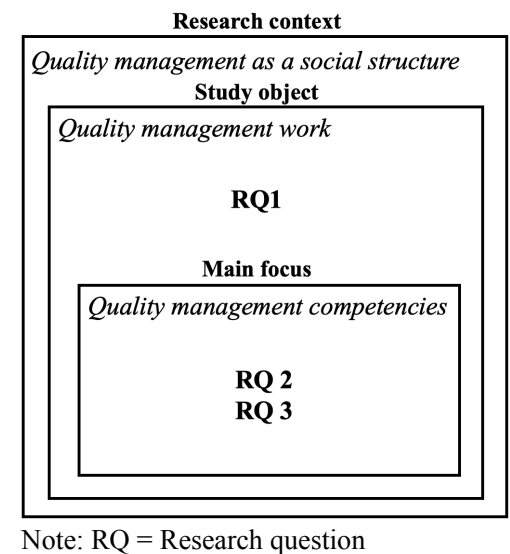

Figure 1. Relationships between the domains of inquiry of the thesis

\subsubsection{Categories of analysis}

Pettigrew (1987) describes three analytical categories for investigating change: content, context and process. Context refers to understanding the rationale of the study object. Context thus positions the thesis by situating quality management, and justifies the analysis of ways of performing quality management work. However, context is not the main category of analysis, but rather forms a back-drop, or setting, for understanding the inner and outer organisational environment in which the study object is situated.

Content describes the specific area of investigation and process as an analytical category, in order to understand how things work within the area of investigation. In this thesis, the content is understood to be the activities that are done in quality management work. The process of quality management is understood to be the ways of performing those activities. The choice of theoretical perspectives and the nature of the study object (i.e. quality management practices) direct the analytical focus onto both the content and the process of the activities of quality management work. In terms of Pettigrew's (1987) categorisation, the main category of analysis in this thesis comprises equal shares of content and process in quality management work.

\subsubsection{Levels and units of analysis}

Scott and Davis (2007) describe a common differentiation between levels of analysis in research within organisational contexts, and state that the levels usually range from the social psychological level (the micro level), the structural level (the meso level), and the ecological level (the macro level). The content and process of quality management relate to both the micro 
level (i.e. individual actions) and the meso level (i.e. how the actions affect the structural level). The empirical material in the papers presented here is based on individual data, and includes both interviews and surveys. However, the individual data are analysed using a structural perspective. According to a critical realist understanding of social science, reality is composed of structures and agents, and the knowledge of reality is best studied by analysing the relationships between structure and agency (Archer, 1995). The work presented here is based on a critical realist perspective, and is thus focussed on the relationships between structure and agency. In particular, it focusses on the relationship between individual quality management work and the social structural conditions in which such work is carried out. Thus, I argue that the main level of analysis is the relationship between the structural level and the individual level, with the main unit of analysis being the relationship between the individual quality management practitioner and the social structure of quality management. Subsection 3.1.1 gives a more extensive outline of the critical realist perspective, which forms the methodological premise of the thesis.

\subsection{Contribution of appended papers}

The five appended papers constitute the core of this thesis. Each paper has its own purpose and research questions. The contribution of each paper illuminates one aspect of the overall purpose and Research Questions 2 and 3 in this thesis. Research Question 1 is addressed mainly in the thesis itself, which reviews and discusses relevant literature, and gives examples using the findings presented in Papers A-E. The contributions of the fives papers are not equal, and some contribute more than others. Each paper, however, is a vital component in the thesis. Table 1 gives an outline of the research fields, including the main frames of reference, contributions to thesis purpose, and relationships with the thesis research questions.

Table 1. The papers and their main connection to the thesis and research questions

\begin{tabular}{|c|c|c|c|c|c|}
\hline & Paper A & Paper B & Paper C & Paper D & Paper E \\
\hline $\begin{array}{l}\text { Research } \\
\text { field }\end{array}$ & $\begin{array}{l}\text { Quality } \\
\text { management. }\end{array}$ & $\begin{array}{l}\text { Quality } \\
\text { management. }\end{array}$ & $\begin{array}{l}\text { Quality } \\
\text { management. }\end{array}$ & $\begin{array}{l}\text { Quality } \\
\text { management. }\end{array}$ & $\begin{array}{l}\text { Quality } \\
\text { management. }\end{array}$ \\
\hline $\begin{array}{l}\text { Main frames } \\
\text { of reference }\end{array}$ & $\begin{array}{l}\text { Bourne et al. } \\
(2002) \text {, } \\
\text { Bourne } \\
(2008), \\
\text { Neely et al. } \\
(2005) \text {, } \\
\text { Ellström } \\
\text { (1992;1997). }\end{array}$ & $\begin{array}{l}\text { Sousa and Voss } \\
(2002), \\
\text { Dean and } \\
\text { Bowen (1994), } \\
\text { Ellström (2001), } \\
\text { Schatzki (2001; } \\
\text { 2005). }\end{array}$ & $\begin{array}{l}\text { Zhang, } \\
\text { Linderman and } \\
\text { Schroeder } \\
(2012) \text {, } \\
\text { March (1991), } \\
\text { Delamare Le } \\
\text { Deist and } \\
\text { Winterton } \\
(2005) .\end{array}$ & $\begin{array}{l}\text { Sousa and } \\
\text { Voss (2002), } \\
\text { Zhang, } \\
\text { Linderman } \\
\text { and Schroeder } \\
\text { (2014), } \\
\text { March (1991), } \\
\text { Verhoef and } \\
\text { Leeflang } \\
(2009) \text {. }\end{array}$ & $\begin{array}{l}\text { Gastaldi et al. } \\
(2018), \\
\text { Parviainen et al. } \\
(2017), \\
\text { Grönroos } \\
(2011) \text {, } \\
\text { March (1991). }\end{array}$ \\
\hline $\begin{array}{l}\text { Contribution } \\
\text { to thesis }\end{array}$ & $\begin{array}{l}\text { Explores the } \\
\text { concept of } \\
\text { agent } \\
\text { discretion and } \\
\text { its relationship } \\
\text { to structural } \\
\text { conditions } \\
\text { and learning } \\
\text { outcomes. }\end{array}$ & $\begin{array}{l}\text { Discusses } \\
\text { misalignment } \\
\text { between actual } \\
\text { and required } \\
\text { competencies } \\
\text { and the need to } \\
\text { use a } \\
\text { competence } \\
\text { perspective. }\end{array}$ & $\begin{array}{l}\text { Identifies and } \\
\text { describes four } \\
\text { main } \\
\text { competence } \\
\text { dimensions. } \\
\text { Proposes roles, } \\
\text { role- } \\
\text { responsibilities } \\
\text { and aspects of } \\
\text { learning. }\end{array}$ & $\begin{array}{l}\text { Provides a role } \\
\text { perspective } \\
\text { and } \\
\text { demonstrates } \\
\text { that } \\
\text { exploration } \\
\text { practices } \\
\text { result in better } \\
\text { performance. }\end{array}$ & $\begin{array}{l}\text { Identifies } \\
\text { exploitative and } \\
\text { explorative roles } \\
\text { and value } \\
\text { creation in both } \\
\text { internal and } \\
\text { external } \\
\text { contexts. }\end{array}$ \\
\hline
\end{tabular}




\begin{tabular}{llllll}
$\begin{array}{l}\text { Main relation } \\
\text { to RQs }\end{array}$ & RQ 1, $2 \& 3$ & RQ 1 \& 2 & RQ 1, 2 \& 3 & RQ 1 \& 2 & RQ 1, 2 \& 3 \\
\hline
\end{tabular}

$\mathrm{RQ}=$ Research question

\subsection{Disposition of the thesis}

This is a compilation thesis presented in the form of a compilation summary and five papers. The summary serves two purposes. The main purpose is to combine the knowledge presented in the five papers into a synthesis that makes an academic contribution that is greater than the sum of the results of the papers. The secondary purpose of the summary is to provide an overview of the papers, and to combine them into a unity. The compilation summary has six chapters. Following this introductory chapter (Chapter 1), the concepts and theoretical perspectives used in the thesis are elaborated (Chapter 2) and a conceptual framework is proposed. Chapter 3 is a methodology chapter, and presents the methodology in more detail. This chapter presents my ontological and epistemological perspectives for the thesis. The methodology chapter also discusses research quality, design and ethics. The papers are briefly summarised in Chapter 4 with their background, empirical material, main results and contribution. Chapter 5 discusses the integration of concepts and theoretical perspectives of the conceptual framework with the empirical material of the appended papers, and in this way answers the research questions and addresses the main purpose of the thesis. Chapter 6 presents the conclusions of the work presented here, describes the contribution to knowledge of the thesis, and suggests further research. This chapter contains also contributions for theory and management practice, and discusses thesis limitations. 



\section{THEORETICAL BACKGROUND}

This chapter reviews relevant literature and theoretical perspectives pertaining to the purpose and research questions of this thesis. The purpose of the chapter is to develop a comprehensive understanding of the concepts and theoretical perspectives used. The chapter has three sections. The first section provides the reader with perspectives on the concept of quality management and the practices in quality management work. The second section presents the key theoretical perspectives of practice and competence in order to better understand what is required to perform quality management work. The foundations for these theoretical perspectives are also presented and positioned in relation to each other in order to facilitate different perspectives and critical standpoints. In the third and final section of this chapter, a conceptual framework is proposed and illustrated.

Van de Ven (2013) claims that any individual theory ${ }^{6}$ or perspective is, in itself, usually insufficient to understand the complexities of reality, or at least our socially constructed image of reality. He thus advocates (2013) a pluralistic view when studying a specific problem or problem domain. In this thesis, the choice and motivation for the concepts and perspectives that form the theoretical background are based on the use of disciplined imagination (Weick, 1989, ), in which variations in representation are creatively examined, selected and retained using the criterion of whether the examination, selection and retention give a more accurate understanding and better theory. However disciplined the imagination may be, the choice of concepts and theoretical perspectives must still pass muster and, above all, serve a purpose. They must be plausible and ultimately useful (Weick, 1989) in advancing our knowledge of reality. The ultimate guiding principle for choosing concepts and perspectives is, therefore, reflected in the purpose and research questions of this thesis.

\subsection{Previous literature on quality management and quality management work}

\subsubsection{The concept and context of quality management}

Quality is an important component in achieving competitiveness (e.g. Elg, Gremyr, Hellström $\&$ Witell, 2011; Powell, 1995) and continuous efforts are directed in organisations to facilitate quality improvement, by continuously looking to the way in which quality management practices are organised (e.g. Sousa \& Voss, 2002, Waddell \& Mallen, 2001). The purpose of the management discipline of quality management is, therefore, to deliver the quality of goods and services that satisfies or preferably exceeds customer expectations (Bergman \& Klefsjö, 2010; ISO, 2015; Weckenmann, Akkasoglu \& Werner, 2015). Quality management consists of practices and techniques ${ }^{7}$ applied in order to continuously improve product quality (Sousa \& Voss, 2002) and service quality (Parasuraman, Zeithaml \& Berry, 1985) by fulfilling the basic quality management principles of customer focus, continuous improvement and teamwork (Dean \& Bowen, 1994). These principles can also be described as the key constructs of quality

\footnotetext{
${ }^{6}$ This thesis uses the term theory in the way defined by Sutherland (1975): 'by theory we mean an ordered set of assertions about a generic behaviour structure assumed to hold throughout a significantly broad range of specific instances' (p. 9).

${ }^{7}$ Traditional quality management techniques, also referred to as tools (Bergman \& Klefsjö, 2010), are usually described as both The Seven Quality Control Tools (i.e. data collection, control charts, scatter plots, stratification diagrams, pareto diagrams, histograms and cause-and-effect diagrams), and The Seven Quality Management Tools. (i.e. affinity diagrams, tree diagrams, matrix diagrams, interrelationship diagraphs, matrix data analysis, process decision program charts and activity network diagrams).
} 
management. Though the concept of quality management is fairly well established (e.g. Dean \& Bowen, 1994; Flynn, Schroeder \& Sakakibara, 1994; Sousa \& Voss, 2001; 2002), empirical research on the daily realities and practices of quality management practitioners is scarce (e.g. Elg, Gremyr, Hellström \& Witell, 2011; Flynn, Schroeder \& Sakakibara, 1994). Stratton (1996), Chen et al. (1997) and Larson (1998) emerge as fairly early examples of work to evaluate the roles and development of quality as a coherent practice environment, though none of these articles develops the link between practices and the capacity and potential to perform them.

It is common to organise quality management work by staffing designated employees who are responsible for performing quality management practices, though often as a part-time responsibility. In larger organisations, quality management work is usually organised in quality departments, sometimes managed as central corporate functions with full-time employees. However, an important point of departure for this thesis is that quality is everyone's responsibility (Deming, 1986). Hence anyone within in an organisation, regardless of this person's ordinary tasks and position, can engage in quality management work and perform its practices. Consequently, every employee is a potential quality management practitioner. However, it is common to refer to quality management practitioners as employees who have designated tasks and formalised roles devoted to quality management. It is quality management practitioners according to the latter description who form most of the empirical base of the thesis study object, which is quality management work. The contents of the thesis can, however, be applied to anyone performing and/or managing quality management work.

The roles and areas of responsibility for quality management practitioners have been described as both confined (Burcher, Lee \& Waddell, 2008) and divided (Elg, Gremyr, Hellström \& Witell, 2011). Sörqvist (2014) describes the identity of a quality management practitioner as generally both weak and diffuse. This ambiguity signals a need to address the practice level in quality management, in order to better understand what is required by quality management practitioners in terms of practices and competencies. This need is further fuelled by the evolving nature of quality management, historically progressing from having a predominantly internal, technical and operational orientation into including a more external, dynamic and strategic orientation (e.g. Antony, 2013; Evans, 2013; Reeves \& Bednar, 1994; Sousa \& Voss, 2002). Such practice development diversifies quality management and makes the practices within it seem more elusive and eclectic. A key example of practice development affecting the way in which work with quality management is performed is the introduction of service quality.

The increased emphasis on service quality (e.g. Grönroos, 2008; 2015; Vargo \& Lusch, 2004) has had a major impact on quality management work. In what is labelled as a service logic or service logic approach, value creation through the provision of services to customers is viewed as a continuous, relational process between the provider and customer (Mathieu, 2001; Edvardsson, Tronvoll \& Gruber, 2011). From the perspective on quality management used in this study, the service logic approach (Grönroos, 2006; 2008; 2015) is also viewed as a foundation for business models in contemporary organisations. Vargo and Lusch (2016) show that a service logic approach also has a great impact on what defines practices and competencies, regardless of the main output, be it goods or services. The approximation between service and quality has been firmly established (e.g. Parasuraman, Zeithaml \& Berry, 1985; Psomas \& Jaca, 2016), not least when it comes to what work is supposed to be done (i.e. practices), and the ability to actually get the work done (i.e. competencies). For instance, Grönroos (1984) incorporates the concept of quality management in a service logic approach by distinguishing between technical and functional quality. According to Grönroos (1984), 
technical quality can be described as a measure of the practices and competencies required to meet the specifications and/or technical standards, i.e. what the customer gets. Functional quality can be described as a measure of the practices and competencies required to understand how the customer experiences the product and/or service, i.e. how the customer gets the what of technical quality. Functional quality is built on relationships and interactions that have no clear start or end. In functional quality, practices and competencies concern how, when and where value is created for the customer (Grönroos, 1984). The influence of a service logic approach on competencies in quality management thus emphasises flexibility in the selection, adoption and engagement in practices on the 'whats?' and the 'hows?' of customer knowledge management and customer communication.

\section{Quality management professionals or practitioners?}

Within both the practice field and research field of quality management, the terms quality management profession and quality management professional are sometimes used to describe people assigned to quality management tasks in contemporary organisations (e.g. American Society for Quality [ASQ], 2015; Antony, 2013; Chartered Quality Institute [CQI], 2018; Fundin, 2018; Kolb \& Hoover, 2012; Sörqvist, 2014). But is it reasonable to claim that quality management is an actual profession staffed by quality management professionals? Abbott (1988) uses a systems perspective in describing professions as knowledge-based social systems that are relatively autonomous and self-selective. Evetts (2003) describes professions as knowledge-based (a concept that includes both academic education and vocational training), middle-class based, and self-regulating as to certification and credentials. She also describes professionalism as normative, constituting value systems and ideologies that create social order by promoting practices through ethical norms and an articulated esprit de corps. Styhre (2012) describes professions as social systems for professional work in which the ability to accomplish certain valued effects in society, or performativity, is important. He defines professional work as encompassing sets of professional knowledge (i.e. normative beliefs and professional ethics, technical expertise and know-how ${ }^{8}$ ) that he equates with the Aristotelian concept of trained judgement or phronesis (e.g. Aristotle, 2012; Barnes, 1995). Styhre also lists professional credentials as signifying professional work with education in general, and higher education in particular, acting as gateways into professions. He (2012) also notes that professions and professional work have formal and informal professional entry barriers that set boundaries in society. As such, professional work can be said to be institutionalised and restricted.

Quality management within a Swedish context is neither institutionalised nor restricted. Indeed, the studies presented here show that there is no agreed and established tertiary education in quality management, and that just about anyone can engage in quality management practice (Papers B and C). Furthermore, there is no self-regulating institution or legitimate body of quality management knowledge accredited with certification or the award of credentials. Certification in quality management is restricted to a few highly specialised practices (e.g. Six Sigma belt certification, and certified auditing within quality management systems and quality management models $^{9}$ ). Furthermore, there are no widely established normative beliefs or ethical systems, and there are no formal or informal entry barriers to working with quality

\footnotetext{
${ }^{8}$ Ryle (1990/1949) argued that 'knowing how' is logically prior to 'knowing that'. In other words, practice precedes theory. In Styhre's (2012) definition of professional work, this infers that professionals sometimes do things within their field of profession that they cannot fully explain or describe.

${ }^{9}$ Examples of quality management models include the EFQM model, the Baldrige Excellence Framework, and the SIQ Management model.
} 
management ${ }^{10}$. The lack of formal entry barriers in combination with the requirement for specialised knowledge skills may qualify the occupation of working with quality management as a semi-profession ${ }^{11}$. However, exact boundaries as to what qualifies as a profession, a semiprofession and professionals/semi-professionals are difficult. In this thesis, quality management is therefore not considered to be a profession or a semi-profession (Hodson \& Sullivan, 2007), but rather as a practice environment in which employees who engage in quality management practices are referred to as quality management practitioners.

\subsubsection{The evolution of quality management}

The management discipline of quality management is fairly young and is still maturing (Maguad, 2006). Consequently, it is a management discipline still developing, forming new ways of creating value by improving quality management practices and developing new ones. Three main types of quality management in contemporary organisations have been defined, based in three orientations: compliance-oriented, improvement-oriented and business management-oriented (Burcher, Lee \& Waddell, 2008; Maguad, 2006; Moorman \& Kreitman, 1997). Maguad (2006) defines compliance-oriented quality management as being focussed on meeting specifications and ensuring consistency mainly through the application of statistical tools. Improvement-oriented quality management is focussed on continuously improving processes and systems within organisations, while business management-oriented quality management is focussed on broader, more extended outcomes, such as following strategies, meeting objectives, and justifying decisions. It is difficult to draw clear boundaries between these three orientations, but they can be said to fulfil organisational purposes that depend on the functional scope in organisations. In this thesis, the term functional scope is used to describe the overall orientation and content level of management initiatives in contemporary organisations (Figure 2). The functional scope illustrates the levels of management practice in contemporary organisations in terms of how the organisation is affected. A more strategic scope in quality management is predominantly aimed towards assuming strategic responsibilities and performing indirect management practices. A more operational scope in quality management is predominantly aimed towards assuming operational responsibilities and performing direct management practices (Paper C).
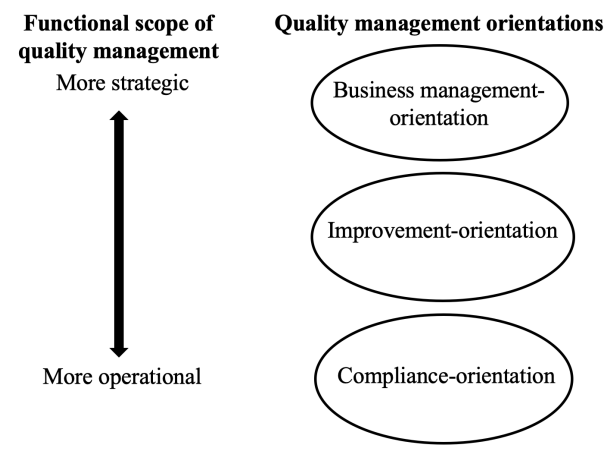

Figure 2. Functional scope of quality management and quality management orientations (adapted from Maguad, 2006)

\footnotetext{
${ }^{10}$ This may help to explain why there are so few attempts in research to systematize a coherent set of competencies in quality management in the same way as, for example, in the military profession (e.g. Johansen, Laberg \& Martinussen, 2014; Rolf, 1998) and in medical professions (e.g. Lane, 2010).

${ }^{11}$ According to Hodson and Sullivan (2007), a semi-profession requires specialized knowledge and skills but lacks formal entry barriers.
} 
It is anticipated that all three orientations are intertwined and exist simultaneously in contemporary organisations, thus affecting quality management practice on all organisational levels in a complex weave of different logics and imperatives (e.g. ASQ, 2015; Burcher, Lee \& Waddell, 2008; Goetsch \& Davis, 2006; Eriksson et al., 2016; Sandholm, 2005; Swedish Quality Management Academy/Swedish Institute for Quality [SQMA/SIQ] 2012; Sörqvist, 2014). While it is true that business management-oriented and compliance-oriented quality management are more-or-less clearly separated, the boundaries of improvement-oriented quality management transgress the whole range of strategic and operational scopes.

This proposed multi-functionality and added dimension of complexity in quality management are challenging, not only for the quality practitioners themselves, but also for the general management and people responsible for organising quality management. Contemporary organisations have become much more heterogenous, allowing for more diversity in the application of quality management practices. This, in turn, makes the requirements of quality management practitioners difficult to grasp (Sörqvist, 2014). In fact, current and future quality management practitioners may need to switch between multiple and unforeseen roles, sometimes at multiple times over short time spans (Paper C). Thus, the context-dependence described by Sousa \& Voss $(2001 ; 2008)$ results in quality management becoming increasingly dynamic and heterogenous, which allows a more diversified portfolio of ways of working with practices, even within one organisation. Examples of such internal diversity of quality management practices given by the various roles of quality departments (Paper D), and the diverse roles of quality management in digitalisation (Paper E). The results suggest that more dynamic and versatile perspectives are needed to guide quality management in general, and to determine how to engage in its practices in particular.

This need can be traced back to the ideas of organisational development and change (Van de Ven \& Poole, 1995), the productivity dilemma (Abernathy, 1978; Benner \& Tushman, 2003), and an understanding of quality management and its practices as ultimately context-dependent (Sousa \& Voss, 2001). Van de Ven and Poole (1995) describe four ideal-type theoretical perspectives on change and stability within organisations: 1 . The lifecycle perspective, in which change is mainly driven by prescribed programs, sequential development, organic growth and logic, 2. The evolution perspective, in which change is predominantly driven by competition, survival, sequences of variation and retention, 3. The dialectic perspective, in which confrontation, conflict and opposition between interests are the key drivers of change, and 4. The teleological perspective, in which purposeful cooperation, planning, evaluation and goal enactment function as main drivers. It can be argued that more dynamic and versatile approaches to perform quality management work are needed within all perspectives, as described by Van de Ven and Poole (1995), but that evolution and dialectic perspectives, in particular, requires more emphasis on dynamics and versatility in quality management work.

The productivity dilemma is described by Abernathy (1978) as the challenge faced by organisations to create production environments that facilitate both stable and incremental practices (cf. the lifecycle and teleological perspectives), and flexible and innovative practices (cf. the evolution and dialectic perspectives). This dilemma has also been described as a balance between achieving external effectiveness and internal efficiency (Benner \& Tushman, 2003; 2015; Backström, 2017; Fundin et al., 2017; Grönroos, 2015; Grönroos \& Helle, 2010; 2012; Gupta, Smith \& Shalley, 2006). External effectiveness can be described as a measure of producing the right output for customers, or 'doing the right things', whereas internal efficiency can be described as optimising the use of resources to produce an output for customers, or 'doing things right' (Gupta, Smith \& Shalley, 2006). Benner and Tushman (2003), Gupta, 
Smith and Shalley (2006), and O'Reilly and Tushman (2013) all describe the need for ambidextrous organisations ${ }^{12}$ to balance March's (1991) notion of exploitation and exploration $^{13}$ in terms of quality management practice. In line with this, Rosing, Frese and Rosenbuch (2010) discuss ambidexterity and the balance between exploitation and exploration in terms of leader behaviour. In quality management research, this also been conceptualised by Zhang, Linderman and Schroeder (2012) as selecting and adopting either quality exploitation-oriented practices or quality exploration-oriented practices. Furthermore, the different natures of learning and knowledge creation are central in the concepts of exploitation and exploration (March, 1991), and have been described as important components in a contingency-based and context-dependent understanding of quality management (e.g. Choo, Linderman \& Schroeder, 2007; Fundin et al., 2017; Linderman et al., 2004). The challenge that the productivity dilemma causes in achieving both external effectiveness and internal efficiency has, in research related to quality management, been described as the quality dilemma (e.g. Fundin et al., 2017), with similar notions having also been addressed in several other studies (e.g. Benner \& Tushman, 2003; 2015; Backström, 2017; Grönroos, 2015; Grönroos \& Helle, 2010; 2012; Gupta, Smith \& Shalley, 2006). One watershed in approaching the productivity dilemma and/or the quality dilemma is that of either choosing a best-practice view or a best-fit view for practices in quality management work.

Ever since Sousa and Voss $(2001 ; 2008)$ suggested that the prevalent best-practice view in quality management should be extended towards more of a best-fit view, much research on quality management suggest a more contingency-based and context-dependent approach (e.g. Elg, Gremyr, Hellström \& Witell, 2011; Evans, Foster \& Linderman, 2014; Zhang, Linderman \& Schroeder, 2012). It can be argued that this stream of research has infused a need to accommodate a rationale of both improvement and development in quality management. Anttila and Jussila (2017) put forward a contemporary understanding of the needs in quality management based on organisational and societal change. In this way, they identified a need for quality integration, in which a more purposive and goal-oriented approach would be combined with subjective perspectives in what can be described as a best-fit and an emergent ${ }^{14}$ approach in quality management.

There are numerous examples of research claiming to have discovered an ongoing paradigm shift within quality management towards such a best-fit approach (e.g. van Kemenade, 2014; Weckenmann et al., 2015; Zhang, Linderman \& Schroeder, 2012). The perception of quality management as being predominantly directed towards practices of control and management (e.g. Cole \& Matsumiya, 2007; Sousa \& Voss, 2002) is described as a thing of the past. As outlined above, Zhang, Linderman and Schroeder (2012) show that exploitative and explorative practices are needed in order to succeed in quality management implementation and to perform in uncertain environments. van Kemenade (2014) identifies an emergent change that emphasises a need to be much more adaptive and context-sensitive in quality management. Weckenmann, Akkasoglu and Werner (2015) follow this line and describe the advent of 'intelligent quality management' in more flexible approaches towards balancing the needs for control and innovation. Backström, (2017), Fundin et al. (2018) and Fundin et al. (2017)

\footnotetext{
${ }^{12}$ Ambidextrous organisations incorporate structural arrangements that facilitate both the initiation of innovation and also the execution of innovation (Tushman \& O'Reilly, 1996).

${ }^{13}$ Exploitation (March, 1991) refers to processes in which individuals or groups of individuals assimilate, acquire, master or refine existing practices. The dichotomous term of exploration denotes processes in which individuals or groups of individuals engage in critical evaluation, accommodation, experimentation, risk-taking, variation, flexibility, discovery and innovation.

${ }^{14}$ The term emergence can be used to describe the process in which a new, higher-order entity is irreducibly developed from the parts of old, lower-order entities (Bunge, 1979; 1993).
} 
describe the need for emergent quality management in order to balance both exploitation and exploration, and internal efficiency and external effectiveness. Research thus indicate that quality management work in contemporary organisations is already evolving towards emergence and best-fit in the selection, adoption and subsequent engagement of quality management practices in quality management work. The competencies required to address this development in handling the quality dilemma and facilitating a best-fit approach in quality management work have yet to be adequately analysed. A logical next step to achieve this could be to start with the basic elements of quality management work, i.e. the practices of quality management.

\subsubsection{Quality management practices}

Dean and Bowen (1994) describe quality management as 'a set of mutually reinforcing principles, each of which is supported by a set of practices and techniques' (Dean \& Bowen, 1994, p. 396). The term quality management is used in this thesis to refer to the set of practices needed to realise the quality management principles; see Subsection 1.4.1. Quality management practices are understood to be the expected behaviours in organisations in order to adhere to the quality management principles (Prajogo \& McDermott, 2005). The common view on the nature of quality management practices in research thus corresponds fairly well to the features of a practice environment (Schatzki, 2001) with its institutionalised and explicit rules, implicit understandings on expected actions and behaviours and its normative presumptions conveying ends and means. Rules primarily govern the particular techniques and, to some extent, the content of practices. Shared understandings and normative presumptions form the basis of practices and overarching principles. Several coherent and relevant sets of quality management practices have been proposed (e.g. Dean \& Bowen, 1994; Hellsten \& Klefsjö, 2000). This thesis accepts to a large extent the findings of $\mathrm{Zu}$ (2009), who offers a well-researched and comprehensive literature review that identifies quality management practices. Table 2 presents a literature-based summary of the quality management practices relevant to this thesis, and gives brief understandings of the practices and their connection to shared normative presumptions (expressed as quality management principles).

Several studies have adopted a role perspective when addressing practices in quality management studies (e.g. Addey, 2004; Elg, Gremyr, Hellström \& Witell, 2011; Evans, 2013; Larson, 1998; Wadell \& Stewart, 2004; Zu, 2009). Role perspectives are also widely used by professional bodies (e.g. The American Society for Quality [ASQ], 2015b; The European Organization for Quality [EOQ], Svenska Förbundet för Kvalitet [SFK], 2015). In this thesis, quality management roles are broadly defined as bundled sets of specific practices needed in defined situations in order to perform quality management work. A quality management role thus entails a specific capacity to perform practices signifying specific quality management work. Quality management roles, as bundled sets of practices, can be either formally predefined or informally discovered. As Paper B shows, misalignment between what is officially demanded and what practices the task really requires sometimes occurs. Understanding the roles and what is actually required is thus a key in order to perform successful quality management work. Any formal working position within quality management thus requires the ability to switch between several defined and undefined roles, each of which corresponds to a set of practices and associated responsibilities (Martin, Elg, Gremyr \& Wallo, 2019). The sets of quality management practices these involve are referred to as roles.

One factor that is becoming important in quality management practice is sustainability. Choo, Linderman and Schroeder (2007) discuss how increased interest in environmental sustainability 
promotes the successful implementation of quality management programs. Siva et al. (2016) argue that quality management practices must be developed in accordance with environmental sustainability considerations. This development is reflected in the publications of professional bodies. For instance, both the ASQ (2015b) and the Swedish Institute for Quality [SIQ] (2018) include three types of sustainability: social, financial and environmental, as important outcomes or results of quality management in their respective management models. It can be argued that sustainability forms its own practice area within quality management, but sustainability is considered in this thesis to be a guiding principle for all practices, rather than being a defined quality management practice in itself.

Table 2. Quality management practices

\begin{tabular}{|c|c|c|}
\hline $\begin{array}{l}\text { Quality } \\
\text { management } \\
\text { practice } \\
(\mathrm{Zu}, 2009)\end{array}$ & $\begin{array}{l}\text { An understanding of the practice } \\
(\mathrm{Zu}, 2009)\end{array}$ & $\begin{array}{l}\text { Normative presumptions expressed as the } \\
\text { main related quality management } \\
\text { principles (Dean \& Bowen, 1994) }\end{array}$ \\
\hline $\begin{array}{l}\text { Top } \\
\text { management } \\
\text { support }\end{array}$ & $\begin{array}{l}\text { The responsibility, performance evaluation, } \\
\text { active involvement and formulation of } \\
\text { quality strategies and goals }\end{array}$ & Teamwork, customer focus \\
\hline $\begin{array}{l}\text { Customer } \\
\text { relationship }\end{array}$ & $\begin{array}{l}\text { Learning customer needs and performing } \\
\text { expectation measurements, involving } \\
\text { customers and an understanding of customer } \\
\text { satisfaction }\end{array}$ & Customer focus \\
\hline $\begin{array}{l}\text { Supplier } \\
\text { relationship }\end{array}$ & $\begin{array}{l}\text { Involving suppliers, quality evaluation, } \\
\text { training and technical assistance }\end{array}$ & $\begin{array}{l}\text { Customer focus, teamwork, continuous } \\
\text { improvement }\end{array}$ \\
\hline $\begin{array}{l}\text { Workforce } \\
\text { management }\end{array}$ & $\begin{array}{l}\text { Recognising employee performance, } \\
\text { teamwork, training and empowerment in } \\
\text { quality issues }\end{array}$ & Teamwork, continuous improvement \\
\hline $\begin{array}{l}\text { Quality } \\
\text { information }\end{array}$ & $\begin{array}{l}\text { Collecting and making data available } \\
\text { throughout the organisation, using data for } \\
\text { quality improvement }\end{array}$ & Customer focus, continuous improvement \\
\hline $\begin{array}{l}\text { Product/ } \\
\text { service design }\end{array}$ & $\begin{array}{l}\text { Employing thorough review processes, } \\
\text { involving multiple departments, simplifying } \\
\text { design for manufacturability }\end{array}$ & Customer focus \\
\hline $\begin{array}{l}\text { Process } \\
\text { management }\end{array}$ & $\begin{array}{l}\text { Using statistical process control [SPC], } \\
\text { optimising processes and planning. }\end{array}$ & Continuous improvement \\
\hline
\end{tabular}

\subsubsection{Key aspects of quality management}

One of the main arguments of this thesis is that the nature of quality management work has only been partly explored and described. Earlier research has been focussed on the conditions for quality management practices, but has rarely increased our understanding of how quality management practitioners actually work, or identified the competencies that such work requires. Such an approach may be sufficient when studying relatively stable and conventional settings. However, the changes to which quality management practices are subject in dynamic, high-paced environments where change is constant require a competence perspective in which the practices and competencies that really are used must be in focus. This subsection summarises the findings of the literature review on quality management featured in Section 2.1 
in characterising quality management as composed of three key balancing aspects. Based on the literature study for this thesis, it is thus proposed that quality management consists of quality management work that requires:

- A balance between quality exploration and quality exploitation (e.g. Backström, 2017; Benner \& Tushman 2003; 2015; Fundin et al., 2018; Fundin et al., 2017; March, 1991; Zhang, Linderman \& Schroeder, 2012).

- A balance between external effectiveness and internal efficiency (Abernathy, 1978; Benner \& Tushman, 2003; 2015; Backström, 2017; Fundin et al., 2017; Grönroos, 2015; Grönroos \& Helle, 2010; 2012).

- A balance between best fit and best practice according to organisational context and the situation and/or task at hand (Anttila \& Jussila, 2017; Antony, 2013; Ellström, 1992; Ellström \& Kock, 2008; Evans, 2013; Lindberg \& Rantatalo, 2014; Reeves \& Bednar, 1994; Sousa \& Voss, 2001; 2002; 2008).

\subsection{Theoretical perspectives on quality management work}

It is assumed that, in order better understand the ways of working with quality management, it will be useful to use theoretical perspectives that extend what can be deduced from observation into generalisable knowledge, applicable in a broad range of quality management settings. One approach is to combine theoretical perspectives that address how quality management work should be performed (i.e. practice) with theoretical perspectives that address the potential to actually perform quality management work (i.e. competence).

\subsubsection{Practice theory}

Practice in quality management forms a research niche in itself (e.g. Dahlgaard et al., 1998; Dean \& Bowen, 1994; Sousa \& Voss, 2001; 2002). However, the approach to practice within the research field of quality management is often dominated by a technical cognitive knowledge interest (Habermas, 1972). Research that has approached a more theoretical understanding of the nature of quality management practice is scarce. Such theorising on practice has been frequently applied in research intended to explain social change and investigate social transition (e.g. Bourdieu, 1977; Giddens, 1979; 1984), but it can be argued that practice theory also provides the means to understand the practices and ways of particular work (e.g. Lindberg \& Rantatalo, 2014). Sandberg and Tsoukas (2011) suggest that practice theory is highly influenced by what they label as practical rational frameworks, in which the existentialist notion of entwinement is central. Entwinement focusses on sense-making and intelligibility which, in turn, depend heavily upon a holistic view of understanding connections and relationships between individuals and structures. Thus, from a practical rational perspective, individuals and structure cannot be separated but are always entwined. The key to understanding what generates sense, meaning and purpose is therefore to study practice itself.

According to such existentialist perceptions of reality, neither structure nor agency should be exclusively in focus when attempting to understanding competence (Sandberg \& Targama, 2007), but rather the activities themselves. In this sense, practice represents its own instrumental logic in providing meaning. The range of practice logics within a particular context provides a sense-making mechanism that guides the researcher to understand the relationships between an individual quality management practitioner and the practice environment and social structure in which the practitioner works. Schatzki (2005) uses the concept of site ontologies to describe 
the nature of knowledge in the social structures of practice environments. He suggests that knowledge is shared understanding of the preferred and approved way of doing things. By virtue of their inherent practices and activities, site ontologies represent particular organisational logics that interconnect structures and individuals by providing rules, common and shared understandings, and meaning, within the social structure of a practice environment (Schatzki, 2005; 2011) such as quality management.

Practice theory adds not only activity (Sandberg \& Tsoukas, 2011; Schatzki, 2001; 2005), but also the ability to reflect in and on practice (Schön, 1983). Schatzki (2005) suggest that social structures determine what practices are correct, and in this way create and maintain social order. Schön (1983) shows that the processes of learning and reflection are necessary for this determination to come into place. Schatzki (2001) describes three constructs in his definition of a practice: 1. Teleo-affective structures, which are practice-guided sentiments that carry normative assumptions of what constitutes the ends and means for actions within the practice, 2. Pools of understanding, which are implicit understandings of how the practices should be performed, and 3. Rules, which are shared, explicit articulations of the correct way of performing practices in actions. Schatzki $(2001 ; 2005)$ defines a practice as a successful way of solving a task determined by a practice environment, and this definition will be used in this thesis.

\subsubsection{Competence theory}

Theoretical perspectives that consider not only the individual quality management practitioner but also the social structure of quality management are needed to extend an understanding of quality management work. Theoretical perspectives on competence offer such a possibility. However, the concept of competence contains multiple perspectives and has been described as fuzzy and ambiguous (van der Klink \& Boon, 2000), and thus an introduction and overview of the concept of competence is in order.

Sandberg (2000) states that a modern understanding of the concept of competence started with Frederick Taylor, who pioneered the classification of competencies in The Principles of Scientific Management (1911). In this book, Taylor introduced modes of analysis (e.g. 'time study work') by which basic competencies could be deduced by studying and analysing work procedures. A research-based approach to understanding competence was then picked up by White (1959), and subsequently developed by McClelland (1973) and Boyatzis (1982). Both McClelland (1973) and Boyatzis (1982) rejected intelligence and education as indicators of performance, and emphasised the performance of practices as key elements in defining competence. Mulder (2014) describes three approaches to competence: micro-oriented approaches that focus on individual gaps between actual and desired competence, macrooriented approaches that sort competence into occupationally structured competence frameworks, and meso-oriented approaches that situate competence in particular contexts.

Some research defines and describes the aspects of competence in a more generic and context-independent manner (e.g. van der Klink \& Boon, 2003; Eraut, 2000), but many studies are based on macro-oriented approaches that focus on particular aspects or dimensions of competence in order to create useful models or frameworks of professional competence (e.g. Preuss \& Lohff, 2003). Cheetham and Chivers (1996; 1998) use pie chart illustrations to describe an occupational competence mix with four core competencies: personal competence, values/ethical competence, functional competence and knowledge/cognitive competence. These are, in turn, supplemented by meta-competencies such as communication, self- 
development, creativity, analysis and problem-solving ability. Delamare Le Deist and Winterton (2005) elevate the core competence perspective into a more conceptual and holistic model that combines the cognitive, functional and social competence dimensions, which are, in turn, facilitated by a meta-competence dimension labelled as practical competence. Traditional management literature contains some 'hard' management-oriented studies, in which internal firm-specific competencies are strongly related to firm performance (e.g. Prahalad \& Hamel, 1990). On the other hand, 'soft' management-oriented studies tend to focus more on learning processes and the transfer or development of competencies (e.g. Delamare Le Deist \& Winterton, 2005).

Research that is more micro-oriented and meso-oriented emphasises the more abstract and latent dimensions of competence. Much more emphasis is placed on behaviours, action, and interaction. Bartram (2005) and Kurz and Bartram (2002), for example, define competence as a range of behaviours that are instrumental in achieving the desired results. Ellström (1992; 1997) emphasises the interactional aspect, and addresses the multitude of factors that determine which competence is to be used. Further examples of research that emphasises the complexity and elusiveness of competence are McClelland (1973), Epstein and Hundert (2002), Illeris (2013) and Leach (2002).

\subsubsection{The perspective on competence and practice adopted in this thesis}

In this thesis, competence is viewed as a complex and multidimensional concept focussed on interaction. As such, it draws mainly on the constructs of occupational competence outlined by Ellström (1992; 1997). Occupational competence is described as a multidimensional construct of potential or capacity for performance in a specific situation (Ellström, 1992; 1997). The multidimensionality of competence is described by Ellström $(1992 ; 1997)$ as the interaction between an individual's formal and actual competence, and the requirements of the task and organisation (i.e. qualifications). This results in a particular competence being used to perform a task in a specific situation, i.e. the competence-in-use (Figure 3). Lindberg \& Rantatalo (2014) also focussed on the interaction within defined situations, and describe competence as the inferred capacity for desirable activity in a particular and defined situation. Any competence that defines a practice can thus be viewed as a perceived contextual suitability for how to perform actions related to the practice.

The perspectives on competence and practice used in this thesis are viewed as interrelated due to the emphasis that both perspectives place on action. Schatzki (2001) uses the words performance and action when describing the three constructs of shared rules, pools of understanding and teleo-affective structures. These concepts of action and activity resemble the link between competence and action described by Ellström (1992; 1997; 2001), while the concept of practice is common in conceptualisations of competence (e.g. Delamare Le Deist and Winterton, 2005; Mulder, 2014). For instance, Ryle (1990/1949), an early interpreter of competence, combined the concepts of skills (i.e. individual practical knowledge), know-how, (i.e. collectively and socially asserted practical knowledge), and reflection into an understanding of competence. Rolf $(1995 ; 1998)$ extends Ryle's perspective, and describes competence as a relationship between individual practical knowledge (including both skills and know-how) and a social system of rules mediated by individual and collective reflection. Rolf (1998) also bring a social dimension to competence, in describing it as 'bounded in social units' (p. 31) that can also be described as social structures and/or practice environments. The views on the dynamics between individual and collective phenomena, and views of what constitutes the normative mechanisms that regulate the perception of desired competencies and successful 
practices, are considered to be sufficiently similar in both competence theory and practice theory (within the theoretical realm of this thesis).

The competence diagram in Figure 3 outlines the concept of competence used in this thesis as certain individually related constructs and certain structurally related constructs. The individual construct (also aspect) of formal competence is the set of competencies gained by the individual through formal education. These are usually documented as licences, certificates and grades, etc. The individual construct of actual competence is the competence accumulated by having done the same task before (previous experience). The officially demanded competence is a taskrelated and/or job-related construct that can be described as a formalised description of what is demanded and required. This is also referred to as qualifications. The task-related and/or jobrelated construct of competence required by the job is what the task actually requires in order to be successfully completed. The competence required by the job may not always be manifest. The competence-in-use, where the combined competence of the individual meets an actual task or job to performed, is located in the centre of the diagram. Competence-in-use is a measure of success for an individual, and can be described as how well the individual potential or capacity for action stands the test of a real task, set in a real situation. Competence is viewed as ultimately context-dependent in this thesis. With this view, the measure of success following the application of competence-in-use depends on the particular circumstances, situation, task and/or personal mood (e.g. Lindberg \& Rantatalo, 2014, Ellström \& Kock, 2008).

Individual

Formal competence

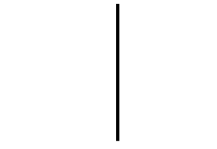

Actual competence

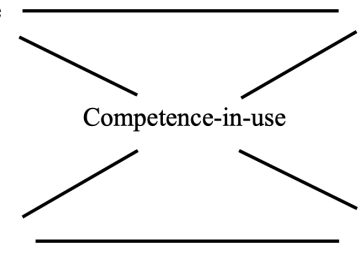

Competence required by the task/job

Task/job

Officially demanded competence

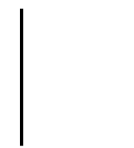

Figure 3. Ellström's competence diagram (1997, p. 268)

The relationships between the aspects in the competence diagram and the way in which the concept of competence is used in this thesis can be illustrated by an example from truck driving.

A truck driver with more than ten years' experience of driving trucks in many environments and situations has recently upgraded his/her formal competence by qualifying for a licence that permits driving trucks with heavy trailers. This means that the formal competence of the individual is that of a certified truckand-trailer driver, possessing a truck and heavy trailer driving licence. The extensive experience of driving trailerless trucks has given considerable actual competence of driving trailerless trucks. However, the experience of driving trucks with heavy trailers is limited to the experience gained while practising for the heavy trailer licence (about one month of summer driving).

The truck driver gets a new job at a transport and logistics company in northern Sweden. In the recruitment profile, the officially demanded competence was stated as 'experienced truck driver with heavy trailer licence'. Since the truck 
driver possessed the qualifications outlined in the officially demanded competence requirements, he/she got the job. Since the job is located in the northern part of Sweden, the competence it requires includes driving trucks with heavy trailers in winter conditions, with snow, ice and slippery roads. On the truck driver's first day at work, he/she is given an assignment to drive a heavy trailerload of hazardous chemicals, by night, in a heavy blizzard. This is a real task in a real situation, for which the competence-in-use of the truck driver is woefully inadequate.

The example shows that the competence-in-use, i.e. the truck driver's capacity or potential for action in a real task set in a real situation, is inadequate, and there is a high risk of a negative outcome with severe consequences. Competence-in-use is thus a complex, real-life test of how well individual practical knowledge, including both formal and actual competence in the form of skills and know-how, is related to the requirements of the context in which the individual is acting.

The complexity of competence-in-use is also reflected in what Boyatzis (1982) and Mulder (2014) describe as needed sets of competencies. Sets of competencies are arranged in order to describe competence-in-use for both routine and non-routine work, allowing variation in complexity. This thesis adopts the taxonomy of competence that describes 'perceptual motor skills, cognitive factors, affective factors, personality traits and social skills' (Ellström, 1997, p. 267) within intuitive and cognitive dimensions (e.g. Ellström, 1997; Sadler-Smith \& Sheffy, 2004). Other properties that are components of the sets of competencies included in the notion of competence-in-use are cultural and/or context awareness (Brown, Collins \& Duguid, 1989; Mulder, 2014), and scope of action or degrees of freedom (cf. Ellström, 1997) afforded in the practitioner role (cf. affordance, Gibson, 1979).

Ellström (1992) suggests that competence-in-use may be constrained or enabled by objective or subjective limitations to discretion. The term discretion relates to the degree of freedom for individuals or collectives to choose what to do, how to do it and how to manage the results. Objective limitations are bound in the social structure of the organisational context (Ellström, 1992), by, for example, limitations in information sharing, or limited access to critical tools and equipment. Subjective limitations to discretion are internally construed, and they are linked to affective factors and the specific personality traits of the individual. A dominating example of a subjective factor that affects discretion is self-efficacy (Bandura, 1977), which determines coping initiation, effort, and persistence in the exercise of competence-in-use. Bandura (1977) shows that self-efficacy is affected by previous performance (i.e. enactive experience), observing or modelling the competence-in-use displayed by others (i.e. vicarious experience), effects of persuasion (i.e. exhortative experience), and emotive, psychological states.

Ellström (1997) emphasises also the need to relate capacity for action to levels of learning, where higher levels of competence require an ability for higher levels of learning. Ellström (2006) distinguishes between a logic of performance and a logic of development, and this distinction is, in turn, based on March's (1991) theory of exploitation and exploration. Ellström (1992; 1997) categorises work-learning situations as being either given or not given as to the task, method and/or results. Learning can be described as a function of the discretion regarding aspects of the learning environment (i.e. the degrees of freedom in choosing task, method and result) in any given work-learning situation (Ellström, 1992; 2001). Environments with low agent discretion in affecting the task, method and results result in more adaptive learning (cf. 
exploitation, March, 1991), while environments with higher agent discretion in affecting the task, method and results result in more developmental learning (Ellström, 1997). In order to conclude this chapter on the theoretical background, the final section in this chapter will amalgamate the key concepts in a cohesive framework outlining how they relate and interact.

\subsection{Conceptual framework}

A conceptual framework explains the main phenomena to be studied, i.e. the most important elements, constructs and/or variables and how they relate to each other (Miles \& Huberman, 1994). Figure 4 illustrates a proposed conceptual framework for this thesis by conjoining the key concepts and theoretical perspectives and outlining how they relate and interact in the process of performing quality management work.

The practice environment of quality management (guided by specific principles)

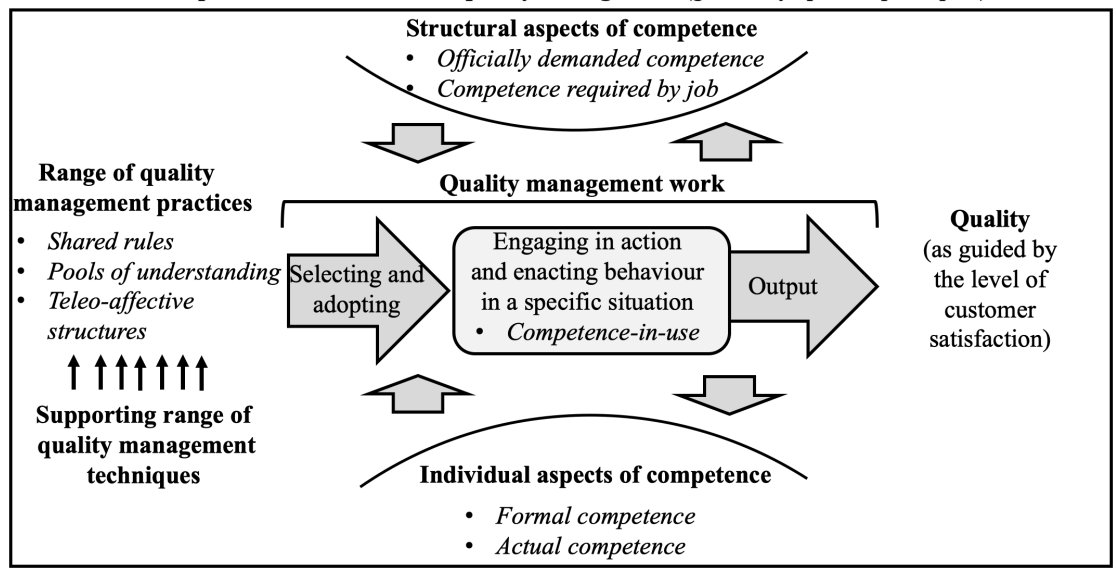

Figure 4. The conceptual framework for this thesis

Quality and quality management forms the practice environment, in which the guiding principles of quality management forms the shared normative assumptions. There is a range of quality management practices that constitute shared explicit rules, pools of implicit common understandings and teleo-affective structures dictating the means and ends for the practices. The practices are supported by a range of quality management techniques (or tools). The structural aspects of competence, i.e. the representation of competencies related to the organisation, task and/or job, are described as officially demanded competence and competence required by the job. The individual aspects of competence represent the formal competence and actual competence as possessed by the quality management practitioner or practitioners. In the process of quality management work, aspects of structural and individual competence interact in the selection, adoption and engagement of quality management practices. This interaction contains both feed-forward and feed-back to the structural and individual levels. The particular action and behaviour carried out are described as the actual competence that is in use in order to perform quality management practice in a particular situation. The output of this action/these actions affects the level of quality achieved. The quality level is defined using the principles (which also form the conceptual constructs) of quality management. 


\section{RESEARCH METHODOLOGY}

This chapter presents the methodological approach, research design and evaluation of the research methodology, in three sections. The first section outlines the methodological approach, the research strategy and the research process for this thesis. The second section features an overview of the research design with an outline on the elements of interactive research and an overview of the design, data and analysis in the five studies. In this section, the similarities and differences of the research designs of the individual papers are outlined and discussed ${ }^{15}$. The third section of this chapter features a methodological evaluation, and discusses issues of research quality. Important ethical considerations of the research in this thesis are also covered.

\subsection{Methodological approach}

\subsubsection{Methodological premise}

I am influenced and inspired by the social scientific philosophy of critical realism as a premise that guides the methodological approach of this thesis. Critical realism departs from a pure empiricist/positivistic and objective ${ }^{16}$ ontology that, in its extreme forms, claims a naïve realism ${ }^{17}$. Critical realism departs also from a pure constructivist/hermeneutic and subjective ontology that claims relativism, and acknowledges the existence of many realities no one of which is intrinsically more relevant than any other. A critical realist ontology claims that an objective reality exists, but that we, as humans, have only subjective and limited access to it (Danermark et al., 2002).

In order to fully understand the observations of quality management work, a researcher must use the empirical material in a reflective way that challenges the definition of what constitutes our knowledge of reality (Bhaskar, 1998; Wynn \& Williams, 2012), and the theories and concepts of reality (Guba \& Lincoln, 1994). Critical realists hold that any kind of direct, unmediated knowledge about reality cannot be obtained, since we, as scientists, have access only to what we can observe via our limited senses and cognition. Thus, from a critical realist epistemological perspective, what can be observed can never be assumed to represent a $100 \%$ accurate depiction of reality.

This challenges both realist and idealist ontological claims for the aims of science. Realists hold that the aim of science is to provide a true description of the complete world, whereas idealists claim that the aim of science is to provide true descriptions of certain parts of it (Okasha, 2002). Critical realists, in contrast, hold that any knowledge of reality is, by necessity, biased and relative, since the ontological constitution of reality is always perceived, described and explained from a specific epistemological perspective, inevitably set somewhere within the realm of what can be observed (Weick, 1989). As such, our knowledge of reality can be described as socially responsive, open and emergent. In this thesis, knowledge of reality in general is viewed as a subjective epistemological construction, dependent upon the researcher's

\footnotetext{
${ }^{15}$ It should be duly noted that in this chapter, the general research designs are in focus. Specific methodological considerations and details (e.g. sampling, coding and specific analytical procedures) can be found in the papers.

${ }^{16}$ The distinction between subjective and objective primarily refers to Burrell and Morgan's (1979) distinction between the subjective dimension of social science (with a nominalist ontology, anti-positivist epistemology, voluntarist view on human nature and an ideographic approach to methodology), and the objective dimension of social science (with a realist ontology, positivist epistemology, a deterministic view on human nature and a nomothetic approach to methodology).

${ }^{17}$ Naïve realism is an ontological position in which it is believed that there is but one reality and that it is possible to describe it.
} 
choice of epistemological and theoretical perspective. Any idea of reality thus depends on theoretical perspectives.

This is not an exclusive view for critical realists. For example, both Popper (1997/1963) and Kuhn (1979/1962) state that facts (i.e. observations) are always theory-laden. Critical realists (e.g. Sayer, 1992) highlight the important amendment that facts should never be viewed as theory-determined, as in the principal constructivist view (e.g. Guba \& Lincoln, 1994), but instead theory-dependent. Though critical realists agree with constructivists that any claim for absolute and objective truth should be considered an epistemological fallacy, all facts might not all be equally well supported by the particular theory at hand. A key tenet of critical realism, which is not a tenet of constructivism, is that the quest for better ${ }^{18}$ explanations may be closer to the conception of truth, as an understanding of what constitutes reality. Critical realists thus acknowledge that some claims for truth (or, rather, claims for knowledge of reality) are more relevant than others, by virtue of the relative explanatory power of theories (e.g. Dobson, 2001; Sayer, 1992; Wynn \& Williams, 2012). To summarise my basic ontological and epistemological assumptions, I quote $\operatorname{Archer}(1998$, p. xi): 'critical realism claims to be able to combine an ontological realism, an epistemological relativism and a judgemental rationality'.

Critical realist perspectives on management relate to individual perspectives and structural perspectives (Fleetwood, 2005). It has previously been proposed that organisations and their collectives of members always participate and interact within the realm of social structures (Giddens, 1979; Archer, 2008). Sayer (1992) argues that social structures incorporate 'sets of internally related objects or practices' (p. 92). It is reasonable to suggest that practices form the very fabric of social structures, and this thesis argues also that that social structures, such as the practice environment of quality management, are manifested by the enactment of practices. Based on this reasoning and the above definition of social structures, practice environments are equated with social structures in this thesis.

Quality management work can be described as a social phenomenon that involves particular practices (e.g. Zu, 2009), where social structures are populated by agents (in the form of quality management practitioners) who form the principal objects of study (Archer, 1995). Archer (1995) describes how structure always precedes agency, i.e. how agents always act in a predetermined structure that was present from the start. As such, the work presented in this thesis is based on the assumption that the rules, positions and social relationships or objects of the organisational context govern the practices used in quality management work in a process described as structural conditioning. Likewise, the term social agency, or just agency, denotes the social role characteristics that agents assume within social structures (Archer, 1995). The metaphor of acting is often used to describe agency as an institutional script, used by actors when pursuing their roles as agents on an organisational stage, i.e. within the realm of the social structure. Agents tend to act in accordance with the social role encapsulated in the internal relationships and interests dictated by the social structures, but they can also interact and contribute to changes in the social structure in a process described as structural elaboration (Archer, 1995). In this thesis, agents (i.e. quality management practitioners) are thus defined as intentionally acting subjects, i.e. individual actors or collectives of actors, who occupy structural positions in social structures (i.e. the practice environment of quality management) and can either reproduce or transform social structures (Danermark et al., 2002).

\footnotetext{
${ }^{18}$ By better explanations, this thesis adheres to Danermark et al., (2002) who state that knowledge and explanations can be more or less truthful in relation to reality and that better knowledge and explanations are more truthful than other knowledge and explanations.
} 
Quality management work can be said to independently exist, to a certain degree, inasmuch as agency, more or less, transgresses organisational boundaries. The practices of quality management work thereby forms the very fabric of the social structure of quality management that conditions its agents. The agents of quality management (i.e. quality management practitioners) can also be said to identify and relate to other agents who hold similar structural positions in other organisations with contextual similarities. Structure is always established a priori, and it can be argued that it always precedes agency, but neither agency nor the social structure should have any predetermined analytical precedence. Rather, the interaction of structure and agency should be in focus when trying to understand the phenomena studied (Archer, 1995). Agency and structure affect each other over time in the dynamics of structural elaboration (Archer, 1995). Thus, the interaction itself forms a level of analysis that lies between the structural and individual levels of analysis.

The natures of social structures and agency tend to be transitive, i.e. they exist in open-systems environments ${ }^{19}$ in which change is a constitutive characteristic (Danermark et al., 2002). The transitive nature of social structures and agency means that knowledge about them is socially responsive and theory-dependent. Hence, any study of the ever-changing social structures must be aimed at analysing the conditions for interaction between social structures and agents by asking two fundamental and critical realist questions: What makes $X$ possible? and What properties must exist for $X$ to exist and to be what $X$ is? (Sayer, 1992). This thesis follows the critical realist tradition in focusing on methods that investigate relationships, roles, actions and practices in order to address these questions.

\section{My critical realist perspective on quality management work}

I believe that research into issues that concern how competence theory contributes to the organising and organisation of quality management work benefits from a deeper understanding of quality management practices and competencies viewed as socially structured phenomena. This does not necessarily require a strict, dogmatic critical realist approach, but one in which such an approach has influenced, inspired and guided the research described in this thesis in three major ways:

- First, quality management work is viewed as being performed within the realm of open-system social structures (i.e. practice environments) in which agents (i.e. quality management practitioners) engage in and carry out certain practices in agreed ways. Social structures and agents are considered to be different entities, while being mutually dependent and continuously conditioning each other (Archer, 1995).

- Second, the causing entities within the social structures that form quality management practice environments are viewed as the generative processes needed to cause, or prevent, events (Bhaskar, 1978; Easton, 2010). The causing entities are situated in quality management settings (or structures) and take the form of quality management practices, language, power, artefacts, agents, etc. in order for events, such as observable quality management work, to happen (Easton, 2010).

- Third, the perspective on competence in this thesis is focussed on the relationship and interaction between the entities within the practice environment of quality management work. The units of analysis in this thesis (Section 1.5) are therefore considered to be well-suited for critical realist perspectives.

\footnotetext{
${ }^{19}$ Buckley (1967) describes an open-systems perspective as that taken when organizations engage in interchanges with the environment, where such interchange is important in signifying the viability of the system (i.e. organization).
} 


\subsubsection{Relating the theoretical background to the domains of inquiry}

Figure 5 illustrates the relationships between the methodological premise, the theoretical background and the domains of inquiry of this thesis.

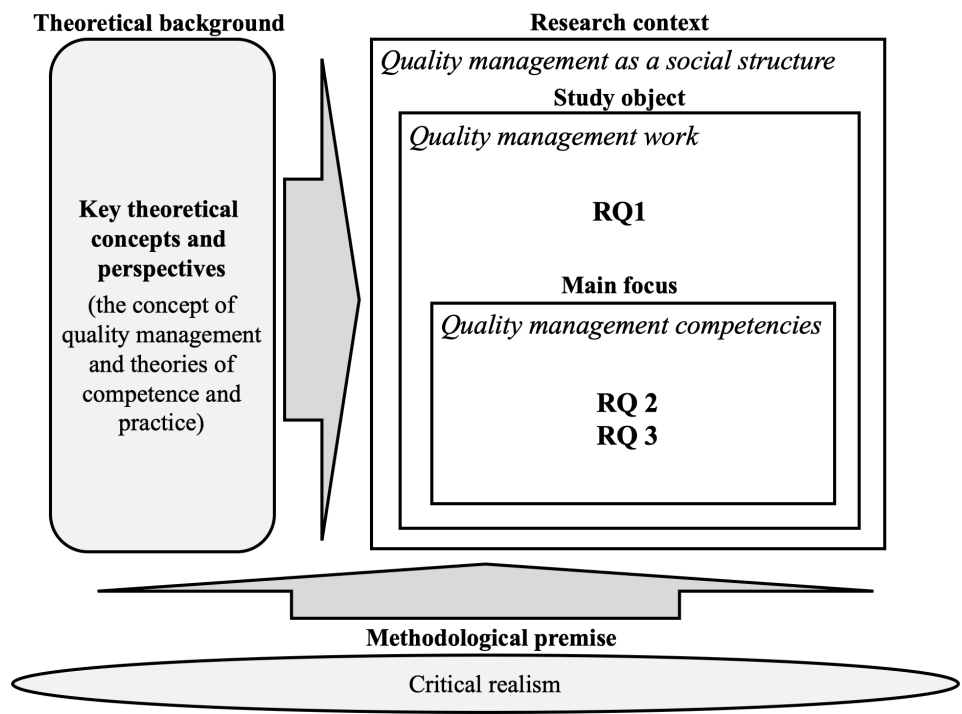

Note: RQ = Research Question

Figure 5. Relationships between the methodological premise, theoretical background and domains of inquiry of this thesis.

Critical realism acts as a premise for methodological consideration which, in turn, guides and influences the understanding of the research phenomena. The concept of quality management along with competence theory and practice theory are viewed as the main theoretical perspectives forming the theoretical background viewed as complementary in forming a conceptual framework. The theoretical perspectives are adopted in order to better understand the study object set within the particular research context. Critical realism assumes that knowledge is theory dependent, hence the selected concepts and theoretical perspectives are first and foremost guided by the methodological premise and then positioned in relation to the research context, study object and main focus of the thesis. The nested and stratified nature between the domains of inquiry is reflected in the different analytical levels, whereby the requirements to perform quality management work by engaging in its practices can be described as quality management competencies. The adoption of the theoretical perspectives used in this thesis allows for utilising similarities such as conceptual definitions, action orientation, and the shared view on the dynamics between individual and structure to be studied. It should be noted that the selected theoretical perspectives in the conceptual framework are used in an abductive scientific reasoning strategy, in which data featured in the papers are recontextualised in an iterative process, during which the theoretical perspectives are integrated. The research strategy is further elaborated in the next section. 


\subsection{Research strategy}

The data presented in the papers that are included in the thesis have been collected from the different organisational contexts that form the social structures/practice environments and contribute to the understanding of the meaning of quality management work. This thesis explores the ways in which theoretical perspectives of competence and practice can contribute to an increased understanding of what is required to perform quality management work. This requires going beyond the obvious, observable events that occur during the everyday work of quality management practitioners. With a critical realist perspective, research objects can be understood only through theoretical perspectives and theoretical reasoning. Abduction (Peirce, 1931-1958; Danermark et al., 2002) is therefore considered to be a more appropriate research strategy and guide for research methodology. According to critical realism, abduction is useful because it allows thought and abstraction to be ontologically and epistemologically elevated in an effort to reveal obscured dimensions of reality that contribute to a better understanding of what constitutes reality. Abduction also makes it easier to expand the boundaries of available theoretical perspectives (Bhaskar, 1978). The papers presented treat the subject in certain settings, while this summary discusses general principles, and seeks to advance the specific and structurally bound findings presented in the papers to a generalised body of knowledge about how competence theory can contribute to a better understanding of quality management.

Giere's (1997) model of scientific episode (Figure 6), outlines four components of a research project. First, there is a real-world object of science that is the study object or problem to be researched. In this thesis, the real-world object of science is the study object: quality management work. We can partly access the real-world object of science by observing it, and in this way collect data. Real-world objects are infinitely complex structures to which it is impossible, according to critical realism, to have total access. The choice of data collection methods dictates what can be accessed. In this thesis, the data principally consist of the what of the content and the how of the process (Pettigrew, 1987). The content and process data were collected in the form of documents, interviews and surveys. Abstractions (also known as theories) of a real-world object such as quality management work are constructed, in order to expand our understanding. Theory or theories are understood to be conceptualised constructs, definitions and relationships, ordered in sets of assertions about structures of generic behaviour, and applicable in a broad range of situations (Sutherland, 1975). Theories in this way provide tools for expanding our understanding of the real world. Figure 6 uses the term model of explanation, and the means of explaining reality rely heavily on the theoretical background, which is in line with the methodological premise of critical realism. By necessity, explanations (or theory) are abstract concepts that relate to the real world, and they must be carefully adapted to suit the design of data collection. The final component of the model of scientific episode are predictions. Predictions show the appearance of data if the theory, or theories, hold explanatory relevance. Predictions are practice-oriented operationalised theory, and are also known as 'practical theory' (Svensson, 2002b, p.175). 


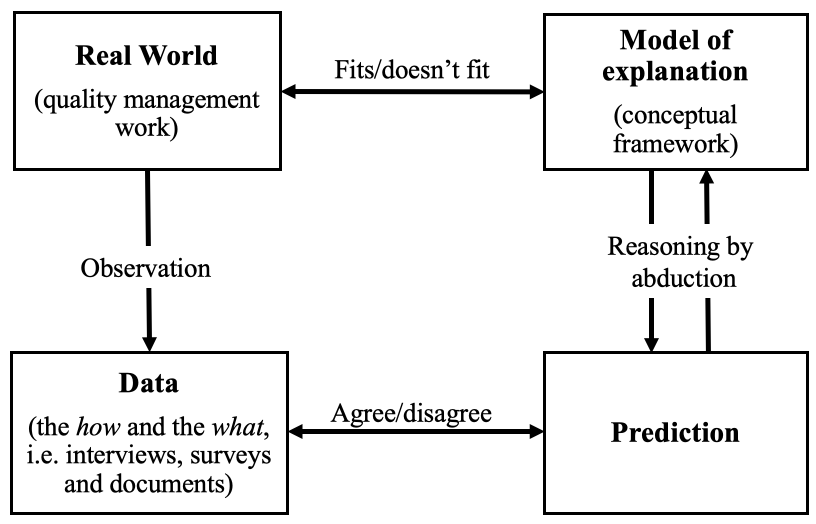

Figure 6. A model of scientific reasoning (adapted from Giere, 1997, p. 30)

The relationship between explanation and prediction is the foundation for the scientific reasoning employed in this thesis. The methodological premise of critical realism offers abduction as a suitable main research strategy.

Abduction is a method of scientific reasoning that is based on a specific result (i.e. data) that has initially been interpreted using one set of theoretical perspectives. This result is then recontextualised using other theoretical perspectives, in order to give further understanding of the real world (Peirce, 1931-1958). Abduction, as a recontextualisation strategy, is described by Svensson (2002b) and Danermark et al. (2002) as the application of multiple theoretical perspectives to a set of data by utilising creative, iterative reinterpretation, and in this way describing the object in new ways. An important component of abduction, and indeed of this thesis, is thus the development of theory/theories, and moving iteratively between prediction and theory (Figure 6). Previous research into quality management and quality management work has been based on several theoretical perspectives (e.g. organisational theory, marketing theory, production theory, operations management theory, leadership theory, etc). As previously mentioned, quality management research using competence theory is scarce. This justifies the choice of an abductive strategy in which previous results and data may be recontextualised into an expanded understanding of quality management and the requirements to perform quality management work. The choice of an abductive strategy is also justified by the use of constitutive reasoning as the mode of intended theoretical contribution (Cornelissen \& Durand, 2014) and exaptation as guiding the knowledge contribution (Gregor \& Hevner, 2013). According to Bryman and Bell (2015), a division between quantitative/deductive and qualitative/inductive material is common in research strategies. However, by mixing both qualitative and quantitative research designs in this thesis, it becomes clear that an abductive strategy is the most suitable option (Danermark et al., 2002).

It has long been discussed how theory best contributes to practice (e.g. Argyris \& Schön, 1974). Van de Ven and Johnson (2006) discuss the relationship between theory and practice in science, and how these concepts relate to two distinct kinds of knowledge. Van de Ven (2013) proposes a method of doing science in which he outlines these two types as scientific knowledge and practical knowledge. He argues that a more engaged approach to science can facilitate both 
knowledge forms ${ }^{20}$, in an ambition to create science for practice. The primary aim of this thesis is to contribute to the field of quality management. In using an abductive strategy and empirically investigating competence in a quality management setting, both practical knowledge, or prediction, and scientific knowledge, or explanation, are created.

This thesis presents data from several sources (i.e. surveys, interviews and document studies) collected using several research designs (i.e. qualitative and quantitative). This makes it possible to use triangulation (Stake, 1995). The main purpose of the triangulation of data is to strengthen validity in order to maintain the accuracy of descriptions and to support the assertions and interpretations presented (Stake, 1995; Taylor, 1979). However, the reasons for using such a mixed approach are also based on the work of Yin (2014), which shows that such an approach produces better and richer evidence, and creates the means to further investigate the conditions within participating organisations.

\subsubsection{Research process}

My research process consisted of five studies and has mainly revolved around a research project that was initially funded by the Swedish Quality Management Academy [SQMA] with the title 'Organising for Quality Management'. This project, conducted from February 2016 until December 2017, forms the mainstay of my overall research process and produced the data in Papers B, C and E. However, during my first year as a doctoral student, my research process was initiated by a study on how performance measurement creates the conditions required for different types of learning (Paper A). This caught my personal interest for two reasons:

First, I have a professional background of nearly 15 years as a commissioned officer in the Swedish Armed Forces. During my time as an army officer, I was particularly interested in leadership, management, and how to organise learning. After this period, I worked as a business consultant in recruitment, selection and organisational development, and as a CEO with managerial responsibilities. In both of these roles, I had ample opportunities to further my interest and understand more about the practices and practical issues concerning leadership, management, and what improves individual and organisational performance. The accumulated effects of my professional experience have given me a deep-rooted interest and drive to understand more about the factors that affect management and performance in organisations.

Second, I have an academic background predominantly within the social sciences, behavioural science, and pedagogy, with a master's degree from the Human Resource Management and Human Resource Development master's programme at Linköping University. During my undergraduate and master's studies, I found the most interesting subjects to be the management of organisations, leadership and pedagogy, in particular anything concerning theoretical perspectives on organising and organisation in order to create apt and effective organisations.

The work described in Paper A united my professional and academic interests, and was a real eye-opener for what would eventually form the main idea for this thesis, i.e. studying the competencies that are required to perform quality management work. The work described in Paper A made it clear that the nature of the performance measurement, together with the discretion exercised by the participants in performance measurement, defined the type of learning and the potential for different types of learning. How these processes could and should

\footnotetext{
${ }^{20}$ In Van De Ven's (2013) 'diamond model', the research process is described as an iterative process built on the integration of four study activities: problem formulation, theory building, research design and problem solving.
} 
be managed evolved as my prime research focus, together with a desire for insight into the practices that are necessary and what is required to perform them.

Performance measurement has been described as a quality management practice that involves the measurement, collection and processing of data: in other words, it is the management of facts. Such measurement, however, adopts a process perspective rather than a conventional Balanced Score Card perspective (e.g. Ali, Jain, Ali \& Munir., 2017; Kumar, de Grosbois \& Choisne, 2008; Motwani, 2001; van Schalkwyk, 1998). This made the idea of investigating in more detail further areas of quality management practice and the competencies required to perform quality management work extremely interesting. When I was invited to participate in the SQMA research project, I realised it was a golden opportunity to extend the idea of quality management, competencies and learning into a bigger context. During this project, I was also invited to participate in work with a content highly applicable to my own research context (later published in Paper D). Further research was then conducted funded by HELIX Competence Centre at Linköping University. Figure 7 presents an overview of the research process, featuring the time frames for the papers, the SQMA research project together with the HELIX Competence Centre project (on which Papers B, C and E are based).

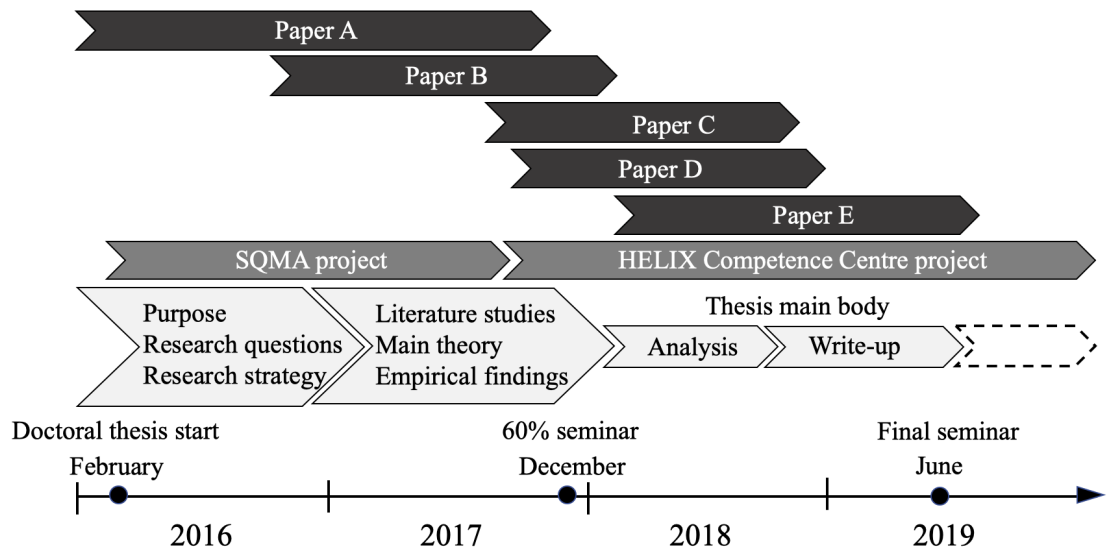

Figure 7. Overview of the research process for the thesis, 2016-2019

During the course of my doctoral studies, which included compulsory courses in scientific methodology and the philosophy of science, I nurtured a growing interest in the perspectives offered by the social scientific philosophy of critical realism. I was most fortunate to have a main supervisor who shared this interest, which led to many interesting discussions and debates on the inner workings of critical realism. This led to a deeper understanding and knowledge about this most useful perspective on ontology and epistemology. I also read extensive research and took doctoral courses related to organisation theory, including institutional theory and service management. These activities, together with other interesting courses and seminars, added important analytical tools that enabled me to understand the phenomena I was studying.

\subsection{Research design}

Patton (2015) defines 'research design' as the plan that sets the stage for how the research will be conducted. This subsection describes the research design and outlines how the purpose will 
be addressed and how the research questions will be answered. It initially describes the research designs for the papers included in the thesis, and then describes the methodological foundations of the chosen research design. The following subsection addresses and evaluates quality issues in the research methods.

\subsubsection{Overview}

This thesis include the findings from five studies that draw data from four datasets, resulting in five papers. Table 3 summarises the research designs. The studies include both quantitative and qualitative data. Multi-design studies that include both qualitative and quantitative data allow better generalisation (e.g. Danermark et al., 2002; Yin, 2014). The quantitative data contain two survey datasets gathered in two cases. One case (Paper B) contains survey data from quality 249 management practitioners in eight large organisations, while the other case (Paper D) contains survey data from 211 quality managers in different organisations. The qualitative data contain two interview datasets gathered in two cases. One case (Paper A) contains interview data from 17 healthcare professionals working at a healthcare unit, while the other (Papers C \& E) contains interview data from 33 quality management practitioners in four organisations.

In three of the five studies in this thesis (Papers B, C and E), an interactive research approach that used both quantitative and qualitative designs was adopted. An interactive approach was adopted in these studies as a result of the involvement in the two-year research project funded by the SQMA. This had been planned together with the participating organisations and, from the very beginning, was designed to incorporate and facilitate integration and collaboration between researchers and the participating organisations. This was to lead to continuous and joint learning.

Table 3. Summary of the appended paper's research designs

\begin{tabular}{|c|c|c|c|c|c|}
\hline & Paper A & Paper B & Paper C & Paper D & Paper E \\
\hline Scope & $\begin{array}{l}\text { Performance } \\
\text { measurement } \\
\text { and learning. }\end{array}$ & $\begin{array}{l}\text { Competencies } \\
\text { of quality } \\
\text { management } \\
\text { practitioners. }\end{array}$ & $\begin{array}{l}\text { Required quality } \\
\text { management } \\
\text { competencies. }\end{array}$ & $\begin{array}{l}\text { Roles of quality } \\
\text { management } \\
\text { departments. }\end{array}$ & $\begin{array}{l}\text { Quality } \\
\text { management } \\
\text { challenges in } \\
\text { digitalisation. }\end{array}$ \\
\hline Purpose & $\begin{array}{l}\text { Exploring } \\
\text { theoretical } \\
\text { foundations. } \\
\text { Creating } \\
\text { conceptual } \\
\text { model. }\end{array}$ & $\begin{array}{l}\text { Understanding } \\
\text { quality } \\
\text { management } \\
\text { work and } \\
\text { quality } \\
\text { management } \\
\text { competence. }\end{array}$ & $\begin{array}{l}\text { Developing a } \\
\text { competence } \\
\text { framework for } \\
\text { quality } \\
\text { management } \\
\text { practices. }\end{array}$ & $\begin{array}{l}\text { Identifying and } \\
\text { describing roles } \\
\text { of quality } \\
\text { management } \\
\text { departments and } \\
\text { their effects on } \\
\text { business results. }\end{array}$ & $\begin{array}{l}\text { Identify and } \\
\text { propose a } \\
\text { typology of } \\
\text { roles for } \\
\text { Quality } \\
\text { management in } \\
\text { digitalisation } \\
\text { initiatives. }\end{array}$ \\
\hline $\begin{array}{l}\text { Research } \\
\text { approach/ } \\
\text { design }\end{array}$ & $\begin{array}{l}\text { Qualitative, } \\
\text { interview. }\end{array}$ & $\begin{array}{l}\text { Interactive, } \\
\text { quantitative, } \\
\text { survey. }\end{array}$ & $\begin{array}{l}\text { Interactive, } \\
\text { qualitative, } \\
\text { interview. }\end{array}$ & $\begin{array}{l}\text { Quantitative, } \\
\text { survey. }\end{array}$ & $\begin{array}{l}\text { Interactive, } \\
\text { qualitative, } \\
\text { interview. }\end{array}$ \\
\hline Data & $\begin{array}{l}\text { Interview } \\
\text { transcripts. }\end{array}$ & $\begin{array}{l}\text { Questionnaire. } \\
\text { Documents. }\end{array}$ & $\begin{array}{l}\text { Interview } \\
\text { transcripts. }\end{array}$ & Questionnaire. & $\begin{array}{l}\text { Interview } \\
\text { transcripts. }\end{array}$ \\
\hline $\begin{array}{l}\text { Method } \\
\text { for data } \\
\text { analysis }\end{array}$ & $\begin{array}{l}\text { 'Critical } \\
\text { incident } \\
\text { technique' } \\
\text { (Flanagan, } \\
\text { 1959). }\end{array}$ & $\begin{array}{l}\text { Descriptive } \\
\text { statistics. } \\
\text { Document } \\
\text { studies. }\end{array}$ & $\begin{array}{l}\text { Coding. } \\
\text { Thematic } \\
\text { analysis. }\end{array}$ & $\begin{array}{l}\text { Factor analysis. } \\
\text { Cluster analysis. } \\
\text { ANOVA. }\end{array}$ & $\begin{array}{l}\text { Coding. } \\
\text { Thematic } \\
\text { analysis. }\end{array}$ \\
\hline
\end{tabular}




\begin{tabular}{|c|c|c|c|c|c|}
\hline $\begin{array}{l}\text { Research } \\
\text { subjects }\end{array}$ & $\begin{array}{l}17 \text { healthcare } \\
\text { professionals } \\
\text { in a healthcare } \\
\text { unit. }\end{array}$ & $\begin{array}{l}249 \text { quality } \\
\text { management } \\
\text { practitioners } \\
\text { from eight } \\
\text { organisations } \\
\text { (the SQMA } \\
\text { project). }\end{array}$ & $\begin{array}{l}33 \text { quality } \\
\text { management } \\
\text { practitioners } \\
\text { from four } \\
\text { organisations } \\
\text { (the SQMA } \\
\text { project). }\end{array}$ & $\begin{array}{l}211 \text { quality } \\
\text { managers from } \\
211 \\
\text { organisations. }\end{array}$ & $\begin{array}{l}33 \text { quality } \\
\text { management } \\
\text { practitioners } \\
\text { from four } \\
\text { organisations } \\
\text { (the SQMA } \\
\text { project). }\end{array}$ \\
\hline
\end{tabular}

\subsubsection{Interactive research}

Interactive research is a collaborative approach to research, and is an offspring of action research (Svensson, 2002a). It is conducted with the practitioners through collaboration between the researcher system and the practitioner system, and integration of them (Agaard Nielsen \& Svensson, 2006; Svensson, Brulin \& Ellström, 2015; Svensson, 2002a). The aim of interactive research can be described as to create bidirectional cycles that contribute to the needs of both practitioners and researchers, and to give the possibility to recontextualise the tentative knowledge discovered in the empirical material. Svensson, Brulin and Ellström (2015) points out that the practitioner system and the research system have different needs and different tasks, but that the two systems are interconnected in a mutual, co-operative process of research; see Figure 8. In the research process, a common knowledge of reality is created by the regular participation and interaction of both systems. The knowledge of reality for researchers is aimed mainly at theoretical development, while the knowledge of reality for practitioners is mainly practice-oriented. For researchers, interactive research facilitates alternative takes and views on the empirical observations, allowing new theoretical perspectives to be applied in order to deepen understanding. For practitioners, practice also becomes applied theory, which brings a critical realist way to close any perceived gaps between theory and practice. However, according to Svensson (2002b), any conceived distinction between theory and practice is not absolute. He argues that theory and practice are intertwined, and that theory is either mainly academic or mainly practical. Svensson (2002b) continues to argue that the former is more long-term, aimed at producing research, whereas the latter is more short-term and aimed at producing familiar knowledge (in Swedish: förtrogenhetskunskap, Björklund, 2014). This familiar knowledge is equated with knowing how (Björklund, 2013; Dreyfus \& Dreyfus, 1980; Ryle 1990/1949) and tacit knowledge (Polanyi, 1967) in this thesis. 


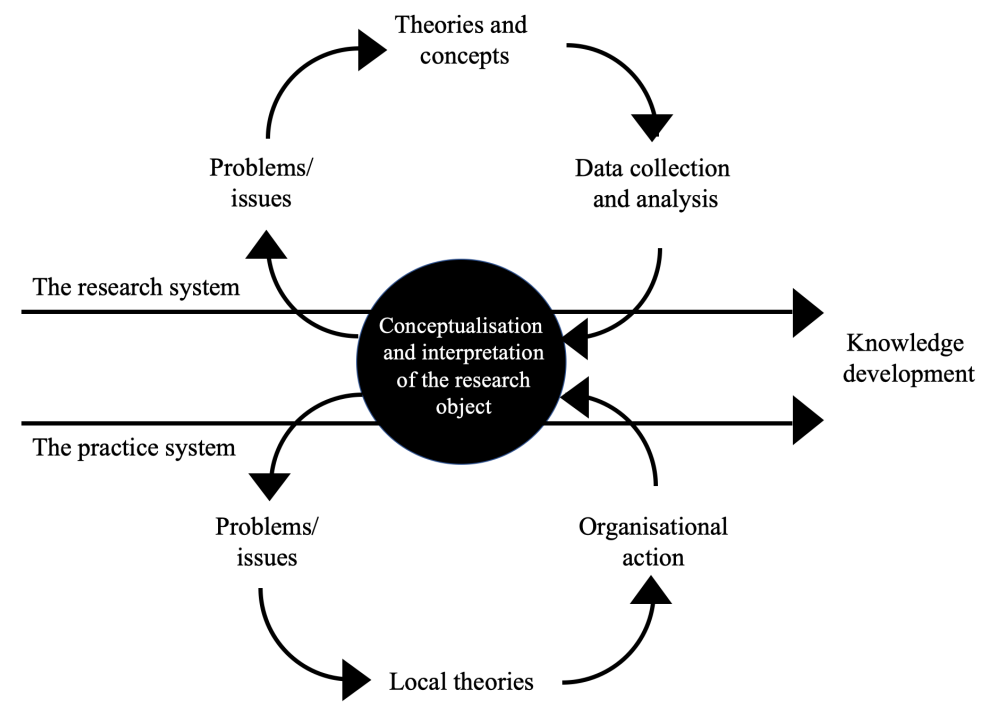

Figure 8. The bi-directional interactive research process (adapted from Svensson, Brulin and Ellström, 2015, p. 352)

The SQMA project, an interactive research approach

In the work presented in this thesis, the conditions were particularly suitable for using an interactive research approach in the SQMA research project that was the foundation for three of the studies (Papers B, C \& E). The choice of an interactive approach was primarily motivated by the opportunity to reach a better contextual understanding of the organisations. This approach not only facilitated a holistic perspective, which facilitated both internal and external perspectives on the actions and activities in the participating organisations, it also improved commitment from the organisations and helped to maintain continuous interest. In practice, it was achieved by long-term planning and management (by the author of this thesis) of the research process, involving all participating organisations. The planning ensured that regular workshops and activities that involved both researchers and practitioners were held.

The SQMA research project was initiated in February 2016 with a joint workshop. It was structured in three phases (Figure 9): an initial qualitative pre-study phase (to be held between February and April 2016), a quantitative survey phase (between April and November 2016), and a subsequent qualitative phase, based on a semi-structured interview design (between November 2016 and September 2017). A pre-study phase included key informants from the organisations to be studied and external experts from both industry and academia. During the course of the project, three main workshops were held with participants from the organisations studied, and some local workshops with each organisation. In addition, several feed-back and feed-forward activities involving practitioners were arranged. The workshops were planned as interactive seminars during which results were initially presented and discussed, followed by insights, suggestions and feedback. During the seminars, time was allocated for the production of common conceptualisations and interpretations.

In preparation for the third and final main workshop, local workshops were conducted in which designated teams from the organisations worked with tentative models and results. These were 
then discussed and validated during the third workshop. The interactive research activities described in this thesis included continuous feed-back \& feed-forward, the main workshops, and the local workshops. The activities were set in different collaborative environments, and not only provided invaluable input to the analysis of the studies in Papers B, C and E, they also proved to be an important component in the abductive strategy of the research. In addition, they facilitated the creation of practical theory that was fed-back into the organisations studied as practice-based knowledge. In the abductive research process, this proved to be particularly important when testing and validating a tentative version of the competence framework and the role-responsibility characteristics of quality management, as described in Paper E, before and during the third main workshop in September 2017.

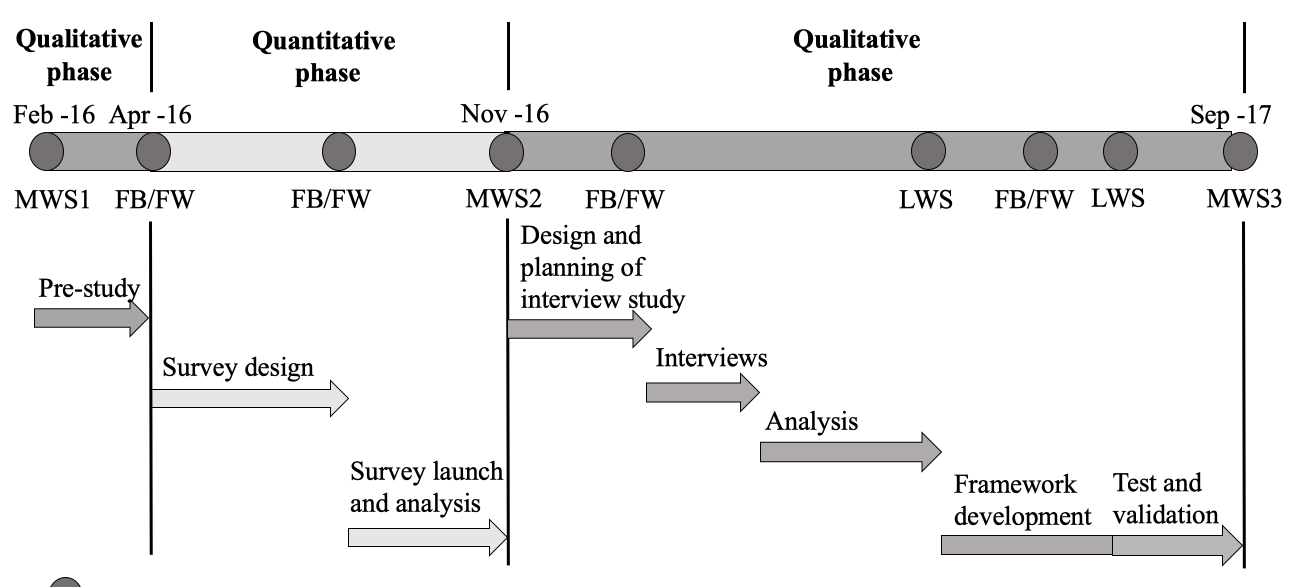

: Intervention/activity

MWS: Main workshop, LWS: Local workshop, FB/FW: Feedback/Feed forward

Figure 9. Interactive research activities for the SQMA research project

\subsubsection{The interview studies: design, sampling, data and analysis}

\section{Paper A}

Paper A relates mainly to the second and third research questions in this thesis. The purpose of Paper A was to contribute to an improved understanding of the role of learning in performance measurement. A qualitative design with semi-structured interviews was used (Bryman \& Bell, 2015 ) to investigate the complexity of learning processes. This was primarily justified by the need to collect information from a large range of respondents, covering a wide array of situations in which the phenomena were present (Alvesson \& Sköldberg, 2009). In interviews, the respondents were allowed to recall specific situations from which the dialogue could evolve.

A case-study design was selected (Eisenhardt, 1989; Voss, Tsikriktsis \& Frohlich, 2002; Morais, 2011) in order to obtain a large amount of primary data from a specific environment. This facilitated making sense of the key dimensions and the types of environment that framed the phenomenon in question, which was learning in performance measurement. The phenomenon that constituted the case was performance measurement. The case was considered to be an instrumental case (Stake, 1995), in which the intrinsic qualities of the particular case environment settings were not as important as the actions and practices related to performance measurement. This enabled the research team to understand the phenomenon, and develop 
theoretical ideas through analytical generalisation (Firestone, 1993; Miles \& Huberman, 1994). The case-sampling strategy could be described as a combination of typical case and critical case (Miles \& Huberman, 1994) to facilitate analytical generalisation (Firestone, 1993). The research team had access to a dataset that consisted of 17 interview transcripts gathered in a previous study that had studied how performance measurements drive improvement. The particular organisational context used a variety of performance measurement activities that represented both critical and typical cases.

The case was set within a healthcare context in a regional hospital with a broad range of healthcare professionals, engaged in many different performance measurement activities. The data were analysed using the critical incident technique [CIT] (Flanagan, 1959), in which each identified critical incident represented a specific type of performance measurement situation that created different conditions for learning, or different learning environments. Our proposed theoretical background guided the coding and analysis of critical incidents, making it possible to develop the concept and key dimensions, to discuss types of learning environment, and to specify facets of learning.

\section{Papers $C$ and $E$}

Papers $\mathrm{C}$ and $\mathrm{E}$ relate mainly to the second and third research questions of this thesis. The purpose of Paper $\mathrm{C}$ was to introduce a competence-based terminology in order to outline general competencies of quality management work in organisations. This terminology was then used to construct a competence framework to further an understanding of what is needed to be a quality management practitioner. The purpose of the work described in Paper E was to identify the various roles that QM takes in digitalisation initiatives, and to propose a typology of roles that would aid in uncovering the potential of QM digitalisation. Both Paper C and E were part of the above-mentioned SQMA project, and the research team wanted to explore and understand the general practices of quality management practitioners, lifted out of their specific local context. In this way, the team expected to be able to generalise the findings into generic roles (Paper E) and a competence framework (Paper C).

A qualitative, embedded multiple-case study design (Miles \& Huberman, 1994; Yin, 2014), with semi-structured interviews, was selected (Bryman \& Bell, 2015). A multiple-case study design is considered to be particularly useful when exploring new perspectives (Patton, 2015) and extending the understanding of the studied phenomena (Miles \& Huberman, 1994), and when building theory by identifying the key variables and their relationships (Eisenhardt, 1989; Voss et al., 2002). The case-sampling strategy was guided by the ambition to identify common patterns across various case contexts (Patton, 2015), and to cover a wide variety of quality management practices. The interview study methodology was designed against the background of the findings gained in a previous quantitative study (Paper B), which provided input when writing the interview guide used during data collection. The questions were designed to facilitate the purposes and research questions in both Papers $\mathrm{C}$ and $\mathrm{E}$.

Since the studies described in both Papers C and E were intended to cut across the particular case contexts, the cases studied were considered to be instrumental (Stake, 1995). The multiple units of analysis set within each case context were, therefore, particularly suitable for both Papers $\mathrm{C}$ and $\mathrm{E}$. The selection of interviewees for the studies was based on a need to cover a wide spectrum of quality management. Interview data were thus collected by interviewing 33 practitioners in four different organisations who represented a wide range of quality management, embedded on different levels, in each of the case organisations. 
The analysis for Papers $\mathrm{C}$ and $\mathrm{E}$ followed an abductive two-step design that combined iterations with inductive thematic analysis, together with deductive pattern clarification (Miles \& Huberman, 1994; Miles, Huberman \& Saldaña, 2014). In the analysis in Paper C, the content and variables were analysed and themes within the data extracted in a first step. In the next step, patterns were clarified with thematic patterns and patterns shared between variables being identified. Based on this analysis, an empirically grounded and conceptually guided framework for quality management practitioner competencies was constructed.

The research design of the analysis presented in Paper E was aimed at identifying key variables, where digitalisation initiatives and their relationships within the research context were targeted (Eisenhardt, 1989; Voss, Tsikriktsis \& Frohlich, 2002). The data analysis included the following steps: 1) reading and re-reading, 2) reducing data by coding (Miles \& Huberman, 1994), 3) clustering of codes, together with their ordering and categorisation, 4) comparing, integrating and searching for relationships between the code clusters (Campbell, Quincy, Osserman \& Pedersen, 2013), and finally, 5) drawing conclusions.

\subsubsection{The survey studies: design, sampling, empirical data and analysis}

\section{Paper B}

Paper B relates mainly to the second research question in this thesis. The purpose of Paper B was to use competence theory to explore the fit between actual competencies of quality management practitioners and the perception of the quality management competence that is needed in organisations. A quantitative survey design (Bryman \& Bell, 2015) with a selfassessment questionnaire was used to collect data. The planned survey study was a component of the SQMA research project that was aimed at using competence theory when discussing the fit between actual and needed quality management competence in contemporary organisations. As with Papers $\mathrm{C}$ and $\mathrm{E}$, the case-sampling strategy was primarily guided by the need to identify common patterns in the fit between actual competencies and perceived competence needs in organisations across diverse case contexts (Patton, 2015). The case-sampling strategy was guided also by an ambition to cover as wide a variety as possible of established quality management practices. This survey study was a supplement to the subsequent qualitative study performed within the framework of the SQMA project and, as such, shows that survey studies can easily support studies that rely on a general qualitative case-study design (Yin, 2014).

Data were collected using a web-based questionnaire with 43 self-assessment questions (i.e. items) generated through a literature review, expert discussions (including experienced practitioners and scholars), and reviews of previous survey research. The questionnaire included validated measures ${ }^{21}$ and items that covered internal and external dimensions, situational/contingency aspects and outcomes (Van de Ven \& Chu, 1989). Measures to increase the validity of the questionnaire included several peer and practitioner reviews of the questionnaire during its development. The survey was tested before launch, and particular attention was given to the language and phrasing in order to minimise the risk of misinterpretation. Several changes and adjustments were made during the test rounds, before the questionnaire was made live. Out of 308 potential respondents contacted, 249 respondents in eight organisations participated in the survey. The data used reflected individual, selfassessment responses that described the respondents' perceptions of organisational and task-related settings. The analysis was purely descriptive, since we wanted to explore patterns of generic practitioner competencies on a general and structural level.

\footnotetext{
${ }^{21}$ Paper B describes the validated measures used.
} 


\section{Paper D}

Paper D relates mainly to the second and third research questions in this thesis. The purpose of the work described in this paper was to explore the roles of quality departments and inquire into whether these roles have different impact on the business results. A quantitative research design (Bryman \& Bell, 2015) that used a survey study was chosen. The research instrument (a questionnaire) was designed to capture respondents' practical experiences of quality management. The items in the questionnaire were developed through a combination of a literature review and discussions with experienced practitioners and quality management scholars.

The survey studies were reviewed. In order to ensure face validity; see Table 5, and to reduce the possibility of non-random errors, experienced quality managers reviewed the questionnaire. The final questionnaire contained 28 items with validated measures ${ }^{22}$ that covered quality management practices, characteristics of organisations, and effects on business results. 800 Swedish quality managers were then identified through a database search (PAR), and contacted. Of these, 211 respondents from 211 organisations completed the questionnaire. The case-sampling strategy was designed to cover a wide variety of both manufacturing industries and service firms that comprised both pure and mixed manufacturing and/or service operations.

The data analysis used three quantitative techniques. Initially, a factor analysis was carried out in order to identify the core quality management practices used in a quality department. This was followed by a cluster analysis, intended to determine whether these practices created specific quality department roles. The third and final step involved performing ANOVAs, in order to identify quality practice differences between the various quality department roles that had been identified in the cluster analysis. The research team used the results from the ANOVAs also to determine whether the particular quality department roles gave rise to different business results.

\subsection{Evaluation of the research methodology}

\subsubsection{Quality criteria}

It is a formidable challenge to assemble a coherent compilation thesis, with an exploratory research purpose, that describes results obtained using both quantitative and qualitative methods (e.g. Patton, 2015). The thesis is to form a methodological and empirical unity, address the purpose of the work presented, and answer the research questions. In its discussion of research quality, this thesis uses primarily the measures and definitions of research quality laid down by Bryman and Bell (2015), Campbell et al. (2013), Campbell and Stanley (1966), Cronbach and Meehl (1955), Merriam (2009), and Yin (2014). Tables 4 and 5 summarise the main quality evaluations of the five papers, together with quality criteria and descriptions. Four aspects of quality in the qualitative research designs used are addressed: credibility, dependability, confirmability and transferability. Further, four aspects of quality in the quantitative research designs used are addressed: construct validity, reliability, external validity and face validity. It should be mentioned that Yin (2014) suggests that internal validity (i.e. the relative strength of the link between cause and effect) is not relevant for exploratory research

\footnotetext{
${ }^{22}$ Paper D describes the validated measures used.
} 
and, since the work presented in the thesis has been exploratory, internal validity will not be addressed.

Table 4. Summary of quality criteria and evaluation for the qualitative study designs (Paper A, C \& E)

\begin{tabular}{|c|c|c|}
\hline Quality criteria & Criteria descriptions & Quality evaluation \\
\hline Credibility & $\begin{array}{l}\text { Research of high credibility has a design } \\
\text { and methodology that are suitable to } \\
\text { give an adequate rendering of the } \\
\text { perceived reality, i.e. credibility } \\
\text { measures trustworthiness (e.g. Bryman } \\
\text { \& Bell, 2015). }\end{array}$ & $\begin{array}{l}\text { Internal cross-validation of analysis, multiple } \\
\text { data sources (documents, interviews, } \\
\text { workshops), feed-back/feed-forward to the } \\
\text { organisations studied to confirm findings. }\end{array}$ \\
\hline Dependability & $\begin{array}{l}\text { Research of high dependability has high } \\
\text { rigour, precision and stability of the } \\
\text { research process (e.g. Bryman \& Bell, } \\
\text { 2015). }\end{array}$ & $\begin{array}{l}\text { Due diligence in the choice of methods and } \\
\text { methodology such as: sampling strategy, } \\
\text { transcriptions of interview data, validation of } \\
\text { workshops, construction of coding tables, and } \\
\text { use of analytical procedures. Further, } \\
\text { continuous documentation of processes and } \\
\text { methods. }\end{array}$ \\
\hline Confirmability & $\begin{array}{l}\text { Research of high confirmability is } \\
\text { research that has been carried out by a } \\
\text { researcher who is objective and truthful } \\
\text { to the empirical material without letting } \\
\text { personal or group bias or values } \\
\text { interfere in the research process (e.g. } \\
\text { Bryman \& Bell, 2015). }\end{array}$ & $\begin{array}{l}\text { Analytical frameworks and conceptual models } \\
\text { must be well founded in established theory. } \\
\text { Inter-coder and inter-rater reliability ensured } \\
\text { through dual analysis and test processes with } \\
\text { additional researchers (Campbell et al., 2013). } \\
\text { Data saved for future reference. }\end{array}$ \\
\hline Transferability & $\begin{array}{l}\text { Research of high transferability gives } \\
\text { findings that can be generalised from } \\
\text { one context to others (e.g. Bryman \& } \\
\text { Bell, 2015). }\end{array}$ & $\begin{array}{l}\text { Description of study object context in all } \\
\text { papers. For Papers } \mathrm{C} \text { and } \mathrm{E} \text {, a representation of } \\
\text { the organisations and contextual conditions. } \\
\text { Standardised interview guide for all interviews. } \\
\text { Cross-case analysis in order to extract } \\
\text { generalisable findings. }\end{array}$ \\
\hline
\end{tabular}

Table 5. Summary of quality criteria and evaluation for the quantitative study designs (Paper B \& D)

\begin{tabular}{|c|c|c|}
\hline Quality criteria & Criteria descriptions & Quality evaluation \\
\hline Construct validity & $\begin{array}{l}\text { The construct validity reflects the } \\
\text { degree to which a test measures what it } \\
\text { claims to be measuring and a measure of } \\
\text { the fit between the test measure and the } \\
\text { theory (e.g. Cronbach \& Meehl, 1955). }\end{array}$ & $\begin{array}{l}\text { Questionnaire items in Papers B and D were } \\
\text { based on measures from previous studies with } \\
\text { tested and validated scales. Questionnaires } \\
\text { were tested and adjusted before the survey. }\end{array}$ \\
\hline Reliability & $\begin{array}{l}\text { Research of high reliability uses } \\
\text { measures with high overall consistency } \\
\text { and repeatability (e.g. Yin, 2014; } \\
\text { Merriam, 2009). }\end{array}$ & $\begin{array}{l}\text { The Cronbach alpha values for the data } \\
\text { presented in Paper D were } 0.77,0.72 \text {, and } 0.67 \text {, } \\
\text { which are perceived as acceptable levels for } \\
\text { exploratory research (Nunnally \& Bernstein, } \\
\text { 1994). }\end{array}$ \\
\hline External validity & $\begin{array}{l}\text { External validity is used to measure the } \\
\text { extent to which the results of a study can } \\
\text { be held to be valid and true for other } \\
\text { cases, i.e. external validity measures } \\
\text { generalisability (e.g. Bryman \& Bell, } \\
\text { 2015; Campbell \& Stanley, 1966). }\end{array}$ & $\begin{array}{l}\text { Both Papers B and D are surveys with } \\
\text { populations sampled from Swedish } \\
\text { organisations in a Swedish context. The } \\
\text { findings and conclusions refer only to a } \\
\text { Swedish quality management context. }\end{array}$ \\
\hline Face validity & $\begin{array}{l}\text { Face validity is a measure used in order } \\
\text { to ensure the effectiveness of the }\end{array}$ & $\begin{array}{l}\text { Pre-tests and interviews with practitioners and } \\
\text { experts were used in both Papers B and D to }\end{array}$ \\
\hline
\end{tabular}




\subsubsection{Discussion on research design}

The data presented in this thesis were collected by two methods: interviews and surveys. These have been supplemented by document studies pertaining to the studied organisations. Eraut (1998) discusses two ways of understanding competence: through 'observation' and 'recollection' (p. 134). It could thus be argued that one limitation of the thesis is that it mainly relies on recollection and that observation studies are not included. While it is true that several reasons speak in favour of including observation, its use in order to understand competence is not self-evident. Atkinson, Coffey and Delamont (2003) point out that 'we must not assume that what is done should enjoy primacy over what is said, and therefore observation and interviewing stand in opposition to one another' (p. 97). It can be argued that observations do not necessarily increase our understanding of central aspects of quality management practice, nor our understanding of how to convey these into distinct forms of quality management competence.

Furthermore, observation does not necessarily convey how the people being observed understand the practice or context, nor how they perceive its meaning. Such understanding may be particularly relevant when conducting research into knowledge-intense work, such as quality management. Observation may be laden with the researcher's own biased inferences of what is going on, and in this way obscure what is actually happening (e.g. Atkinson \& Coffey, 2003; Hammersley, 2008; Trow, 1957). It can be argued, therefore, that interviews are more suitable to reach deeper levels of knowledge (Johnson, 2003). This is important also in a critical realist sense, where it can be argued that interviews increase the knowledge depth, and are thus more likely to reveal issues beyond what can be observed. It could, of course, be argued that a combination of observations and interviews is more suitable. Hultman (2001) has labelled this combination contextual interviews, or observiews (= OBSERvations + interVIEWS). Contextual interviews are a viable way to incorporate observation studies with immediately subsequent interviews, such that the interviewer can better understand context and meaning. This gives the interviewee the opportunity for reflection on action in what has been labelled as a double dialogue (Hultman, 2001). The use of contextual interviews was discussed in the planning stage of the research projects, but it was concluded that it was not feasible to carry them out, given the time-frame of the projects and the accessibility of the organisations.

It is possible that the choice of interactive research has introduced issues associated with a bias of the researcher. Close proximity to practitioners within the studied organisations and continuous interaction with them may lead to an overly uncritical stance. Time with practitioners may lead to them having an influence on the organisational discourse and culture, which may affect the objectivity and integrity of the researcher. However, the research team made unceasing efforts to address such issues, and frequently discussed ways of limiting such risks. Discussing the results obtained with fellow researchers was one method used to identify possible bias and undue organisational influence. Frequent critical self-reviewing and review by fellow researchers resulting in adjustments to methods to ensure that the methods used were compatible with the knowledge interest minimised the risk of researcher bias. Further, results and findings were cross-validated in cross-case comparisons in order to minimise organisational bias and maximise generalisability. 
Some design issues concerning the findings presented here must be discussed. The research designs of Papers $\mathrm{C}, \mathrm{D}$ and $\mathrm{E}$ include both qualitative and quantitative designs. Mixed designs provide a means for triangulation and assertion (Stake, 1995; Taylor, 1979; Yin, 2014), but it is unclear whether the sampling strategies used for the data collected for Papers $\mathrm{C}$ and $\mathrm{E}$ provided the adequate and truly representative range of interviewees needed to answer Research Question 1. The empirical support could, therefore, be considered to be strong (supporting what Bryman \& Bell (2015) label as credibility), but Paper A may not be relevant in the context of quality management. Does this paper really fit in among the other papers, which have a clearer orientation towards quality management? The structure and contents of the thesis ensure that it does. For example, several studies include performance measurement as a way to manage facts in quality management practice (e.g. Ali, Jain, Ali \& Munir, 2017; Kumar, de Grosbois \& Choisne, 2008; Motwani, 2001; van Schalkwyk, 1998).

Papers B, C and D include both qualitative and quantitative designs, which increases their credibility (Bryman \& Bell, 2015). Another strength is the interconnection of Papers B and C. The results from Paper B influenced the design of the studies whose results are presented Paper $\mathrm{C}$, and this increases the dependability of the findings (Bryman \& Bell, 2015). Of course, the reverse may also be true - that any inherent faults in the design of the work reported in Paper $\mathrm{B}$ have affected the quality of Paper $\mathrm{C}$. Throughout all papers, measures for confirmability were taken within the research group in order to minimise bias and subjectivity.

\subsubsection{Ethical considerations}

This work presented in this thesis followed the eight general rules given by the Swedish Research Council (Vetenskapsrådet, 2017), and the four ethical considerations ${ }^{23}$ described by Bryman and Bell (2015). During all research activities, care was taken to protect the participants and secure their integrity such that no unintended harm was caused, directly or indirectly, as a result of the research. Particular attention was paid to ensure that participation was voluntary, that informed consent was obtained, and that the data were kept anonymous and confidential. In preparation for the surveys in Papers B and D, and for the interviews in Papers A, C and E, information that described the purpose and scope of the research was sent out (in the interview studies) or provided as an information screen in the online survey (in the survey studies). Every possible effort was made to ensure transparency and openness about the process, content and use of the research. When obtaining informed consent from potential participants, particular attention was paid to describe the premises for voluntary participation. It was made clear that the handling, storage and presentation of any information would not disclose personal information against the will of the participants (i.e. confidentiality) or information that, in any way, would enable identification of participants (i.e. anonymity). It was made clear that information gathered was solely for research purposes within the limits of the research scope. Every participant was also informed about the possibility to withdraw from the study at any stage during the research process.

\footnotetext{
${ }^{23}$ The four ethical considerations are: secure integrity, avoid harm, ensure consent and avert false impressions (Bryman \& Bell, 2015).
} 


\title{
4. OVERVIEW OF APPENDED PAPERS
}

This chapter summarises the five papers that are included in the thesis. Each summary provides a background, an account of the empirical material, and a description of the main methods used in the paper. The summaries also outline the main findings, with a brief account of the main results, conclusions and contributions of each paper. The contribution of each paper to the thesis is described.

\subsection{Paper A}

\section{Four facets of learning in performance measurement}

\author{
Jason Martin ${ }^{\mathrm{a}}$, Mattias Elg ${ }^{\mathrm{a}}$, Andreas Wallo ${ }^{\mathrm{b}}$ and Henrik Kock ${ }^{\mathrm{b}}$ \\ ${ }^{a}$ Department of Management and Engineering, Linköping University, Linköping, Sweden \\ ${ }^{b}$ Department of Behavioural Sciences and Learning, Linköping University, Linköping, \\ Sweden
}

Status: Published in the International Journal of Productivity and Performance Measurement (2018), Vol. 67 No. 9, pp. 1608-1624.

\section{Background and empirical material}

Performance measurement $[\mathrm{PM}]$ is vital for organisations in order to operate, control and improve organisational performance. As such, PM plays a key role in facilitating learning in organisations. The purpose of this paper was to contribute to a better understanding of the role of learning in PM. In this paper, the variety of different kinds of learning that result from PM was investigated by developing a framework that combines facets of workplace learning with the key purposes of PM. This framework was elaborated empirically by identifying critical incidents [CI] from a case situated within a context that contained a broad range of PM activities. The case was set in an orthopaedics and rheumatology department, where 17 respondents were interviewed. The respondents represented a wide range of healthcare professions, including medical doctors [MD], nurses, assistant nurses and physiotherapists. Personnel from the administration and managerial levels, such as care unit managers, administrators and organisational developers, were also included.

\section{Main results and contribution}

A tentative framework for learning as a driver for PM was developed using select theory (Figure 10). The elements of the proposed framework were based on four separate components: the purpose of performance measurement, the level of agent discretion, the learning type and the learning facets. The proposed framework is intended to be used in linking learning with PM, where four main facets of learning were recognized: reproductive, rule-oriented, goal-oriented and creative learning. 


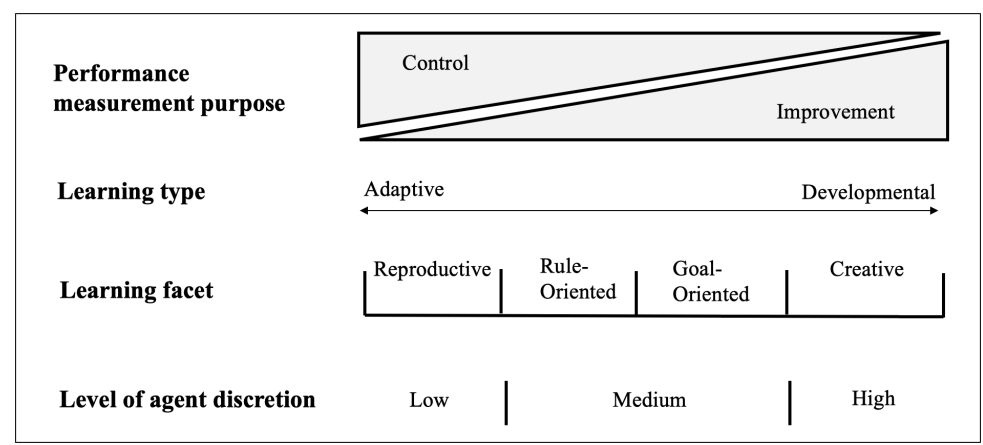

Figure 10. Relationships between performance measurement and learning, a tentative framework for analysis (Martin, Elg, Wallo \& Kock, 2018, p.1612)

The analysis of the CIs identified $(n=73)$ in the interviews revealed 55 separate incidents for which learning environments could be categorised. Two-thirds of the CIs that contained identifiable learning processes were adaptive in nature (that is, reproductive or rule-oriented), while the remaining one-third were developmental in nature (that is, goal-oriented or creative). Table 6 shows the distribution of the learning facets found in the CIs classified by personnel category. The results show that PM is achieved in many different ways and that the particular nature of the learning is reflected closely in the context, design and execution of PM. The results show also that the level of discretion induce certain learning types and vice versa. Furthermore, agent discretion appears to be important in determining the particular facet of learning. The spectrum from control to improvement is also conditioned by three aspects that characterise the workplace: task, method and results.

Table 6. Distribution of learning facets within CIs, classified by personnel category (Martin, Elg, Wallo \& Kock, 2018, p.1617)

\begin{tabular}{lcccc}
\hline & Reproductive & Rule-based & Goal-oriented & Creative \\
\hline MD & 5 & 11 & 4 & 7 \\
$\begin{array}{l}\text { Nurses and other care } \\
\text { personnel }\end{array}$ & 12 & 15 & 4 & 7 \\
$\begin{array}{l}\text { Managers and } \\
\text { administrators }\end{array}$ & 14 & 4 & 8 & 5 \\
$\begin{array}{l}\text { Organisational } \\
\text { developers }\end{array}$ & 2 & 1 & 1 & 3 \\
Total & 33 & 31 & 17 & 22 \\
\hline
\end{tabular}

The paper contributes to a deeper understanding of how workplace learning theory can explain how control or improvement purposes in PM affect the different modes of learning. The paper argues that managers, in general, must contemplate the kind of learning environment characterising their organisation and what kind of learning outcomes that best serve their interests. Deliberate and meticulously designed structural arrangements and learning environments in organisations are more likely to lead to intended learning outcomes in PM. 


\title{
4.2 Paper B
}

\section{Fit for purpose? Exploring competence in quality management}

\author{
Jason Martin ${ }^{\mathrm{a}}$, Mattias Elga and Ida Gremyr ${ }^{\mathrm{c}, \mathrm{a}}$ \\ ${ }^{a}$ Department of Management and Engineering, Linköping University, Linköping, Sweden \\ ${ }^{c}$ Department of Technology Management and Economics, Chalmers University of \\ Technology, Gothenburg, Sweden
}

Status: Published online and in International Journal of Quality and Service Sciences, Vol. 11 No. 3, pp. 317-333.

\section{Background and empirical material}

This paper extends the somewhat moderate stream of previous research focussed on quality management practices and quality management practitioners by the use of competence theory to explore the concept of quality management competencies. The theme is the perceived fit between actual, i.e. based on the past, and needed, i.e. based on current and future quality management competence, in organisations. The purpose of this study was therefore to use competence theory to explore perceptions of the fit between actual quality management competencies of quality management practitioners and the perception of quality management competence needs in organisations.

A literature review revealed three main lines of change in quality management practice in recent decades. First, quality management practices have extended from a mainly internal focus and now include also an external focus, described as a greater focus on effectiveness. Second, practices within quality management are increasing the strategic leverage, and impacting organisational outcomes on a higher organisational level. Third, the inclusion of radical improvement and development that facilitate innovation have resulted in quality management practices becoming more focussed on the development of new services and products in organisations. A cross-case quantitative study design was used, featuring a survey of quality management practitioners $(n=249)$ in eight large Swedish organisations. The research instrument was a questionnaire that covered seven themes in quality management. The analysis in the paper was primarily based on descriptive statistics.

\section{Main results and contribution}

The results show that quality management practitioners perceive themselves as rather well educated, formally competent and generally strategically and externally oriented (Figure 11). Thus, the formal quality management competencies are perceived as rather high. This stands in contrast to the perceived actual quality management competencies, which are described as predominantly operational with an emphasis on internal efficiency (Figure 12). In fact, the results show that a fair amount of quality management work in organisations is predominantly exploitative and oriented towards internal processes. The results thus indicate a discrepancy between the individual's formal and actual competencies, as required by the task and/or situation at hand. 
Do you perform QM-related working tasks that you need more education for?

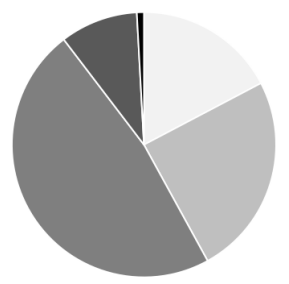

$$
\begin{aligned}
& \text { Very rarely or never } \\
& \text { —uite rarely } \\
& \text { — Sometimes } \\
& \text { — Quite often } \\
& \text { - Very often or always }
\end{aligned}
$$

Figure 11. Degree to which quality management practitioners feel that they perform tasks for which they would have needed more formal competence (Martin, Elg \& Gremyr, 2019, p. 325)

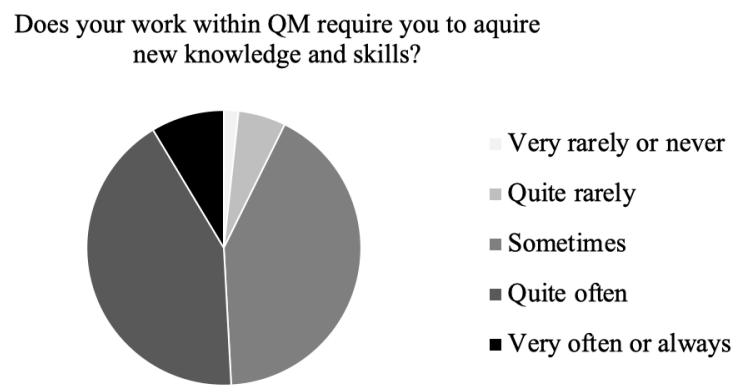

Figure 12. Degree to which quality management practitioners feel that they perform tasks for which they would have needed more actual competence (Martin, Elg \& Gremyr, 2019, p. 325)

The main finding of this paper is a general misalignment between actual and required competencies. Our results show that the situations encountered by quality management practitioners in daily work require additional quality management competencies not formally demanded by the organisations studied. Formal and demanded quality management competences are not readily compatible with the formal and actual competences in the organisations. This paper shows that current quality management competencies are predominantly rooted in traditional, internally focussed quality management practices, considered to play a mainly supporting role.

The paper shows that it is imperative for quality management to evolve and to take a more leading role. Contemporary organisations must organise quality management such that it has the potential to simultaneously act not only with internal, operational and incremental imperatives, but also with external, strategic and radical imperatives. Properly managed, an organisation that features a combination of quality management competencies, with carefully analysed knowledge bases and skillsets that are adapted for both exploitative and explorative 
quality management practices, could facilitate ambidexterity ${ }^{24}$ within the organisation. The paper's main contribution is to quality management research and quality management practice in proposing that competence theory be adopted as a foundation for organising quality management that facilitates ambidexterity in organisations.

\title{
4.3 Paper C
}

\section{Towards a quality management competence framework: exploring needed competencies in quality management}

\author{
Jason Martin ${ }^{\mathrm{a}}$, Mattias Elg ${ }^{\mathrm{a}}$, Ida Gremyr ${ }^{\mathrm{c}, \mathrm{a}}$ and Andreas Wallo ${ }^{\mathrm{b}}$ \\ ${ }^{a}$ Department of Management and Engineering, Linköping University, Linköping, Sweden \\ ${ }^{b}$ Department of Behavioural Sciences and Learning, Linköping University, Linköping, \\ Sweden \\ ${ }^{c}$ Department of Technology Management and Economics, Chalmers University of \\ Technology, Gothenburg, Sweden
}

Status: Accepted for publication and in press in Total Quality Management and Business Excellence (2019).

\section{Background and empirical material}

Few empirical studies elaborate on the actual competencies of quality management and its practitioners, and even fewer acknowledge the need for a competence framework that describes what is required to perform quality management. This paper transcends the mainly role-oriented and practice-oriented approaches of previous research and adopts an extended theoretical understanding of quality management competencies. The purpose of this paper is to advance a competence-based terminology that describes the general competencies of quality management work in organisations, and to construct a competence framework that can be used to understand what a quality management practitioner needs.

Thirty-three quality management practitioners in four large Swedish organisations were selected and interviewed in semi-structured interviews, in an embedded, qualitative multiplecase study design,. The interviewees represented a fairly equal distribution of quality management practitioners across the complete range of strategic and operational organisational levels. The interviews were transcribed and analysed in an abductive two-step process that combined inductive thematic analysis with deductive pattern clarification.

\section{Main results and contribution}

The coding and analysis revealed 63 codes relating to competencies. These codes were then analysed, categorised and clustered into 15 different quality management competencies-in-use that, in turn, were clustered into the three main quality management competence dimensions outlined in the analytical framework. An additional, inductively derived, fourth competence dimension emerged during this process: the contextual competence dimension. Table 7 presents a summary of the results.

\footnotetext{
${ }^{24}$ It should perhaps be reminded that ambidexterity refers to Tushman and O'Reilly's (1996) definition of ambidextrous organisations and describes the structural arrangements to accommodate both initiation of innovation and also the execution of innovation; see Subsection 2.1.2.
} 
Table 7. Main competence dimensions with their respective quality management competencies-in-use (Martin, Elg, Gremyr \& Wallo, 2019, p. 8)

\begin{tabular}{cll}
\hline $\begin{array}{c}\text { Main competence } \\
\text { dimension }\end{array}$ & \multicolumn{1}{c}{ Quality management competencies-in-use } \\
\hline Human & - & \multicolumn{1}{c}{ Change management } \\
& - & Pedagogical abilities \\
& - Organisation-specific quality management concepts \\
- Established tools and methods for quality management \\
process & - Standards and management systems \\
& - Data analysis \\
- Information processing and visualisation \\
- Customer perspective \\
- Developmental approach \\
- Harnessing technology and digitalisation \\
- Holistic and strategic understanding \\
- Experience from external contexts (other organisations) \\
\end{tabular}

The analysis of general quality management competencies revealed a pattern of an empirically derived and idealised, generic quality management role-responsibility structure; see Figure 13. Within this structure, two main role-responsibility characteristics can be distinguished: functional scope and situated range. Functional scope represents the general orientation and content of the performance of the particular quality management role-responsibility - either more operational or more strategic. Situated range represents the organisational context in which the interaction and performance normally have an impact- either centralised or local.

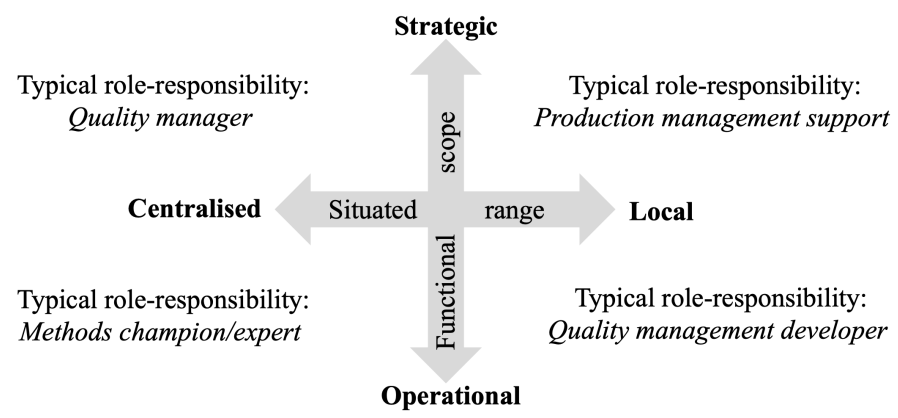

Figure 13. Generic role-responsibility characteristics of quality management (Martin, Elg, Gremyr \& Wallo, 2019, p. 10)

The paper also presents a role-responsibility pattern that incorporates the four competence dimensions and the generic role-responsibility characteristics. It gives examples of concrete competencies-in-use for each role-responsibility. Furthermore, the paper discusses competencies and role-responsibilities in relation to the above described quality dilemma (see 
Subsection 2.1.2) in quality management, and identifies an emerging need to also emphasize integrative and business excellence-oriented quality management. Such would facilitate organisational learning, guided by the proposed competence framework. The main contribution of the paper is two-fold: first, it complements current research into the theory of quality management by adopting a competence theory-based terminology in order to describe quality management competence. Second, the paper unifies an established conceptual framework of competencies that is needed in most organisational contexts.

\title{
4.4 Paper D
}

\section{The roles of quality departments and their influence on business results}

\author{
Ida Gremyr ${ }^{\mathrm{c}, \mathrm{a}}$, Mattias Elga ${ }^{\mathrm{a}}$, Andreas Hellström ${ }^{\mathrm{c}}$, Jason Martin ${ }^{\mathrm{a}}$ and Lars Witell ${ }^{\mathrm{a}}$ \\ ${ }^{c}$ Department of Technology Management and Economics, Chalmers University of \\ Technology, Gothenburg, Sweden \\ ${ }^{a}$ Department of Management and Engineering, Linköping University, Linköping, Sweden
}

Status: Accepted for publication and in press in Total Quality Management and Business Excellence (2019).

\begin{abstract}
Background and empirical material
A problem of previous research into quality management is that it does not adequately recognize the various forms and applications of quality management when evaluating its impact on business results. The purpose of this paper, therefore, was 'to explore the various roles of quality departments and investigate whether these roles have different effects on business results' (p. 2). The concepts of exploitation and exploration are applied using quality management research to categorise quality management practices into two main groups: quality exploitation and quality exploration. The paper investigates whether it matters whether a company in general, or a quality management department in particular, focusses more on exploratory practices, like embracing new approaches, or if it focusses more on exploitative practices, like performing regular internal audits.
\end{abstract}

The paper argues that it is necessary to study the various ways to organise quality management, and that its practices affect business results. A research instrument to capture the practical experiences of quality management of respondents was developed. Validated measures that covered quality management practices, organisational characteristics, and their effects on business results were constructed. A web-based survey was then conducted, addressing 800 Swedish quality managers identified through a database (PAR). 211 respondents completed the questionnaire. Factor analysis was used to identify the various core practices of the quality departments. This was complemented by a cluster analysis to analyse how these practices could be categorised into different quality department roles. The final step involved the use of ANOVAs to identify differences in quality practices between the identified quality department roles, and to determine whether specific roles gave significantly better business results.

\section{Main results and contribution}

The final factor solution revealed three core quality management practices that were named development-focussed practices, process-focussed practices and cost-focussed practices (Table 8). 


\begin{tabular}{|c|c|c|c|c|}
\hline \multirow[t]{2}{*}{ Work practices of a quality department } & \multicolumn{3}{|c|}{ Identified components } & \multirow[t]{2}{*}{ Core practice label } \\
\hline & 1 & 2 & 3 & \\
\hline $\begin{array}{l}\text { Embracing new concepts and approaches within } \\
\text { quality management }\end{array}$ & 0.72 & & & \multirow{4}{*}{$\begin{array}{l}\text { Development- } \\
\text { focussed practices }\end{array}$} \\
\hline \multirow{2}{*}{$\begin{array}{l}\text { Applying statistical tools on a large scale } \\
\text { Educating employees on new concepts and } \\
\text { approaches }\end{array}$} & 0.70 & & & \\
\hline & 0.68 & & & \\
\hline Establishing forums for cross-functional meetings & 0.68 & & & \\
\hline \multirow{3}{*}{$\begin{array}{l}\text { Performing regular internal audits of business } \\
\text { operations } \\
\text { Creating routines and processes for business } \\
\text { operations } \\
\text { Reducing variation in business processes }\end{array}$} & & & 0.86 & \multirow{3}{*}{$\begin{array}{c}\text { Process-focussed } \\
\text { practices }\end{array}$} \\
\hline & & & 0.79 & \\
\hline & & & 0.56 & \\
\hline Potentiating workflows to reduce costs & & 0.81 & & \multirow{3}{*}{$\begin{array}{l}\text { Cost-focussed } \\
\text { practices }\end{array}$} \\
\hline \multirow{2}{*}{$\begin{array}{l}\text { Interacting with suppliers on quality management } \\
\text { Leading the quest to eliminate non-contributing } \\
\text { costs }\end{array}$} & & 0.62 & & \\
\hline & & 0.81 & & \\
\hline Eigenvalues & 3.51 & 1.4 & 1.1 & \\
\hline Variance explained & 35.5 & 14.2 & 10.9 & \\
\hline
\end{tabular}

The results of the factor analysis were used as the input to a cluster analysis. The K-means cluster analysis required that the desired number of clusters be specified in advance. The number of clusters was limited to between $n / 30$ and $n / 60$, where $n$ was the sample size. Therefore, only models ranging between three to seven clusters were considered. The interpretability of the clusters using ANOVAs were also investigated, which showed significant statistical differences separating the different types of quality department. The solution chosen had four clusters, between which ten quality practices discriminated.

Based on this analysis, the quality departments in the four different clusters were denoted as firefighters, auditors, process improvers, and orchestrators, which characterised the different quality department roles. Further, it was investigated whether the role of a quality department has influence on its performance and on that of the organisation in general. ANOVAs were performed to determine whether the type of quality department led to differences between organisations in terms of its contribution to business results, customer satisfaction, profitability, or cost. Table 9 shows the contributions to customer satisfaction and cost in 2005-2007.

Table 9. Differences in business results by quality department role (Gremyr et al., 2019, p. 8)

\begin{tabular}{|c|c|c|c|c|c|c|}
\hline $\begin{array}{l}\text { Quality department work } \\
\text { practices }\end{array}$ & $\begin{array}{c}\text { Cluster } 1 \\
\text { Fire- } \\
\text { fighters } \\
\mathbf{n}=\mathbf{2 8} \\
\end{array}$ & $\begin{array}{c}\text { Cluster } 2 \\
\begin{array}{c}\text { Auditors } \\
n=65\end{array} \\
\end{array}$ & $\begin{array}{c}\text { Cluster } 3 \\
\text { Process } \\
\text { improvers } \\
n=60\end{array}$ & $\begin{array}{c}\text { Cluster } 4 \\
\begin{array}{c}\text { Orchestrators } \\
n=55\end{array}\end{array}$ & $\mathbf{F}$ & Sig. \\
\hline \multicolumn{7}{|l|}{ Contribution to results } \\
\hline \multicolumn{7}{|l|}{$\begin{array}{l}\text { Quality departments' } \\
\text { contribution to results ... }\end{array}$} \\
\hline last year & $4.32^{b}$ & $4.37^{b}$ & $4.97^{\mathrm{a}}$ & $5.04^{\mathrm{a}}$ & 4.29 & $\begin{array}{l}\mathrm{p}< \\
0.01\end{array}$ \\
\hline three years ago & $4.75^{b}$ & $4.72^{b}$ & $5.42^{\mathrm{a}}$ & $5.57^{\mathrm{a}}$ & 5.67 & $\begin{array}{l}\mathrm{p}< \\
0.01\end{array}$ \\
\hline
\end{tabular}




\begin{tabular}{|c|c|c|c|c|c|c|}
\hline \multicolumn{7}{|c|}{$\begin{array}{l}\text { Relative position during the } \\
\text { past three years in... }\end{array}$} \\
\hline Customer satisfaction & $4.62^{b}$ & $4.97^{\mathrm{a}, \mathrm{b}}$ & $4.66^{\mathrm{b}}$ & $5.09^{\mathrm{a}}$ & 2.92 & $\begin{array}{c}\mathrm{p}< \\
0.05\end{array}$ \\
\hline Loyalty & 4.85 & 5.10 & 4.90 & 5.17 & 0.94 & $\begin{aligned} & \mathrm{p} \\
= & 0.42\end{aligned}$ \\
\hline Profitability & 4.46 & 4.59 & 4.85 & 5.04 & 1.81 & $\begin{array}{c}\mathrm{p} \\
=0.15\end{array}$ \\
\hline Cost & $4.46^{\mathrm{b}}$ & $3.97^{\mathrm{a}}$ & $4.37^{\mathrm{b}}$ & $4.39^{b}$ & 2.62 & $\begin{array}{c}\mathrm{p} \\
<0.10\end{array}$ \\
\hline
\end{tabular}

Note: the cluster values are based on graded responses following a 7-point scale from 1 ('do not agree') to 7 ('fully agree'). Values in the table that share a superscript letter are not significantly different.

The results show that organisations that employ exploration practices tend to perform better. Both process improvers and orchestrators adopt quality management exploration practices to a higher degree in organisations that believe that quality work contributes most to results. Thus, it is shown that quality exploration practices are instrumental. The scores for Auditors and firefighters were predominantly lower and these roles performed almost equally on results. The main contribution of the paper is to show that organisations that strive to increase exploration practices and achieve better business results must adopt orchestrator and processor improver roles for their quality management departments.

\title{
4.5 Paper E
}

\section{The Role of Quality Management in an Era of Digitalisation}

\author{
Mattias Elg ${ }^{\mathrm{a}}$, Andrea Birch-Jensen ${ }^{\mathrm{c}}$, Ida Gremyr ${ }^{\mathrm{c}, \mathrm{a}}$, Jason Martin ${ }^{\mathrm{a}}$ and Ulf Melin ${ }^{\mathrm{a}}$ \\ ${ }^{a}$ Department of Management and Engineering, Linköping University, Linköping, Sweden \\ ${ }^{c}$ Department of Technology Management and Economics, Chalmers University of \\ Technology, Gothenburg, Sweden
}

Status: Working paper.

\section{Background and empirical material}

Digitalisation has become an all-pervasive phenomenon in society and impacts every level and aspect of organisational life, in both the public and private sectors. Solutions that embed digital technologies can be found in a wide range of areas, such as big data analytics, automation, digital interfaces, and connectivity. The broad scope of digitalisation allows it to be defined as the process of adopting and using digital technologies in processes, organisations and ecosystems. The challenges of digitalisation often relate to the lack of a digitalisation strategy, a failure to develop appropriate processes, the use of existing infrastructure, a failure to develop a new culture and mindset that facilitate digitalisation, and insufficient skills and knowledge in digitalisation.

This paper addresses these challenges by focusing on the role of quality management in digitalisation, and in particular its principles, practices and techniques that enhance customer focus, continuous improvement, and teamwork. The purpose of the study, therefore, was to identify the various roles that quality management practitioners take in digitalisation initiatives in order to reveal the challenges and potential for QM in digitalisation. A value-creation 
perspective and the exploitation-exploration trade-off are used and conceptualised into an analytical framework that posits six key quality management roles.

An analytical framework was used to analyse and define the interfaces in digitalisation initiatives at which quality management practitioners assume different roles, depending on the value spheres and the choice of orientation: exploitative or explorative. A qualitative, multiple cross-case study design was chosen to explore these roles. Data from thematic, semi-structured interviews with 33 quality management practitioners, who all had clearly defined responsibilities for quality management work and who all had time allocated for such work in their work description, were analysed.

\section{Main results and contribution}

A coding scheme with defined coding guidelines, founded on nine code-clustering categories based on the analytical framework, was used. Five groups of initiatives were reported by the interviewees: increased automation, new business models, practices for problem detection and solving, enhanced communication, and developing an organisation for digitalisation. Examples of three of these - new business models, practices for problem detection and solving, and enhanced communication - came from both exploitative and explorative initiatives. The only examples of increased automation were exploitative initiatives, while for developing an organisation for digitalisation, only explorative initiatives were reported.

Six roles for quality management practitioners and teams were identified in Paper E. Exploitative roles are related to digital technology that has already been implemented. The exploitative-internal quality management role is involved chiefly in the design of the many planted and growing technologies in place. This role must also look out for things that do not seem to be suitable in the context, and must nurture things that work well. The exploitativeintegrative quality management role must connect new digital solutions that enable movement from a human-to-human to a human-to-digital interface. These may be, for instance, new service offerings or organisational forms that make fewer phone calls possible which, in turn, maintains or improves quality. The exploitative-external quality management role contributes to increasing value in the customer sphere for implemented digital solutions.

Explorative roles are related to digital technology aimed at developing new solutions and value for customers. An explorative-internal quality management role must plan, design, and review in collaboration with stakeholders, and in this way provide solutions that create better opportunities for the digitalisation provider to offer value for the customer. An explorativeintegrative quality management role connects the provider with the customer. This role focusses on the continuous management of value-in-use, and opens opportunities for continuous interaction and adding value. Finally, the explorative-external quality management role draws attention to the challenges of the existing power structures, i.e. increased customer power and customer monitoring.

Paper E contributes by exploring the relationships between quality management and digitalisation by describing the potential for quality management to support value creation in digitalisation. This has not been examined before. The paper also puts forward an analytical framework in which digitalisation initiatives that affect quality management are analysed, based on exploitation/exploration, the level of digitalisation, and the location of the impact in the value-creation domain. 


\section{DISCUSSION}

This chapter presents the results and findings from the five papers and relates them to the purpose and research questions of the thesis, in three sections. The first section addresses the first research question and answers it through a literature-based discussion. The second and third sections address the second and third research questions, respectively, by discussing the findings of the papers in relation to the conceptual framework. The overall purpose of this chapter is to answer the research questions by interpreting and recontextualising the empirical findings in the papers using the concepts and perspectives described and framed in the theoretical background; see Chapter 2.

\subsection{Characterising quality management work}

\subsubsection{Introducing expansive and adaptive quality management work}

Based on the literature review and discussion in Chapter 2, I propose a new way to characterise quality management work. The proposed characterisation does not consider compliance, improvement and business management-oriented quality management (Maguad, 2006) to be necessarily separate or structurally determined orientations. I argue that in most organisations these three orientations are, more or less, inseparable and intertwined on all organisational levels. Ideally, quality management work should, therefore, facilitate not only innovation and development, but also productivity and performance on all organisational levels. This rather complex and dynamic view of the organisational context and conditions for quality management requires a more nuanced approach towards describing the nature of quality management work. Such an approach should not only support the co-existing business, improvement and compliance orientations (Maguad, 2006), but also integrate and create leverage for them. This is true for the complete range of possible functional scopes; see Figure 2, Subsection 2.1.2. This section elaborates on the characterisation of quality management work, and presents illustrations from Papers A to E that give examples of the content and process of quality management work in line with this characterisation; see Table 11.

Thus, I propose that two, equally important, major directions in characterising quality management work can be identified, here denoted as expansive quality management work and adaptive quality management work. The words are attributive adjectives that convey the mode of actually performing quality management work. Expansive quality management work thus expands work approaches that facilitate continuous improvement. Expansive quality management work engages in quality management practices that open up for new ideas and explore new, diverse and innovative ways of facilitating continuous improvement to quality. Adaptive quality management work adapts work approaches such that they promote continuous improvement. Adaptive quality management work engages in quality management practices that implement ideas and accommodate ways of working such that continuous quality improvement becomes efficient, reliable and stable. The concepts of expansive and adaptive quality management work are ideal descriptions of how quality management work is done. In reality, clear-cut boundaries between the two directions of quality management work may be difficult to discern.

The term adaptive quality management work refers to ways of engaging in quality management practices that are directed towards facilitating incremental change to existing processes and/or the reproduction, stabilisation, control and monitoring of processes that increase the quality of services and/or products. In contrast, the term expansive quality management work refers to 
ways of engaging in quality management practices that are directed towards the transformation and radical change of existing processes or the development of new processes that improve the quality of services and/or products. Adaptive quality management work is predominant in exploitative (March, 1991) practice and dictated by a logic of performance (Ellström, 2006), whereas expansive quality management work is predominant in explorative (March, 1991) practice and dictated by a logic of development (Ellström, 2006). Table 10 gives a summary of the key factors of adaptive and expansive quality management work.

Table 10. Key factors in adaptive and expansive quality management work

\begin{tabular}{ll}
\hline Adaptive quality management work & Expansive quality management work \\
\hline Exploitative practice & $\begin{array}{l}\text { Explorative practice } \\
\text { Radical change to existing processes or development } \\
\text { of new processes }\end{array}$ \\
\hline Incremental change to existing processes & Directed by a logic of development \\
\hline Goal and productivity-oriented & Development and innovation-oriented \\
\hline Internal efficiency & External effectiveness \\
\hline Decreases process variation & Increases process variation \\
\hline
\end{tabular}

Furthermore, the natures of expansive and adaptive quality management work are not mutually exclusive, a conclusion that is compatible with Ellström (1997; 2006), March (1991), and Gupta, Smith and Shalley (2006). The findings regarding parallel practices and competenciesin-use (Papers C, D and E) further support this conclusion. The two directions are dichotomous but complementary, and both are necessary to ameliorate the productivity dilemma (Abernathy, 1978; Benner \& Tushman, 2003) through the balance between exploitation and exploration (Backström, 2017; Fundin et al., 2018; Fundin, Bergman \& Elg, 2017; Rosing, Frese \& Rosenbuch, 2010; Tushman \& O'Reilly, 1996). I suggest that successful quality management requires the successful management of both expansive and adaptive quality management work, in order to serve the various needs and demands that arise from different quality management orientations (Maguad, 2006) in contemporary organisations.

Based on the discussion above and previous work, a framework is proposed that can be used to understand the complexity of quality management in contemporary organisations and the need to accommodate both expansive and adaptive quality management work; see Figure 14 . The thesis is based on the premise that expansive and adaptive quality management work are mutually dependent and co-exist on all organisational levels, with different purposes and aims. Whereas the purpose of adaptive quality management work is goal-oriented and its aims are to decrease process variation and increase internal efficiency, the purpose of expansive quality management work is development-oriented and its aims are to increase process variation and external effectiveness. The content and process of the quality management work directions depend also on the functional scope of quality management. As shown in Paper $\mathrm{C}$, the functional scope entails different role-responsibilities that depend on the situated range (Section 4.3). I propose that the nature of the orientation affects both the roles and their responsibilities, and the way in which quality management practitioners select, adopt and engage in quality management practices. 
Functional scope of quality management

More strategic

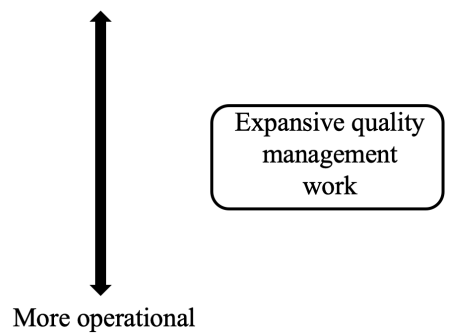

Quality management orientation and directions of quality management work

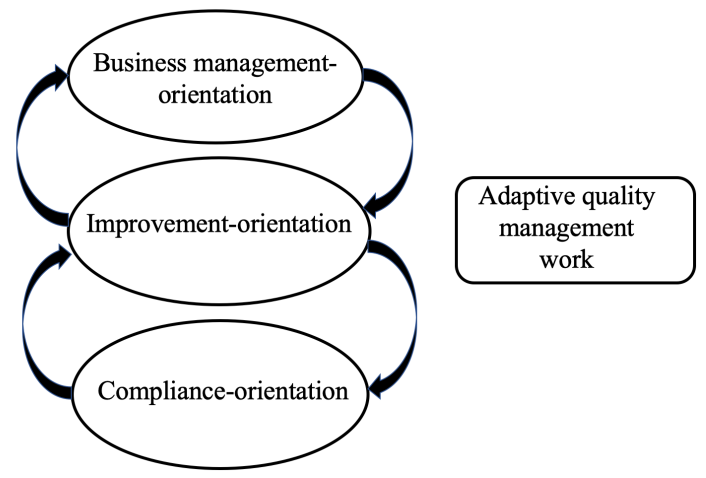

Figure 14. Quality management orientations with directions of quality management work

The dichotomous nature of the two quality management work directions also means that they are carried out separately. This separation of work directions can be either structurally dependent (Duncan, 1976) or contextually dependent (Gibson \& Birkinshaw, 2004). Structurally dependent separation can be either time-managed (Duncan, 1976), in which expansive and adaptive quality management work processes are executed by the same quality management practitioners at different times, or organisation-managed, in which expansive and adaptive quality management work practices are executed simultaneously (Tushman \& O'Reilly, 1996) by different quality management practitioners. Contextually dependent separation describes a situation in which either expansive or adaptive quality management work is chosen and performed at the discretion of the quality management practitioners themselves (Gibson \& Birkinshaw, 2004). Hence, contextually dependent separation of quality management work is emergent and depends on the context. Contextually dependent separation also depends on the flexibility and competence of the individuals engaged, and requires welldeveloped organisational processes that both encourage and enable quality management practitioners to make appropriate judgements about how to engage in quality management practices and perform quality management work. It follows that contextually dependent separation of quality management work directions requires higher levels of individual and collective competence. The two directions that characterise quality management work thus require different ways of engaging in the various quality management practices, which, in turn, requires different ranges of competence.

\subsubsection{Expansive and adaptive quality management work in the papers}

Subsection 5.1.1 proposes the dual directions of expansive and adaptive quality management work. Practices in expansive quality management work emphasise exploration, external effectiveness and best fit, while practices in adaptive Quality Work emphasise exploitation, internal efficiency and best practice. This characterisation of expansive and adaptive quality management work forms a basis for addressing Research Question 1. Table 11 outlines the quality management practices according to $\mathrm{Zu}$ (2009), with examples that illustrate elements of 
the content and process of quality management work. The information has been derived from the data collected during the work described in the appended papers, and from the results. Table 11 supports the existence of the proposed quality management work directions.

Table 11. Examples of adaptive and expansive quality management work in the performance of quality management practices

\begin{tabular}{|c|c|c|}
\hline $\begin{array}{c}\text { Quality } \\
\text { management } \\
\text { practice } \\
(\mathrm{Zu}, 2009)\end{array}$ & $\begin{array}{l}\text { Content and processes in adaptive } \\
\text { quality management work }\end{array}$ & $\begin{array}{l}\text { Content and processes in expansive } \\
\text { quality management work }\end{array}$ \\
\hline $\begin{array}{l}\text { Top management } \\
\text { support }\end{array}$ & $\begin{array}{l}\text { Primarily direct leadership skills in } \\
\text { directing practices (Paper C). } \\
\text { Establishing an organisational } \\
\text { commitment to quality management } \\
\text { (Paper C). }\end{array}$ & $\begin{array}{l}\text { Active carrier of quality management } \\
\text { principles through leadership skills } \\
\text { (Paper C). } \\
\text { Balancing long and short-term quality issues } \\
\text { (Paper C). } \\
\text { Developing new decision-making processes } \\
\text { that accommodate increased complexity } \\
\text { (Paper E). }\end{array}$ \\
\hline $\begin{array}{l}\text { Customer } \\
\text { relationships }\end{array}$ & $\begin{array}{l}\text { Collaboration with external customers in } \\
\text { QM not emphasised (Paper B). } \\
\text { Internal customer focus (Paper C). }\end{array}$ & $\begin{array}{l}\text { Work with customer-focussed } \\
\text { business-excellence models (Paper B). } \\
\text { Understanding customers (Paper C). } \\
\text { Customer value orientation. } \\
\text { Developing new customer feed-back } \\
\text { channels (Paper E). }\end{array}$ \\
\hline $\begin{array}{l}\text { Supplier } \\
\text { relationships }\end{array}$ & $\begin{array}{l}\text { Limited supplier interaction with a } \\
\text { mainly internal focus for quality } \\
\text { management (Papers C and E). }\end{array}$ & $\begin{array}{l}\text { Wide and extensive organisation } \\
\text { perspective. External network development } \\
\text { orientation (Paper C). } \\
\text { Proactive interaction with suppliers on } \\
\text { quality management (Paper D). } \\
\text { Quality management practice challenging } \\
\text { the internal and traditional supply chain } \\
\text { (Paper E). }\end{array}$ \\
\hline $\begin{array}{l}\text { Workforce } \\
\text { management }\end{array}$ & $\begin{array}{l}\text { Performance measurement for control } \\
\text { purposes (Paper A). } \\
\text { Translating strategic quality management } \\
\text { initiatives into operations with a focus on } \\
\text { own organisation } \\
\text { (Paper C). }\end{array}$ & $\begin{array}{l}\text { Performance measurement for development } \\
\text { purposes (Paper A). } \\
\text { Mediating between theory and practice. } \\
\text { Communication interface between } \\
\text { organisational levels (Paper C). } \\
\text { Employee education on new concepts and } \\
\text { establishing cross-functional arenas for } \\
\text { meeting (Paper D). } \\
\text { Cross-functional collaboration and } \\
\text { facilitation of communication (Paper E). }\end{array}$ \\
\hline $\begin{array}{l}\text { Quality } \\
\text { information }\end{array}$ & $\begin{array}{l}\text { Data collection for control purposes } \\
\text { (Paper A). } \\
\text { Driving adaptation and quality assurance } \\
\text { (Paper C). } \\
\text { Auditing operational performance } \\
\text { (Paper D). }\end{array}$ & $\begin{array}{l}\text { Data collection for development purposes } \\
\text { (Paper A). } \\
\text { Translation between organisational contexts. } \\
\text { Communication skills for development } \\
\text { (Paper C). } \\
\text { Developing an increased ability for data } \\
\text { analysis. Understanding how processed data } \\
\text { has impact on markets and business (Paper } \\
\text { E). }\end{array}$ \\
\hline $\begin{array}{l}\text { Product/service } \\
\text { design }\end{array}$ & $\begin{array}{l}\text { Understanding and facilitating structural } \\
\text { conditions for production (Paper C). } \\
\text { Improving existing service offerings to } \\
\text { existing customers (Paper E). }\end{array}$ & $\begin{array}{l}\text { Business-management orientation with } \\
\text { detailed knowledge of products and services } \\
\text { (Paper C). } \\
\text { Developing new business models and } \\
\text { offerings (Paper E). }\end{array}$ \\
\hline
\end{tabular}




\begin{tabular}{|c|c|c|}
\hline $\begin{array}{l}\text { Process } \\
\text { management }\end{array}$ & $\begin{array}{l}\text { Designing routines, performing audits, } \\
\text { increasing efficiency (Paper B). } \\
\text { Applying statistical tools (Paper D). } \\
\text { Methods and process skills to drive local } \\
\text { adaptation and quality assurance } \\
\text { (Paper C). } \\
\text { Focus on reducing variation and on cost } \\
\text { (Paper D). } \\
\text { Focus on reproducing existing processes, } \\
\text { practices and tools for resource } \\
\text { efficiency } \\
\text { (Paper E). }\end{array}$ & $\begin{array}{l}\text { Translation and decontextualisation skills in } \\
\text { applying tools. Ability to define needs and } \\
\text { actions in organisations (Paper C). } \\
\text { Embracing new concepts and techniques } \\
\text { (Paper D). } \\
\text { Utilising technology to create new planning } \\
\text { forms and methods (Paper E). }\end{array}$ \\
\hline
\end{tabular}

\subsubsection{Key factors that characterise the nature of quality management work}

It can be concluded that understanding quality management work and competencies requires a more complex and nuanced analysis of how its practices are engaged and enacted. In Subsection 5.1.1 I suggest that two directions of quality management work exist: expansive and adaptive. The key factors that characterise expansive work are: explorative practice, radical change to existing processes or development of new processes, a logic of development, an orientation towards development and innovation, a striving to increase external effectiveness and to increase process variation. The key factors that characterise adaptive work are: exploitative practice, incremental change to existing processes, a logic of performance, an orientation towards goals and productivity, a striving to increase internal efficiency and to decrease process variation.

\subsection{Relationships between quality management competencies and quality management work}

Paper C lists 15 quality management competencies-in-use that have been identified and clustered into four competence dimensions: human competence, methods and process competence, conceptual competence and contextual competence (see Section 4.3, Table 7). Each of these competencies is described in Paper C, but only to the extent that it relates to the role-responsibilities identified by analysing the functional scope and situated range (see Section 4.3, Figure 13). The analysis in terms of role-responsibility is sufficient to identify and describe the key competencies in quality management. However, a more fine-grained analysis, in which the content and process of actions depends more strongly on the directions of quality management work, requires a deeper understanding of the relationships between competencies and actual work in quality management. In this section, the competence dimensions in Paper $\mathrm{C}$ provide a natural starting point for a discussion of the relationships between quality management competencies and quality management work. The discussion revolves around the findings of the five papers, and how these findings can be interpreted using the conceptual framework. For simplicity, the word competence is used interchangeably with the words competence dimensions.

\subsubsection{The importance of contextually dependent separation}

The findings presented in Papers D and E support the idea that successful performance in quality management cannot rest entirely upon a structurally dependent separation (Duncan, 1976; Tushman \& O'Reilly, 1996) between expansive and adaptive quality management work. Furthermore, neither can it rest entirely upon any formalised role separation between internally 
and externally oriented practices, or on any role separation that depends on functional scope. Papers D and E show that quality management work, including modern technical applications such as digital solutions, requires both explorative roles and exploitative roles. Such coexistence of both explorative and exploitative roles would require much more emphasis on managing contextually dependent separation (Gibson \& Birkinshaw, 2004) between expansive and adaptive quality management work than that outlined by, for example, Zhang, Linderman and Schroeder (2012), or Choo, Linderman and Schroeder (2007). An increased contextually dependent separation is in line with the ideas of those who advocate more emergent approaches to quality management practice, such as Backström (2017) and Fundin (2017). These ideas not only presuppose an ability to distinguish between exploitative practices and explorative practices in a specific situation, but also emphasise emergence and the specific tactics to handle key dilemmas in quality management.

I argue that in order for work to be truly emergent, understanding the necessary competencies requires an even more sophisticated approach than simply distinguishing between practices carried out by an individual, or the strategic choice of certain tactics. I argue that directions in quality management work are important, possibly critically important, also on a micro level. In Subsection 5.1.1 it is argued that a more developed understanding of the characteristics of quality management work leads to expansive and adaptive quality management work being found within both explicitly exploitative and explicitly explorative quality management practices. For example, performing an exploitative quality management practice may require contextually dependent separation that includes both expansive and adaptive quality management work. The findings in Paper A concerning modes of learning confirm that alternating expansive and adaptive approaches to micro level work can be present within a practice environment. The paper argues that performing quality management work thus requires that the individual quality management practitioner understands, in a sophisticated manner, the rules, shared understandings and teleo-affective structures in his or her practice environment (Schatzki, 2001; 2005). This is necessary to micromanage contextually dependent separation. A clear understanding of the particular practice environment and how the individual may engage in its practices can be conveyed as an individual awareness of the potential for role dependency.

\subsubsection{Role dependency}

The term role dependency is used in this thesis to emphasise that different roles, or different sets of competencies linked to specific responsibilities, are important when performing quality management work in different situations and contexts. The importance of role-responsibility was one of the key findings of Paper C, while role perspectives are also featured in Papers D and E. On a structural level, the four roles of quality management departments featured in Paper D cover both adaptive and expansive quality management work. Paper D argues that quality management contributions to results depend on role performance, and this means that a role perspective that includes both individual and structural roles is viable when describing the relationships between quality management competencies and quality management work. Paper D further shows that quality management work should allow for a multitude of roles on a structural level, which confirms that context dependency (Sousa \& Voss, 2001; 2002) and contextually dependent separation (Gibson \& Birkinshaw, 2004) are critical in quality management work. On a more individual level, Paper $\mathrm{C}$ shows how competencies are role-dependent by characterising quality management roles according to the dimensions of situated range and functional scope. Paper E describes six roles in quality management work that engage in practices that are either predominantly adaptive or predominantly expansive. The 
findings in Paper C suggest that the relationships between quality management competencies and quality management work can be further understood when role dependency (as an individual or collective potential or capacity) is further deconstructed into two components: role-responsibility and role duality.

\section{Role-responsibility}

Quality management roles are specific sets of bundled practices, each comprising a range of competencies linked to specific role-responsibilities that carry expectations for performing quality management work within specific contexts; see Subsection 2.1.3. Role-responsibilities can be either explicit or implicit and carry practical, normative and socially dependent dimensions of site ontologies (Schatzki, 2001; 2005) that can be used when expressing the particular commitments and obligations linked to each role in a particular organisational context. Paper $\mathrm{C}$ describes the dimensions of functional scope and situated range that allow such roleresponsibilities to be categorised in a manner that can be applied in both micro and meso level contexts. The results presented in Paper E support the idea of such role-responsibilities. If a role-responsibility perspective is applied to the results as presented in Paper E, the roles and their adjoining range of competencies can accommodate flexibility between the choice between exploitative and explorative practices. The additional analysis provided in this thesis shows that this is not exclusive to the context-dependent choice between exploitative or explorative practices (Zhang, Linderman \& Schroeder, 2012), but is valid also for the more emergent perspective of contextually dependent separation between expansive and adaptive quality management work. Paper $\mathrm{C}$ shows that structural factors are important in conditioning the directions of quality management work, which affects the actual and interpreted roleresponsibilities of the individual quality management practitioner. The results presented in Papers C, D and E provides examples how quality management work can facilitate both external effectiveness and internal effectiveness. This emphasises the need to maximise the level of freedom, or discretion, such that quality management practitioners can adopt formal or emergent role-responsibilities that allow contextually dependent separation between expansive and adaptive quality management work.

\section{Role duality}

Difficulties in evaluating which practices are suitable in a particular context and contingency require constant reconfiguration of competencies in the practice environment. The concept of role duality (i.e. the potential or capacity to shift and adapt between existing roles, and the potential to develop new roles with new and emerging practices) is important in the relationships between competencies used in the actual work. Both Papers D and E address the need to constantly analyse processes and their practices in both internal and external contexts. The need to constantly define and re-define practices and their impact on quality management work means that institutionalised learning processes are necessary (Ellström \& Kock, 2008) in the practice environment. Practices, and the competencies needed to perform them, evolve in a process of duality in which the emerging competencies cannot be reduced to their pre-existing components. Consequently, also role duality and the development of expansive quality management work competencies rely on constant learning, facilitated by enabling and supportive learning environments (Coetzer, 2007; Fuller \& Unwin, 2004). The relationship between learning and competencies will be further discussed in Subsection 5.3.2. The understanding of role dependency also includes an awareness of the freedom to select and engage in quality management practices that depend on the situation and task. The ability to do so can be described as degrees of freedom, affordance or discretion (Ellström, 1992; 1997; Gibson, 1979). 


\subsubsection{Discretion}

The management of contextually dependent separation when performing quality management work is conditioned by the ability of the agent to freely select, adopt and engage in practices, depending on the task and situation, i.e. discretion. The level of discretion is directly dependent upon the objective and subjective limitations (Ellström, 1992) that exist in the specific social structure. Objective and subjective limitations thus affect the level of discretion that can be afforded when trying to cope with contextually dependent separation of quality management work. The array of potential objective limitations can be labelled as the structural conditions that has direct and/or indirect impact on the level of discretion (Ellström, 1992;1997). Objective limitations can be either manifest (e.g. explicit rules, actions by other agents or organisation elements) or latent (e.g. implicit rules, norms, assumptions and culture).

The role dependency discussed above (see Subsection 5.2.2) represents a range of practices that is needed to perform according to a particular logic. In adhering to Schatzki $(2001 ; 2005)$, I argue that role dependency, as discussed above in Subsection 5.2.2, is ultimately structurally conditioned by the particular site ontology characterizing the practice environment (Schatzki, 2001 ; 2005) and that this is, in turn, dominated by the ideal logics of either performance and/or development (Ellström, 2006) in the specific organisation. I further argue that the dominating logic constitutes the major structural conditioning element in objective limitations of discretion that relate to contextually dependent separation in quality management work. Following this line of argument, it is also proposed that that the structural conditions for contextually dependent separation should be clearly communicated and described in the officially demanded competencies (or qualifications) of a quality management task or job. This helps in exposing, identifying and addressing the dominating logic allowing for structural and individual aspects of competencies to be better matched.

The importance of the structural conditioning of discretion was also one of the main findings presented in Paper A, when discussing how performance can be measured. Paper A describes how the discretion exercised by the agent when managing the tasks, methods and results affects the type and facets of learning. The results presented in Papers A, D and E show that structural conditions based on the logics of performance and of development (Ellström, 2006) affect the level of discretion differently. Whereas the logic of development accommodates both exploitative and explorative practices (thus also both adaptive and expansive quality management work), the logic of performance limits the potential for explorative practices and expansive quality management work (Table 12). This also shows that the level of agent discretion is critical in order to understand the relationship between quality management competencies and performing successful quality management work.

Table 12. Potential for exploitation and exploration depending on level of agent discretion (adapted from Ellström, 1997, p. 221).

\begin{tabular}{ccc}
\hline Agent discretion & $\begin{array}{c}\text { Potential for } \\
\text { exploitation }\end{array}$ & $\begin{array}{c}\text { Potential for } \\
\text { exploration }\end{array}$ \\
\hline High & Yes & Yes \\
Low & Yes & No \\
\hline
\end{tabular}


The subjective limitations to contextually dependent separation include individual, contingency-based affective factors and more stable personality traits (Ellström, 1992). Temporary psychological states such as mood, fatigue and stress and the psychological effects of temporary physical states such as illness or injury are more contingent and may vary in impact, whereas individual self-efficacy (Bandura, 1977) is perhaps the most critical stable factor, and has the greatest enduring impact on subjective limitations to discretion.

\subsubsection{Summarising the relationship between quality management competencies and performing quality management work}

The discussion on the relationship between quality management competencies and performing quality management work reveals structural and individual aspects that affect the level and nature of contextually dependent separation. These are illustrated in Figure 15.

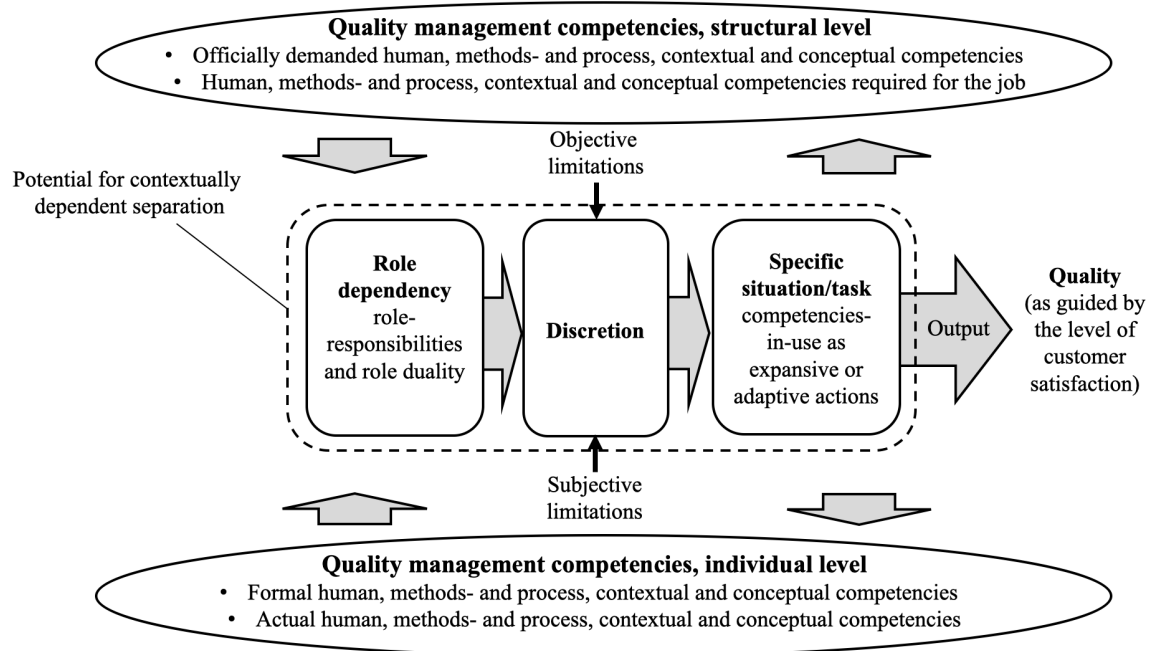

Figure 15. The relationship between quality management competencies and quality management work

The structural and individual aspects of quality management competencies are construed using the four quality management competence dimensions: human competence, methods and process competence, conceptual competence and contextual competence (Paper C). The structural aspects of quality management competencies are conditioned by the social structure that forms the work and practice environment, while individual aspects of quality management competencies are conditioned by the agency (Danermark et al., 2002) representing the individual quality management practitioner. The relationship between quality management competencies and performing quality management work combines the potentials for role dependency and discretion.

The discussion revealed role dependency as one of two basic potentials, or capacities, that may, or may not, realise contextually dependent separation of quality management work. Role dependency consists of role-responsibilities and role duality that are both structurally and individually dependent in order to realise the potential for contextually dependent separation. This relationship between competencies and work also points to a need to understand how of 
competencies interplay in affecting the potential for assuming and developing roleresponsibilities and shifting between needed roles (i.e. role duality).

The discussion also revealed that discretion is another important factor determining the potential for contextually dependent separation. Discretion is moderated by objective limitations and/or subjective limitations. The objective limitations are a consequence of structural conditions, of which the prevailing logic of the site ontology in the practice environment is the most important. The structural conditioning (Archer, 1995) of objective limitations thus affects the perception and interpretation of the role-responsibilities of quality management work. The subjective limitations are a consequence of individual conditions, of which self-efficacy (Bandura, 1977) is the most important.

\subsection{Understanding the interplay between quality management competencies}

Continuous change is a characteristic of quality management (Chapters 1 and 2, and, e.g., Backström, 2017; Fundin, Bergman \& Elg, 2017; Fundin et al., 2018; van Kemenade, 2014; Weckenmann, Akkasoglu \& Werner, 2015; Zhang, Linderman \& Schroeder, 2012). In this section I suggest that change and learning are competence antecedents that signify the nature of the interplay between quality management competencies. The results of the appended papers are interpreted using the concepts and perspectives of the conceptual framework developed in Chapter 2.

\subsubsection{Disposition to change}

'Everything concerning change, that is our main practice'

(Quality manager in a large industrial company)

The ability to change is key in understanding the interplay between the Quality Competence dimensions and the understanding that a disposition to change is a competence antecedent that moderates and conditions the potential and capacity for change in all of the competence dimensions. Paper D describes the importance of managing and leading change processes in quality management. The explorative practices presented in Paper D all include actions and activities that are intended to embrace new concepts and approaches. This is also reflected in Paper $\mathrm{C}$, in which change management forms one of the components of the human competence dimension of quality management. However, the specific potential for change management should not be equated with the broader idea of a disposition to change. This particular potential for change denotes the disposition of an individual to change, but limits itself to the management of change. It follows that reactive management of change does not necessarily require a disposition to change. However, based on the previous discussion, I argue that a disposition to change is crucial in order to instigate change proactively and to subsequently develop and explore whatever the change entails.

Change in a quality management context is strongly imbued by its principles, especially the imperative principle of customer focus (Dean \& Bowen, 1994; Sousa \& Voss, 2001). Paper E addresses quality management roles and practices in environments in which customer focus and the ability to adapt (i.e. change) in response to customers is strongly emphasised. The results show that contextually dependent separation of quality management work is pivotal in a service 
logic approach in which creativity and flexibility in the alignment with customer processes is vital (Grönroos, 2015). Grönroos $(2008 ; 2015)$ goes so far as to state that an alignment of processes with customer processes, with a focus on external effectiveness, will enable processes to develop in a manner that also optimises internal efficiency. External effectiveness, i.e. the measure of producing the right output for customers, or 'doing the right things' (Gupta, Smith $\&$ Shalley, 2006) is, therefore, conceived as the driver of change in any organisation.

This externally oriented view of structural elaboration (Archer, 1995) and this identification of the true driver of change positions quality management work in the front seat as a driver of change. The way in which quality management competencies are transformed into emerging forms of quality management work, balancing both expansive and adaptive quality management, has been described above. Paper E investigates the complexity of managing structural ambidexterity (Benner \& Tushman, 2003) in organising quality management and its practices. The results of Paper $\mathrm{E}$ indicate that a disposition to change can be conceived as a competence antecedent that moderates and affects all other competencies in quality management. Thereby, a disposition to change reflects one aspect of the interplay between quality management competencies and the continuous drive for improvement. Paper B shows that the social structures of quality management, in the form of dual and sometimes conflicting practice environments, can preserve rules, common understandings and teleo-affective structures through structural conditioning (Archer, 1995). The results in Paper B constitute further arguments that the competence antecedent of a disposition to change is important in order to counteract the risk of practice environments stifling development. A disposition to change will reduce this risk, and pave the way for contextually dependent separation by shaping and conditioning all other quality management competencies.

\subsubsection{Learning disposition}

Paper A addresses learning in general and describes how the type of learning depends on the prevalent organisational arrangements and learning environments. As has already been noted, change requires learning, and this is reflected in the fundamentals of organisational change (Van de Ven \& Poole, 1995), the productivity dilemma (Abernathy, 1978; Benner \& Tushman, 2003; 2015), the balance between exploitation and exploration (March, 1991), and the concepts of developmental learning and adaptive learning as two aspects of developing competence (Ellström, 1992; 1997; 2001; 2006; 2010). Change also requires the acceptance of context dependency and a contingency-based view (Sousa \& Voss, 2001). Both Bate, Mendel and Robert (2008) and Bourke and Roper (2017) provide case examples in which the implementation of quality management with a developmental focus created infrastructure on both micro and meso levels to support innovation and learning. Learning in organisations is facilitated by creating learning cultures and communities/environments of learning (Ellström, Ekholm \& Ellström, 2008) with a high degree of discretion over the task, methods and results (Ellström, 1992; 1997).

Developmental learning (Ellström, 2010) is needed to achieve radical change and innovation, and is therefore both a process and an outcome of expansive quality management work. Adaptive learning (Ellström, 2010) is needed to achieve incremental change and innovation, and is therefore both a process and an outcome of adaptive quality management work. The results presented in Paper A reflect this, showing that developmental learning is enabled by agency discretion. Paper $\mathrm{C}$ further examines learning and pedagogy, and presents the competencies-in-use in all four competence dimensions. The role-responsibility approach described in Paper $\mathrm{C}$ enables an analysis of how needed competencies depend on contingency 
and contextual factors. Of particular importance in expansive quality management work is the increased focus on learning about customers that is required in a service logic approach (e.g. Grönroos, 2006; 2008; 2011; 2015), and the need to identify relevant competencies to accommodate this (Vargo \& Lusch, 2004; 2016).

The work presented here thus leads to the proposal that a learning disposition forms a second competence antecedent, in addition to a disposition to change. This disposition shapes and conditions the interplay between the competencies in quality management. Proponents of a service logic approach suggest that a complete organisational alignment is required in order to facilitate customer value-in-use (Grönroos \& Voima, 2013) and to close in on customer processes (Grönroos, 2006). This is echoed in the proposed reorientation to achieve a more informed balance between internal efficiency and external effectiveness in the context separation between expansive and adaptive quality management work in ambidextrous organisations (Backström, 2017; Fundin et al., 2017). Proponents of a service logic approach (Grönroos, 2011; 2015) also acknowledge the importance of creating a learning culture and enabling learning environments (Billett, 2001; Coetzer, 2007; Ellström, 1997; Ellström, Ekholm \& Ellström, 2008; Fuller \& Unwin, 2004). A business culture (Grönroos, 2011; 2015) that closes in on customers thus requires a learning culture. I argue that expansive quality management work is a driver for exploration and developmental learning (Ellström, 2006) and, conversely, adaptive quality management work is a driver for exploitation and adaptive learning. Business cultures that encompass both quality management work directions, while at the same time facilitating both learning types, require not only the competence antecedent of a learning disposition, but also social structures in the form of practice environments that affirm all facets of learning (Paper A). A learning disposition is necessary in order to embrace both quality exploitation and quality exploration (Zhang, Linderman \& Schroeder, 2012), and to achieve a balance between adaptive and developmental learning (Ellström, 2010).

\subsubsection{The interplay between quality management competencies}

The interplay between quality management competencies in quality management work produces combined effects of two competence antecedents: a disposition to change and a disposition to learning. These antecedents precede and moderate all other competencies, and are vital for continuous competence development; see Figure 16.

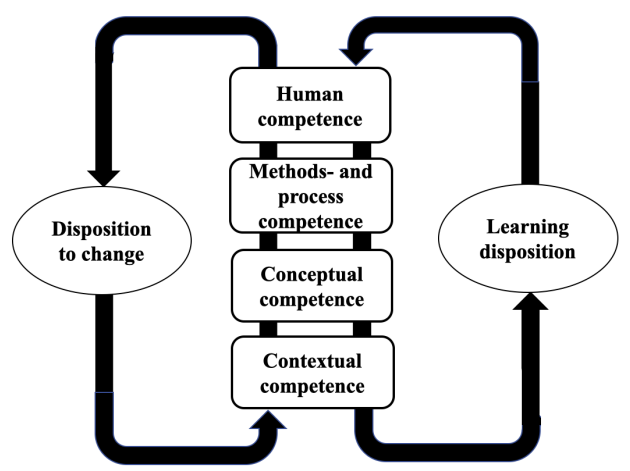

Figure 16. Proposed interplay between quality management competencies due to competence antecedents 
Dispositions to change and learning are also critical components in the concepts of exploitation and exploration (March, 1991), competence theory (Ellström, 1992; 1997; 2001), and the concept of ambidextrous organisations (e.g. Benner \& Tushman, 2003; Gupta, Smith \& Shalley, 2006; O’Reilly \& Tushman, 2013) and a service logic approach (e.g. Grönroos, 2015; Grönroos \& Helle, 2010; 2012). 



\section{CONCLUSIONS, CONTRIBUTIONS AND LIMITATIONS}

The final chapter of the thesis presents general conclusions by compiling the answers to the research questions and addressing the purpose of the thesis. The chapter also briefly discusses and outlines the anticipated contributions to theory and management. The final part of the chapter contains a brief discussion of the limitations of the thesis, together with suggestions for future research.

\subsection{Conclusions}

Quality management has always been changing. The changes conceived in quality management follow an uninterrupted chain of events that has been going on for decades. Change is therefore not new. It is, rather, the basis on which change in quality management is managed that is the novelty presented by this thesis. An underlying rationale that follows from the findings of this thesis is that an improved, theoretically substantiated understanding of what is required to perform quality management work creates not only an organisational readiness to cope with change, but also a willingness to embrace change and make change a true driver of success. In this thesis, two main directions that characterise quality management work have been identified: expansive and adaptive quality management work. Engaging in either expansive or adaptive quality management work entails:

- A balance between quality exploration and quality exploitation.

- A balance between external effectiveness and internal efficiency.

- A balance between best fit and best practice, according to organisational context and the situation and/or task at hand.

The key factors that characterise expansive work are: explorative practice, radical change to existing processes or the development of new processes, a logic of development, an orientation towards development and innovation, a striving to increase external efficiency, and to increase process variation. The key factors that characterise adaptive work are: exploitative practice, incremental change to existing processes, a logic of performance, an orientation towards goals and productivity, a striving to increase internal efficiency, and to decrease process variation. It was suggested that contextually dependent separation of quality management practices facilitates both expansive and adaptive quality management work.

The quality management competencies of human competence, methods- and process competence, conceptual competence and contextual competence are related to quality management work through a combination of role dependency and discretion. Role dependency consists of both role-responsibilities and role duality. Role-responsibilities describe the potential or capacity for quality management practitioners to adopt defined sets of quality management practices in order to engage in quality management work within a given situation, task and/or context. Role duality describes the potential or capacity for the quality management practitioner to shift and adapt between existing roles, while maintaining the potential to develop new roles with new and emerging practices.

Discretion is the 'freedom of movement' for quality practitioners to engage in practices and choose expansive or adaptive quality management work directions according to task and situation. Maximising discretion not only increases the ability for quality management 
practitioners to be both efficient and effective, it also increases the potential for individual competence development. The level of discretion is affected by both organisational circumstances (i.e. objective limitations) and individual circumstances (i.e. subjective limitations). Organisational circumstances (objective limitations) that affect discretion are affected to a large degree by normalised ways of performing quality management, and by existing rules, norms and values within the organisation (i.e. the prevailing logic of the practice environment). Individual circumstances (subjective limitations) that affect discretion are affected to a large degree by individual experience, observation, pressure and psychological states.

The analysis of the relationship between quality management competencies and performing quality management work revealed structural and individual conditioning that affects the level and nature of contextually dependent separation. Structural aspects concern the conditioning by the social structure that forms the work and practice environment. Individual aspects concern the individual quality management practitioner. Both structural conditioning and individual conditioning affect the perception and interpretation of the role-responsibilities of quality management work and, in turn, the way quality management work is performed.

The interplay between quality management competencies in quality management work was explained as the combined effects of two competence antecedents: a disposition to change and learning disposition. It is suggested that these antecedents moderate all other competencies, and are critical not only for individual quality management practitioners, but also for groups of practitioners, in facilitating continuous competence development.

The purpose of this thesis was to explore how the theoretical perspectives of competence and practice can contribute to an increased understanding of what is required to perform quality management work. The thesis distinguishes between expansive and adaptive quality management work, and suggests that competence theory can be used to better understand the process by which quality management practices are selected, adopted and engaged in, in contexts determined by the three quality management orientations described, and by the functional scope. Furthermore, the thesis suggests that competence theory and practice theory contribute to an increased understanding by shedding light on structural and individual conditioning and how competencies are transformed into action in quality management.

The concepts of competence and practice are important components when organising and designing organisations in contingency-based and context-dependent organisational environments. This thesis emphasises how important competence theory and practice theory are in understanding quality management work and the competencies required.

\subsection{Contributions}

This section describes in detail the theoretical and managerial contributions. The thesis has connected quality management to the theoretical perspectives of competence, practice and a social scientific critical realist-based perspective on agency and structure, and thus contributes to a deeper understanding of quality management. In particular, it contributes to our understanding of the requirements to not only select and perform existing quality management practices, but also to adopt and engage in practices in which emergence is accommodated by ambidexterity. A further key theoretical contribution of this thesis is to extend the differentiation between quality exploitation practices and quality exploration practices such that it describes a more emergent perspective on quality management work. 


\subsubsection{Theoretical contributions}

Quality management work requires competencies not only to select and adopt suitable quality management practices, but also to engage in any kind of quality management practice in two significantly different ways, or directions. It is, therefore, a main conclusion of this thesis that quality management work is not limited to selecting either quality exploitation or quality exploration practices. It is necessary that quality management practitioners have competencies that enable them to work in either expansive or adaptive directions with any kind of quality management practice. These more advanced conceptions of quality management practice and quality management work cannot be adequately anticipated and planned for, which means that competencies are needed that not only allow but also encourage change and emergence in quality management. The most important theoretical contributions are thus the following:

- The findings add to findings from the few previous studies that have adopted competence and practice perspectives on quality management (e.g. Ingason \& Jonsdottír, 2017), thereby contributing to an increased general conceptual understanding of quality management.

- The findings extend research that has focussed on roles and practices in quality management (Dahlgaard et al., 1998; Chen, Paetsch \& Paulraj, 1997; Elg, Gremyr, Hellström \& Witell, 2011; Evans, 2013; Fundin, Bergman \& Elg, 2017; Flynn, Schroeder \& Sakakibara, 1994; Larson, 1998; Kim, Kumar \& Kumar, 2012; Saraph, Benson \& Schroeder, 1989; Stratton, 1996; Wadell \& Stewart, 2004; Zu, 2009). In particular, the results extend knowledge about explorative and exploitative quality management practices (e.g. Backström, 2017; Benner \& Tushman, 2003; 2015; Fundin et al., 2017; Fundin et al., 2018; Zhang, Linderman \& Schroeder, 2012).

- The findings provide an example of how perspectives on competence theory and practice theory can be used, with the social scientific perspective of critical realism as a methodological premise. The structure and agency perspective in critical realism provides aspects of both competence theory and practice theory that contribute to an extended understanding of how structural constructs of competence relate and interact with individual constructs of competence, and how competencies transform into action in specific situations. This may be useful knowledge to scholars of both competence theory and practice theory.

\subsubsection{Contributions to management}

The work presented here suggests that in order for managers and supporting functions to proactively manage organisational change as dictated by external influences (such as markets, business, globalisation, digitalisation, legislation and societal change), an extended practical understanding of management concepts is vital. This includes an understanding of quality management. The thesis extends our understanding of how the required competencies interact and relate in quality management work, and it provides both a rationale and ideas for developing and improving practices. By defining practices, characterising competencies and identifying how these competencies transform into action, this thesis provides intellectual tools that can be used by, for example, managers and HR practitioners, to design and organise quality management. In particular, it provides a theoretically grounded analysis that contributes to the concept of competence within professional bodies of knowledge in quality management (e.g. ASQ, EFQM, JUSE, and SIQ). The most important contributions to management are as follows: 
- The results provide tools for organising and developing quality management and its practitioners in organisations. As such, HR practitioners, quality management practitioners and management representatives can use the results to develop organisations and policy, in recruitment, talent mapping and training, and to develop education.

- The results provide a deeper understanding of the nature of quality management, and allow the emergent development and adoption of quality management practices. The thesis argues that organisations that facilitate contextually dependent separation of quality management work are better prepared to accommodate change and development. This will have implications for both leadership, management and training. The understanding of the role of quality management as a driver for change contributes to the ability of management to develop better business and management strategies and make more accurately informed choices of strategy.

\subsection{Limitations and further research}

This thesis is one of the first attempts to link the theoretical perspectives of competence and practice to quality management. Some limitations became evident during the work and in this section I discuss two main areas of these; methodology and conceptual framework. Also, in the discussion on limitations, some guidance and suggestions for further research are proposed.

\subsubsection{Methodology}

The first area of limitation concerns methodology. The sampling used for the data collection suffers from limitations. In Paper A, the organisational context and sample of interviewees were specific and narrow. In Papers B, C and E, a broad range of organisations was studied, and the sampling of respondents, in both the survey studies and the interview studies, may have been somewhat biased. Adding managerial perspectives and/or other empirical perspectives would have improved the analysis and findings. Further, the range of operational context (i.e. empirical context) was limited. These limitations lead to the suggestion that further studies should be conducted, including smaller organisations (e.g. small and medium-sized enterprises $(\mathrm{SMEs})^{25}$. Such studies could also include managerial perspectives, to complement the work presented here. Certainly, widening the operational context of the sample of organisations would benefit further research.

Furthermore, the range of designs could be extended in future work. It has already been discussed how ethnographic approaches, including observation studies, could strengthen the findings presented. Also, by reinforcing the analysis on meso and macro levels, case-study designs would complement and give additional perspectives on competence in and between different case contexts. The temporal nature of the studies in this thesis makes longitudinal comparisons difficult, and more long-term studies and an examination of the development of competencies over time would greatly contribute to the knowledge presented in this thesis.

\footnotetext{
${ }^{25}$ The definition of what constitutes an SME differs between regions but the definition of an SME used in Europe is one having less than 250 employees and an annual turnover below EUR 50 million (European Commission, 2016).
} 


\subsubsection{Conceptual framework}

The second area of limitation concerns the conceptual framework. The selection of theoretical perspectives in the thesis represent only a fraction of the many possible perspectives available on the knowledge of reality. Van de Ven (2013) advocates a pluralistic view in the use of theoretical perspectives, and the choice of an abductive research strategy was an attempt to adopt this view. The use of only two main theoretical perspectives can, perhaps, be considered an overly meagre approach, and it is possible that adding more and different sets of theoretical perspectives with other research strategies would have added further valuable knowledge to the knowledge gathered during the work. In accordance with the critical realist view of this thesis, there will always be a hierarchy of explanations - some are better than others. It is, therefore, suggested that further studies be carefully analysed, and that they adopt theoretical perspectives that best contribute to further knowledge.

Theoretical perspectives and concepts that are candidates for further abductive analysis include theoretical perspectives on innovation and entrepreneurship in order to analyse sources and modes of change in organisations. Linked to innovation, theory and research within project management may be a valuable complement to an innovation perspective. Another theoretical field of interest is leadership. Leadership has only been addressed in indirect terms and the role of leadership as a driver of quality management (e.g. Samson \& Terziovski, 1999) has been beyond the scope of this thesis. Further studies on competencies in quality management may thus benefit from including data on leadership and leadership theory in an extended analysis. Finally, different forms of learning have not been extensively discussed in this thesis. Expanding the theoretical perspective of learning, and examining in detail the inner workings of different learning perspectives might also be useful in further research on competence and competence development. This latter suggestion would also naturally link to the research field of human resource development [HRD], which has not been elaborated or discussed in this thesis. 


\section{REFERENCES}

Abernathy, W. J. (1978), The productivity dilemma: Roadblock to innovation in the automobile industry, Johns Hopkins University Press: Baltimore.

Addey, J. (2004), 'The Modern Quality Manager', Total Quality Management, Vol. 15 No. 5-6, pp. 879 - 889.

Agaard Nielsen, K., and Svensson, L. (2006), Action and Interactive research - Beyond Practice and Theory, Shaker Verlag: Maastricht.

Ahire, S. L., Landeros, R., and Golhar, D. Y. (1995), 'Total Quality Management: a literature review and an agenda for future research', Production and Operations Management, Vol. 4 No. 3, pp. 277 - 306

Albacete-Sáez, C. A., Fuentes-Fuentes, M. M., and Bojica, A. M. (2011), 'Quality management, strategic priorities and performance: the role of quality leadership', Industrial Management \& Data Systems, Vol. 111 No. 8, pp. 1173 1193.

Ali, F. Jain, R., Ali, L., and Munir, K. (2017), 'The Effects of Quality Practices on the Performance Measurement of Business Management', Journal of Advanced Management Science, Vol. 5 No. 6, pp. 440 - 444.

Alvesson, M. (2014), Kommunikation, makt och organisation, närläsning och multipla tolkningar, Studentlitteratur AB: Lund.

Alvesson, M., and Sköldberg, K. (2009), Tolkning och reflek.tion. Vetenskapsfilosofi och kvalitativ metod, Studentlitteratur AB: Lund.

Alvesson, M., and Willmott, H. (1992), 'On the idea of emancipitation in management and organization studies' Academy of Management Review, Vol. 17 No. 3, pp. 432 - 464.

Antony, J. (2013), 'What does the future hold for quality professionals in organizations of the twenty-first century?', The TQM Journal, Vol. 25 Iss. 6, pp. 677 - 685.

Antony, J. (2015), 'The ten commandments of quality: A performance perspective', International Journal of Productivity and Performance Management, Vol. 64 No. 5, pp. 723 - 735.

Anttila, J., and Jussila, K. (2017), 'Understanding quality -conceptualization of the fundamental concepts of quality', International Journal of Quality and Service Sciences, Vol. 9 No. 3/4, pp. $251-268$.

Archer, M. S. (1995), Realist social theory: the morphogenetic approach, Cambridge University Press: New York.

Archer, M. S. (1998), 'Introduction'. In Archer, M. S., Bhaskar, R., Collier, A., Lawson, T., and Norrie, A. (Eds.), Critical Realism. Essential Readings, Routledge: London, pp. ix - xxiv.

Archer, M. S. (2008), Realist Social Theory: The Morphogenetic Approach, Cambridge University Press: Cambridge, UK.

Argyris, C., and Schön, D. A. (1974), Theory in practice: Increasing professional effectiveness, Jossey Bass: San Francisco, CA.

Aristotle (2012). Den Nikomachiska etiken (M. Ringblom, transl.), (3.ed.). Daidalos AB: Gothenburg.

ASQ (2015), 2015 Future of quality report. Quality throughout (report from ASQ, American Society for Quality). Wisconsin: ASQ.

ASQ (2015b), Guide to the quality body of knowledge (QBOK) Version 2.0, Wisconsin: ASQ.

Atkinson, P., and Coffey, A. (2003), 'Revisiting the relationship between participant observation and interviewing'. In Gubrium, J. F., and Holstein, J. A. (Eds), Postmodern Interviewing, SAGE Publications: Thousand Oaks, CA, pp. $109-22$

Atkinson, P., Coffey, A., and Delamont, S. (2003), Key Themes in Qualitative Research. Continuities and Change, Alta Mira Press: Walnut Creek, CA.

Backström, T. (2017), 'Solving the Quality Dilemma: Emergent Quality Management'. In Backström, T., Fundin, A., and Johansson, P. E. (Eds.), Innovative Quality Improvements in Operations. Introducing Emergent Quality Management, Springer: Cham, pp. $151-167$.

Bandura, A. (1977), 'Self-efficacy: Toward a Unifying Theory of Behavioral Change', Psycholocical Review, Vol. 84 No. 2 , pp. $191-215$.

Barnes, J. (1995), The Cambridge Companion to Aristotle, Cambridge University Press: Cambridge.

Bartram, D. (2005), 'The Great Eight Competencies: A Criterion-Centric Approach to Validation', Journal of Applied Psychology, Vol. 90 No. 6, pp. 1185 - 1203.

Bate, P., Mendel, P., and Robert, G. (2008), Organizing for Quality, the improvement journeys of leading hospitals in Europe, and the United States, CRC Group: Boca Raton, FL.

Benner, M. J., and Tushman, M. L. (2003), 'Exploitation, exploration, and process management: The productivity dilemma revisited', Academy of Management Review, Vol. 28 No. 2, pp. 238 - 256.

Benner, M. J., and Tushman, M. L. (2015), 'Reflections on the 2013-decade award: 'Exploitation, exploration, and process management: The productivity dilemma revisited', Academy of Management Review, Vol. 40 No. 4, pp. 238 -256 .

Bergman, B., and Klefsjö, B. (2010), Quality. From Customer Needs to Customer Satisfaction (3d ed.), Studentlitteratur AB: Lund.

Bhaskar, R. (1978), A Realist Theory of Science, Harvester: Hemel Hempstead.

Bhaskar, R. (1998), The Possibility of Naturalism, Routledge: London.

Billett, S. (2001), 'Learning Through Work: Workplace Affordances and Individual Engagement', Journal of Workplace Learning, Vol. 13 No. 5, pp. $209-214$. 
Björklund, L. (2013), 'Why Do They Not See What I See?: The Difference Between Knowing How and Knowing That'. In Middleton, H., and Baartman, L. K. J. (Eds.), Transfer, Transitions and Transformations of Learning (Vol. 11). Sense Publishers: Rotterdam, pp. 149 - 168.

Björklund, L. (2014), 'Att medvetandegöra det omedvetna: de fyra F-n och andra kunskapsbegrepp i skola och forskning om lärande’. In Wedin, A-S., Markström, A-M., and Hellberg, K. (Eds.), Dynamiska och komplexa miljöer: reflektioner över pedagogiska praktiker. LiU-tryck: Linköping, pp. 1 - 11.

Bourdieu, P. (1977), Outline of a theory of practice, Cambridge University Press: Cambridge.

Bourke, J., and Roper, S. (2017), 'Innovation, quality management and learning: Short-term and longer-term effects', Research Policy, Vol. 46 Iss. 8, pp. $1505-1518$.

Boyatzis, R. E. (1982), The Competent Manager: A Model for Effective Performance, John Wiley and Sons, Inc.: New York.

Brown, J. S., Collins, A., and Duguid, S. (1989), 'Situated cognition and the culture of learning', Educational Researcher, Vol. 18 No. 1, pp. $32-42$.

Bryman, A., and Bell, E. (2015), Business research methods (4th ed.), Oxford University Press: Oxford, UK.

Buckley, W. (1967), Sociology and Modern Systems Theory, Prentice Hall: Upper Saddle River, NJ.

Bunge, M. (1979), Causality and modern science, Dover Classics: New York.

Bunge, M. (1993), 'Realism and Antirealism in Social Science', Theory and Decision, Vol. 35 No. 3, pp. 207 - 235.

Burcher, P. G., Lee, G. L., and Waddell, D. (2008), 'The challenges for quality managers in Britain and Australia', Total Quality Management, Vol. 20 No.1, 45 - 58.

Burrell, G., and Morgan, G. (1979), Sociological paradigms and organizational analysis, Routledge: London.

Campbell, D.T., and Stanley, J.C. (1966), Experimental and Quasi Experimental Designs, Rand McNally: Chicago, Ill.

Campbell, J. L., Quincy, C., Osserman, J., and Pedersen, O.K. (2013), 'Coding In-depth Semistructured Interviews: Problems of Unitization and Intercoder Reliability and Agreement', Sociological Methods \& Research, Vol. 42 No. 3, pp. $294-320$.

Cheetham, G., and Chivers, G. (1996), 'Towards a holistic model of professional Competence', Journal of European Industrial Training, Vol. 20 No. 5, pp. $20-30$.

Cheetham, G., and Chivers, G. (1998), 'The reflective (and competent) practitioner: a model of professional competence which seeks to harmonise the reflective practitioner and competence-based approaches.', Journal of European Industrial Training, Vol. 22 No. 7, pp. 267 - 276.

Chen, I. J., Paetsch, K. A., and Paulraj, A. (1997), 'Quality manager involvement and quality performance', International Journal of Operations \& Production Management, Vol. 17 No. 4, pp. 399 - 412.

Choo, A. S., Linderman, K. W., and Schroeder, R. G. (2007), 'Method and context perspectives on learning and knowledge creation in quality management', Journal of Operations Management, Vol. 25, pp. 918 - 931.

Coetzer, A. (2007), 'Employee perceptions of their workplaces as learning environments', Journal of Workplace Learning, Vol. 19 No. 7, pp. $417-434$.

Cole, R. E., and Matsumiya, T. (2007), ‘Too much of a good thing? Quality as an impediment to innovation', California Management Review, Vol. 50 No. 1, pp. 77 - 93.

Collier, A. (1994), Critical Realism: An Introduction to Roy Bhaskar's Philosophy, Verso: Michigan, Ill.

Cornelissen, J. P., and Durand, R. (2014), 'Moving forward: Developing Theoretical Contributions in Management Studies', Journal of Management Studies, Vol. 51 No. 6, pp. 995 - 1022.

Cronbach, L. J., and Meehl, P. E. (1955), "Construct validity in psychological tests". Psychological Bulletin, Vol. 52 No. 4 , pp. $281-302$.

CQI (2018), The quality profession, driving organisational excellence. Retrieved April 15, 2018 from https://www.quality.org/knowledge/cqi-competency-framework.

Dahlgaard-Park, S. M. (2011), 'The quality movement: where are you going?', Total Quality Management, Vol. 22 No. 5 , pp. $493-516$.

Dahlgaard, J. J., Kristensen, K., Kanji, G. K., Juhl, H. J., and Sohal, A. S. (1998), 'Quality management practices: a comparative study between East and West', International Journal of Quality \& Reliability Management, Vol. 15 No. $8-9$, pp. $812-826$.

Danermark, B., Ekström, M., Jakobsen, L., and Karlsson, J. Ch. (2002), Explaining Society: Critical realism in the social sciences, Routledge: London.

Dean, J. W., and Bowen, D. E. (1994), 'Management theory and total quality: improving research and practice through theory development', Academy of Management Review, Vol. 19 No. 3, pp. 392 - 418.

Delamare Le Deist, F., and Winterton, J. (2005), 'What Is Competence?', Human Resource Development International, Vol. 8 Iss. 1 , pp. $27-46$.

Deming, W.E. (1986), Out of the crisis, Massachusetts Institute of Technology: Cambridge, MA.

Dreyfus S. E., and Dreyfus, H. L. (1980), A five-stage model of the mental activities involved in directed skill acquisition (University of California Report, ORC 80-2). University of California, Operations Research Center: Berkeley, CA.

Duncan, R. B. (1976), 'The ambidextrous organization: Designing dual structures for innovation'. In Kilmann, R. H., Pondy, L. R., and Slevin, D. (Eds.), The management of organization design: Strategies and implementation, North Holland: New York, pp. $167-188$.

Easton, G. (2010), 'Critical realism in case study research', Industrial Marketing Management, Vol. 39, pp. 118 - 128. 
Edvardsson, B., Tronvoll, B., and Gruber, T. (2011), 'Expanding understanding of service exchange and value cocreation: a social construction approach', Journal of the Academy of Marketing Science, Vol. 39 No. 2, pp. 327 - 39.

Eisenhardt, K. M. (1989), 'Building Theories from Case Study Research', The Academy of Management Review, Vol. 14 No. 4, pp. $532-50$.

Elg, M., Gremyr, I., Hellström, A., and Witell, L. (2011), 'The role of quality managers in contemporary organizations', Total Quality Management, Vol. 22 No. 8, pp. 795 - 806.

Elg, M., Birch-Jensen, A., Gremyr, I., Martin, J., and Melin, U. (2019), 'The Role of Quality Management in an Era of Digitalisation'. Revised version of paper presented at the 21 ${ }^{\text {st }}$ QMOD-ICQSS conference, Cardiff, UK, 2018. Working paper.

Ellström, P-E. (1992), Kompetens, utbildning och lärande i arbetslivet, Nordstedts Juridik: Stockholm.

Ellström, P-E. (1997), 'The many meanings of occupational competence and qualification', Journal of European Industrial Training, Vol. 21 No. 6/7, pp. $266-273$.

Ellström, P-E. (2001), 'Integrating Learning and Work: Problems and Prospects', Human Resource Development Quarterly, Vol. 12 No. 4, pp. $421-435$.

Ellström, P-E. (2006), 'Two logics of learning'. In Antonacopoulou, E. P., Jarvis, P., Andersen, V., Elkjaer, B., and Høyrup. S. (Eds.), Learning, Working and Living. Mapping the Terrain of Working Life Learning, Palgrave Macmillan: New York, NY, pp. $33-48$.

Ellström, P-E. (2010), 'Organizational Learning'. In Peterson, P., Baker, E., and McGaw, B. (Eds.), International Encyclopedia of Education, Vol. 1, Elsevier: Oxford, pp. 47 - 52.

Ellström, P-E. (2011), 'Informal Learning at Work: Conditions, Processes and Logics'. In Malloch, M., Cairns, L., Evens, K., and O'Connor, B. N. (Eds.), The SAGE handbook of Workplace Learning, SAGE Publications, Inc., Thousand Oaks, CA., pp. $105-119$.

Ellström, P-E., and Kock, H. (2008), 'Competence Development in the Workplace: Concepts, Strategies and Effects', Asian Pacific Education Review, Vol. 9 Iss. 1, pp. 5 - 20.

Ellström, E., Ekholm, B., and Ellström, P-E. (2008), 'Two Types of Learning Environment: Enabling and Constraining. A Study of Care Work'. Journal of Workplace Learning, Vol. 20 No. 2, pp. $84-97$.

Epstein, R. M., and Hundert, E. M. (2002), 'Defining and assessing professional competence', JAMA: The Journal of the American Medical Association, Vol. 287 No.2, pp. 226 - 235.

Eraut, M. (1998), 'Concepts of competence’, Journal of Interprofessional Care, Vol. 12 No. 2, pp. 127 - 139.

Eraut, M. (2000), 'Non-formal learning and tacit knowledge in professional work', British Journal of Educational Psychology, Vol. 70, pp. $113-136$.

Eriksson, H., Gremyr, I., Bergquist, B., Garvare, R., Fundin, A., Wiklund, H., Wester, M., and Sörqvist, L. (2016), 'Exploring quality challenges and the validity of excellence models', International Journal of Operations \& Production Management, Vol. 36 Iss. 10, 1201 - 1221.

European Commission (2016), Annual report on European SMEs 2015/2016, SME recovery continues (European Commission report, EASME/COSME/2015/012), Brussels: European Commission.

Evans, J. R. (2013), 'Insights on the Future of Quality Management Research', Quality Management Journal, Vol. 20 No. 1, pp. $48-55$.

Evans, J. R. Foster, T. S., and Linderman, K. (2014), 'A Content Analysis of Research in Quality Management and a Proposed Agenda for Future Research', Quality Management Journal, Vol. 21 No. 2, pp. 17 - 44.

Evans, J. R., and Lindsay, W. M. (2011), Managing for quality and performance excellence (9th ed.), South Western Educational.: Mason, $\mathrm{OH}$.

Evetts, J. (2003), 'The Sociological Analysis of Professionalism. Occupational Change in the Modern World. International Sociology, Vol. 18 No. 2, pp. $395-415$.

Firestone, W. A. (1993), ‘Alternative arguments for generalizing from data as applied to qualitative research', Educational Researcher, Vol. 22 No. 4, pp. $16-23$.

Fleetwood, S. (2004), 'An ontology for organization and management studies'. In Fleetwood, S., and Ackroyd, S. (Eds.), Critical Realist Applications in Organization and Management Studies, Routledge: Oxon, UK, pp. 27 - 53

Fleetwood, S. (2005), 'Ontology in Organization and Management Studies: A Critical Realist Perspective', Organization, Vol. 12 No. 2, pp. $197-222$.

Flanagan, J. C. (1959), 'The critical incident technique', Psychological Bulletin, Vol. 51 No. 4, pp. 327 - 358.

Flynn, B. B., Schroeder, R. G., and Sakakibara, S. (1994), 'A framework for Quality Management research and an associated measurement instrument', Journal of Operations Management, Vol. 11 No. 4, pp. 339 - 366.

Fuller, A., and Unwin, L. (2004), 'Expansive Learning Environments: Integrating Organizational and Personal Development'. In Rainbird, H., Fuller, A., and Munro, A. (Eds.), Workplace Learning in Context, Routledge: London, pp. $126-144$.

Fundin, A. (2017), 'Strategies for emergent quality improvement'. Paper presented at the Participatory Innovation Conference (PIN-C) 2018 conference, Eskilstuna, Sweden.

Fundin, A., Bergman, B., and Elg, M. (2017), 'The Quality Dilemma: Combining Development and Stability'. In Backström, T., Fundin, A., and Johansson, P. E. (Eds.), Innovative Quality Improvements in Operations. Introducing Emergent Quality Management, Cham: Springer, pp. 9 - 33. 
Fundin, A., Bergquist, B., Eriksson, H., and Gremyr, I. (2018), 'Challenges and propositions for research in quality management', International Journal of Production Economics, Vol. 199, pp. 125 - 137.

Gibson, J. J. (1979), The Ecological Approach to Visual Perception, Houghton Mifflin: Boston.

Gibson, C. B., and Birkinshaw, J. (2004), 'The antecedents, consequences, and mediating role of organizational ambidexterity', Academy of Management Journal, Vol. 47 No. 2, pp. 209 - 226.

Giddens, A. (1979), Central Problems in Social Theory, University of California Press: Berkeley.

Giddens, A. (1984), The constitution of society, University of California Press: Berkeley.

Giere, R. N. (1997), Understanding scientific reasoning (4th ed.), Harcourt Brace: New York.

Goetsch, D. L., and Davis, S. B. (2006), Quality Management: Introduction to Total Quality Management for Production, Processing and Services (5th ed.), Pearson-Prentice-Hall: Englewood Cliffs, NJ.

Gregor, S., and Hevner, A.R. (2013), 'Positioning and Presenting Design Science Research for Maximum Impact', Management Information Systems Quarterly, Vol. 37 No. 2, pp. 337 - 355.

Gremyr, I., Elg, M., Hellström, A., Martin, J., and Witell, L. (2019), 'The roles of Quality Departments and their Influence on Business Results', Total Quality Management \& Business Excellence. In press. DOI: 10.1080/14783363.2019.1643713

Grönroos, C. (1984), 'A Service Quality Model and its Marketing Implications', European Journal of Marketing, Vol. 18 Iss. 4 , pp. $36-44$.

Grönroos, C. (1999), 'Relationship marketing. Challenges for the organization', Journal of Business Research, Vol. 43 No. 3 , pp. $327-335$.

Grönroos, C. (2006), 'Adopting a service logic for marketing', Marketing Theory, Vol. 6 No. 3, pp. 317 - 333.

Grönroos, C. (2008), 'Service logic revisited: who creates value? And who co-creates?', European Business Review, Vol. 20 No. 4, pp. $298-314$.

Grönroos, C. (2011), 'Value co-creation in service logic: A critical analysis', Marketing Theory, Vol. 11 No. 3, pp. 279 310.

Grönroos, C. (2015), Service Management and Marketing. Managing the Service Profit Logic, Wiley \& Sons: Chichester, UK.

Grönroos, C., and Helle, P. (2010), 'Adopting a Service Logic in Manufacturing: Conceptual Foundation and Metrics for Mutual Value Creation', Journal of Service Management, Vol. 21 No. 5, pp. 564 - 590.

Grönroos, C., and Helle, P. (2012), 'Return on relationships: conceptual understanding and measurement of mutual gains from relational business engagements', Journal of Business \& Industrial Marketing, Vol. 27 No. 5, pp. 344 359 .

Grönroos, C., and Voima, P. (2013), 'Critical service logic: making sense of value creation and co-creation', Journal of the Academy Marketing Science, Vol. 41 No. 1, pp. 133 - 150.

Guba, E. G., and Lincoln, Y. S. (1994), 'Competing paradigms in qualitative research'. In Denzin, N. K., and Lincoln, Y. S. (Eds.), Handbook of qualitative research, SAGE Publications: New York, pp. $105-117$.

Gupta, A. K., Smith, K. G., and Shalley, C. E. (2006), 'The interplay between exploration and exploitation', The Academy of Management Journal, Vol. 49 No. 4, pp. $693-706$.

Habermas, J. (1972), Knowledge and human interests, Heinemann: London, UK.

Hammersley, M. (2008), Questioning Qualitative Inquiry, SAGE Publications: London.

Hellsten, U., and Klefsjö, B. (2000), 'TQM as a management system consisting of values, techniques and tools', The TQM Journal, Vol. 12 No. 4, pp. 238 - 244.

Hodson, R., and Sullivan T. A. (2007), The Social Organization of Work, Wadsworth Publishing: Belmont, CA.

Hultman, G. (2001), Intelligenta improvisationer. Om lärares kunskapsbildning och skolans kulturer, Studentlitteratur AB: Lund.

Illeris, K. (2013), Kompetens: vad, varför, hur, Studentlitteratur AB: Lund.

Ingason, H. T., and Jónsdóttir, E. R. (2017), 'The house of competence of the quality manager', Cogent business \& management, Vol. 4 No. 1 , pp. $1-15$.

Ismail, S., and Maling, E. (2002), 'An investigation of the total quality management survey-based research published between 1989 and 2000', International Journal of Quality and Reliability Management, Vol. 19 No. 7, pp. 902 - 970.

ISO (2015), ISO 9001:2015: Quality Management Systems - Requirements.

Johansen, R. B., Laberg, J. C., and Martinussen, M. (2014), 'Military Identity as Predictor of Perceived Military Competence and Skills', Armed Forces \& Society, Vol. 40 No. 3, pp. $521-543$

Johnson, J. M. (2003), 'In-depth interviewing'. In Gubrium, J. J., and Holstein, J. A. (Eds), Handbook of Interview Research. Context and Method. SAGE Publications: Thousand Oaks, CA, pp. $103-20$.

Kaynak, H. (2003), 'The relationship between total quality management practices and their effects on firm performance', Journal of Operations Management, Vol. 21 No. 4, pp. 405 - 35.

van Kemenade, E. (2014), 'Theory C: the near future of Quality Management', The Total Quality Management Journal, Vol. 26 No. 6, pp. $650-657$.

Kim, D-Y., Kumar, V., and Kumar U. (2012), 'Relationship between management practices and innovation', Journal of Operations Management, Vol. 30 No. 1, pp. 295 - 315.

van der Klink, M. R., and Boon, J. (2003), 'Competencies: the triumph of a fuzzy concept', International Journal of Human Resources Development and Management, Vol. 3 Iss. 2, pp. 650 - 657.

Kuhn, T. S. (1979), The structure of scientific revolutions, University of Chicago Press: Chicago. (originally published in 1962). 
Kumar, V., de Grosbois, D., Choisne, F., and Kumar, U. (2008), 'Performance measurement by TQM adopters', The TQM Journal, Vol. 20 Iss. 3, pp. 209 - 222.

Kurz, R., and Bartram, D. (2002), 'Competency and individual performance: Modeling the world of Work'. In Robertson, I. T., Callinan, M., and Bartram, D. (Eds.). Organizational effectiveness: The role of psychology. Wiley: Chichester, pp. $227-255$.

Lakshman, C. (2006), 'A theory of leadership for quality: lessons from TQM for leadership theory', Total Quality Management \& Business Excellence, Vol. 17 No. 1, pp. 41 - 60.

Lane, I. F. (2010), 'Professional competencies in health sciences education: from multiple intelligences to the clinic floor', Advances in Health Sciences Education, Vol. 15 Iss. 1, pp. 129 - 146.

Larson, M. (1998), 'Quality professionals cope with changing roles', Quality Progress, Vol. 37 No. 1, pp. 35 - 42.

Leach, D. C. (2002), 'Competence is a habit', JAMA: The Journal of the American Medical Association, Vol. 287 No. 2, pp. $243-244$.

Lindberg, O., and Rantatalo, O. (2014), 'Competence in professional practice: A practice theory analysis of police and doctors', Human Relations, Vol. 68 No. 4, pp. 561 - 582.

Linderman, K., Schroeder, R. G., Zaheer, S., Liedtke, C., and Choo, A. S. (2004), 'Integrating quality management practices with knowledge creation processes’, Journal of Operations Management, Vol. 22 No. 1, pp. 589 - 607.

Lo, C. K. Y., and Yeung, A. C. L. (2018), 'Quality management standards, institutionalization and organizational implications: A longitudinal analysis', International journal of Production Economics, Vol. 200, pp. 231 - 239.

Maguad, B. A. (2006), 'The modern quality movement: Origins, development and trends', Total Quality Management \& Business Excellence, Vol. 17 No. 2, pp. 179 - 203.

March, J. G. (1991), 'Exploration and exploitation in organizational learning', Organization Science, Vol. 2 No. 1, pp. 71 $-87$.

Martin, J., Elg, M., and Gremyr, I. (2019), 'Fit for purpose? Exploring competence in quality management', International Journal of Quality and Service Sciences, Vol. 11 No. 3, pp. 317 - 333.

Martin, J., Elg, M., Gremyr, I., and Wallo, A. (2019), 'Towards a quality management competence framework: exploring needed competencies in quality management', Total Quality Management and Business Excellence. In press. DOI: 10.1080/14783363.2019.1576516.

Martin, J., Elg, M., Wallo, A., and Kock, H. (2018), 'Four facets of learning in performance measurement', International Journal of Productivity and Performance Measurement, Vol. 67 No. 9, pp. 1608 - 1624.

Mathieu, V. (2001), 'Product services: from a service supporting the product to a service supporting the client', Journal of Business \& Industrial Marketing, Vol. 16 No. 1, pp. 39 - 58.

McClelland, D.C. (1973), 'Testing for Competence Rather Than for 'Intelligence', American Psychologist, Vol. 28 No. 1, pp. $1-14$.

Merriam, S. B. (2009), Qualitative Research: A Guide to Design and Implementation, Jossey-Bass: San Francisco, CA.

Miles, M. B., and Huberman, A.M. (1994), Qualitative Data Analysis, An Expanded Sourcebook. (2nd ed.), Thousand Oaks, CA: SAGE Publications.

Miles, M. B., Huberman, A. M., and Saldaña, J. (2014), Qualitative Data Analysis. A Methods Handbook, SAGE Publications: Thousand Oaks, CA.

Moorman, M. A., and Kreitman, K.B. (1997), 'The 21st Century Organization: What It Will Look Like and How to Make It Happen’. Available at http://www.well.com/user/kbk/AQPPPR.html (downloaded 17 May 2019).

Morais, R. (2011), 'Critical realism and case studies in international business research'. In Piekkari, R., and Welch, C. (Eds.), Rethinking the Case Study in International Business and Management Research, Edward Elgar: Cheltenham.

Motwani, J. (2001), 'Critical factors and performance measures of TQM', The TQM Magazine, Vol. 13 No. 4, pp. 292 300.

Nunnally, J. C., and Bernstein, I. H. (1994), Psychometric theory, McGraw Hill: New York.

Okasha, S. (2002), Philosophy of Science. A Very Short Introduction, Oxford University Press: Oxford, UK.

Parasuraman, A., Zeithaml, V. A., and Berry, L. L. (1985), 'A Conceptual Model of Service Quality and Its Implications for Future Research', Journal of Marketing, Vol. 49 No. 4, pp. 41 - 50.

Parviainen, P., Tihinen, M., Kääriäinen, J., and Teppola, S. (2017), 'Tackling the digitalization challenge: how to benefit from digitalization practice', International Journal of Informations Systems and Project Management, Vol. 5 No. 1, pp. 63 -76 .

Patton, M. Q. (2015), Qualitative Research \& Evaluation Methods (4th ed.), SAGE Publications: Thousand Oaks, CA.

Peirce, C. S. (1931-1958), 'Collected papers Vol. II'. In Hartshorne, C., Weiss, P., and Burkes, A. (Eds.), Collected Papers of Charles Sanders Peirce, Harvard University Press, Cambridge, MA. pp. 619 - 644.

Pettigrew, A. M. (1987), 'Context and action in the transformation of the firm', Journal of Management Studies, Vol. 24 No. 6, pp. $649-670$.

Polanyi, M. (1967), The Tacit Dimension, Routledge: London.

Popper, K. R. (1997), Conjectures and refutations: The growth of scientific knowledge, Routledge \& K. Paul: London. (originally published in 1963).

Powell, T. C. (1995), 'Total Quality Management as Competitive Advantage: A Review and Empirical Study', Strategic Management Journal, Vol. 16 No. 1, pp. 15 - 37 
Prahalad, C., and Hamel, G. (1990), 'The core competence of the corporation', Harvard Business Review, Vol. 68 No. 3 pp. $79-91$.

Prajogo, D. I., and McDermott, C.M. (2005), 'The relationship between total quality management practices and organizational culture', International Journal of Operations and Production Management, Vol. 25 No. 11, pp. 1101 1122.

Prajogo, D. I., and Sohal, A. (2003), 'The relationship between TQM practices, quality performance, and innovation performance: An empirical examination', International Journal of Quality \& Reliability Management, Vol. 20 No. 80, pp. $901-918$.

Preuss, A., and Lohff, A. (2003), Shapes inside - psychometric quality characteristics. Instrument manual: technical documentation. Cut-e GmbH.

Psomas, E. L., and Jaca, C. (2016), 'The impact of total quality management on service company performance', International Journal of Quality \& Reliability Management, Vol. 33 Iss. 3, pp. 380 - 398.

Reed, R., Lemak, D. J., and Mero, N. P. (2000), 'Total quality management and sustainable competitive advantage', Journal of Quality Management, Vol. 5 Iss. 1, pp. 5 - 26.

Reeves, C. A., and Bednar, D. A. (1994), 'Defining Quality: Alternatives and Implications', Academy of Management Review, Vol. 19 No. 3, pp. 419 - 445.

Rogala, P. (2016), 'Identification of barriers to improving quality management systems', The TQM Journal, Vol. 28 No. 1, pp. $79-88$.

Rolf, B. (1995), Profession, tradition och tyst kunskap, Nya Doxa: Nora.

Rolf, B. (1998), Militär kompetens. Traditioners förnyelse 1500-1940, Nya Doxa: Nora.

Rosing, K., Frese, M., and Rosenbusch, N. (2010), 'Ambidextrous leadership in the innovation process'. In Gerybadze, A., Hommel, U., Reiners, H. W., and Thomaschewski, D. (Eds.), Innovation and international corporate growth, Springer Verlag: Heidelberg, pp. 191 - 204.

Ryle, G. (1990), The Concept of Mind, Penguin Classics: London, UK. (originally published in 1949).

Sadler-Smith, E., and Sheffy, E. (2004), 'The intuitive executive: Understanding and applying 'gut feel' in decisionmaking', Academy of Management Executive, Vol. 14 No. 4, pp. 76 - 91.

Samson, D., and Terziovski, M. (1999), 'The link between total quality management practice and organisational performance', International Journal of Quality and Reliability Management, Vol. 16 Iss. 3, pp. 226 - 237.

Sandberg, J. (2000), 'Understanding human competence at work: An interpretive approach', Academy of Management Review, Vol. 43 No. 1, pp. $9-25$.

Sandberg, J., and Targama, A. (2007), Managing Understanding in Organizations, SAGE Publications: London.

Sandberg, J., and Tsoukas, H. (2011), 'Grasping the logic of Practice: Theorizing through practical rationality', Academy of Management Review, Vol. 36 No. 2, pp. 338 - 360.

Sandholm, L. (2005, September), 'Is there a role for a quality manager?'. Paper presented at the International Conference on Quality (ICQ'05), Tokyo, Japan.

Saraph, J. V., Benson, G. P., and Schroeder, R. G. (1989), 'An instrument for measuring the critical factors of quality management', Decision Sciences, Vol. 20 Iss. 4, pp. $810-829$.

Sayer, A. (1992), Method in Social Science: A Realist Approach, Routledge: London.

van Schalkwyk, J. C. (1998), Total quality management and the performance measurement barrier', The TQM Magazine, Vol. 10 No. 2, pp. $124-131$.

Schatzki, T. R. (2001), 'Practice mind-ed orders'. In Schatzki, T. R., Cetina, K. K., and von Savigny, E. (Eds.), The Practice Turn in Contemporary Theory, Routledge: London, pp. $64-82$.

Schatzki, T. R. (2005), 'The Sites of Organizations', Organization Studies, Vol. 26 No. 3, pp. 465 - 484.

Schön, D. (1983), The Reflective Practitioner: How Professionals Think in Action, Maurice Temple Smith: London.

Scott, W. R., and Davis, G. F. (2007), Organizations and organizing. Rational, Natural and Open System Perspectives, Routledge: New York.

SFK (2015), Att kartlägga morgondagens kvalitetsprofession; -uppdrag, roller och kompetenser (Report, 2015-0515), Svenska Förbundet för Kvalitet.

Sila, I., and Ebrahimpour, M. (2003), 'Examination and comparison of the critical factors of total quality management (TQM) across countries', International Journal of Production Research, Vol. 41 No. 2, pp. 235 - 268.

Sitkin, S.B., Sutcliffe, K. M., and Schroeder, R. G. (1994), 'Distinguishing control from learning in total Quality Management: A contingency perspective', Academy of Management Review, Vol. 19 No. 3, pp. 537 - 564.

Sousa, R., and Voss, C. A. (2001), 'Quality Management: Universal or context dependent?', Production and Operations Management Journal, Vol. 10 No. 4, pp. $383-404$.

Sousa, R., and Voss, C. A. (2002), 'Quality Management re-visited: a reflective review and agenda for future research', Journal of Operations Management, Vol. 20 No. 1, pp. 91 - 109.

Sousa, R., and Voss, C. A. (2008), 'Contingency research in operations management practices, Journal of Operations Management, Vol. 26 No. 6, pp. $697-713$.

SIQ (2018), SIQ Managementmodell (SIQ, Institutet för Kvalitetsutveckling), Göteborg.

SQMA/SIQ (2012), Kvalitetsutmaningar söker svar (SQMA, Swedish Quality Management Academy report), Göteborg.

Stake, R. E. (1995), The Art of Case Study Research, SAGE Publications: Thousand Oaks, CA.

Stratton, B. (1996), 'The future of the quality profession', Quality Progress, Vol. 39 No. 7, pp. 26 - 27. 
Styhre, A. (2012), Knowledge Sharing in Professions. Roles and Identity in Expert Communities, Gower: Farnham, UK.

Sutherland, J. W. (1975), Systems: Analysis, administration and architecture, Van Nostrand: New York.

Svensson, L. (2002a), 'Bakgrund och utgångspunkter'. In Svensson, L., Brulin, G., Ellström, P-E., and Widergren, Ö. (Eds.), Interaktiv forskning - för utveckling av teori och praktik, Arbetslivsinstitutet: Stockholm, pp. 1 - 22.

Svensson, L. (2002b), 'En analys och blick framåt i framtiden’. In Svensson, L., Brulin, G., Ellström, P-E., and Widergren, Ö. (Eds.), Interaktiv forskning - för utveckling av teori och praktik, Arbetslivsinstitutet: Stockholm, pp. $172-207$.

Svensson, L., Brulin, G., and Ellström, P-E. (2015), 'Interactive research and ongoing evaluation as joint learning processes'. In Elg, M., Ellström, P-E., Klofsten, M., and Tillmar, M. (Eds.), Sustainable Development in Organizations. Studies on Innovative Practices, Edward Elgar Publishing Ltd.: Northampton, MA., pp. 346 - 361.

Sörqvist, L. (2014), 'Future development of the quality profession'. Paper presented at the ICQ 2014 conference, Tokyo, Japan.

Taylor, C. (1979), 'The interpretation and the sciences of man'. In Rabinow, P., and Sullivan, W. M. (Eds), Interpretive Social Science. A Reader. University of California Press: Berkeley, CA.

Taylor, F. W. (1911), The Principles of Scientific Management, Harper: New York.

Taylor, W. A., and Wright, G. H. (2003), 'A longitudinal study of TQM implementation: factors influencing success and failure', Omega, Vol. 31 No. 2, pp. 97 - 111.

Temtime, Z. T. (2003), 'The moderating impacts of business planning and firm size on total quality management practices', The TQM Magazine, Vol. 15 Iss.1, pp.52 - 60,

Trow, M. (1957), 'Comment on 'Participant observation and interviewing: a comparison'. Human Organization, Vol. 16 No. 3 , pp. $33-35$.

Tushman, M. L., and O’Reilly, C. A. (1996), 'The ambidextrous organization: managing evolutionary and revolutionary change', California Management Review, Vol. 38 No.4, pp. 1 - 23.

Van de Ven, A. H. (2013), Engaged scholarship. A guide for organizational and social research, Oxford University Press: Oxford, UK.

Van de Ven, A. H., and Chu, Y. (1989), 'A psychometric assessment of the Minnesota innovation study'. In Van de Ven, A. H., Angle, H., and Scott Poole, M. (Eds.), Research on the Management of Innovation: The Minnesota Studies, Ballinger Publishing, Harper and Row: New York, pp. 55 - 103.

Van de Ven, A., and Johnson, P. E. (2006), 'Knowledge for Theory and Practice', Academy of Management Review, Vol. 31 No. 4, pp. $802-821$.

Van de Ven, A., and Poole, M. S. (1995), 'Explaining Development and Change in Organizations', The Academy of Management review, Vol. 20 No. 3, pp. $510-540$.

Vargo. S. L., and Lusch, R. F. (2004), 'Evolving to a new dominant logic for marketing', Journal of Marketing, Vol. 68 No. 1 , pp. $1-17$.

Vargo. S. L., and Lusch, R. F. (2016), 'Institutions and axioms: an extension and update of service-dominant logic', Journal of the Academy of Marketing Science, Vol. 44 No. 1, pp. 5 - 23.

Verhoef, P. C., and Leeflang, P. (2009), 'Understanding the marketing department's influence within the firm', Journal of Marketing, Vol. 73 No. 2, pp. 14 - 37.

Vetenskapsrådet (2017), God forskningssed (Rapport VR1708 från Vetenskapsrådet), Vetenskapsrådet: Stockholm.

Voss, C., Tsikriktsis, N., and Frohlich, M. (2002), 'Case research in operations management', International Journal of Operations \& Production Management, Vol. 22 No. 2, pp. 195 - 219.

Waddell, D., and Mallen, D. (2001), 'Quality managers: Beyond 2000? Total Quality Management', Vol. 12 No. 3, pp. $373-384$.

Weckenmann, A., Akkasoglu, G., and Werner, T. (2015), 'Quality Management -history and trends', The Total Quality Management Journal, Vol. 27 No. 3, pp. $281-293$.

Weick, K. E. (1989), 'Theory construction as Disciplined Imagination', Academy of Management Review, Vol. 14 No. 4 , pp. $516-531$

White, R. W. (1959), 'Motivation reconsidered: The concept of competence', Psychological Review, Vol. 66 No. 5, pp. 297 -333 .

Wynn, D. Jr., and Williams, C. K. (2012), 'Principles for Conducting Critical Realist Case Study Research in Information Systems, MIS Quarterly, Vol. 36 No. 3, pp. 787 - 810.

Yin, R. K. (2014), Case Study Research: Design and Methods, SAGE Publications, Inc.: Thousand Oaks, CA.

Zhang, D., Linderman, K., and Schroeder, R.G. (2012), 'The moderating role of contextual factors on quality management practices', Journal of Operations Management, Vol. 30 No. 1-2, pp. 12 - 23.

Zhang, D., Linderman, K., and Schroeder, R. G. (2014), 'Customizing Quality Management Practices: A Conceptual and Measurement Framework', Decision Sciences, Vol. 45 No. 1, pp. 81 - 14.

$\mathrm{Zu}, \mathrm{X}$. (2009), 'Infrastructure and core quality management practices: How do they affect quality?', International Journal of Quality and Reliability Management, Vol. 26 Iss. 2, pp. 129 - 149. 


\section{Papers}

The papers associated with this thesis have been removed for copyright reasons. For more details about these see:

http://urn.kb.se/resolve?urn=urn:nbn:se:liu:diva-161079 


\section{FACULTY OF SCIENCE AND ENGINEERING}

Linköping Studies in Science and Technology, Dissertation No. 2020, 2019 Department of Management and Engineering

Linköping University

SE-581 83 Linköping, Sweden

wWW.liu.se

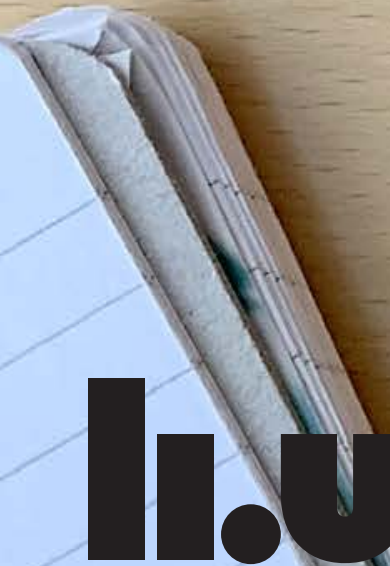

LINKÖPING UUNIVERSITY 